\title{
ELEMENTARY
}

\section{PHYSICS AND CHEMISTRY}

\section{GREGORY AND SIMMONS}

\section{FIRST STAGE}

\section{HIST}

\section{QC \\ 23 \\ M32 \\ 1905 \\ $B K, 1$}

Storage - Item EDUCATION

LP6 - J35B

EL UBC Library 
Digitized by the Internet Archive in 2010 with funding from University of British Columbia Library 
Harem Laurence

HISTORICAL COLLECTION EDUCATION LIBRARY UBC 


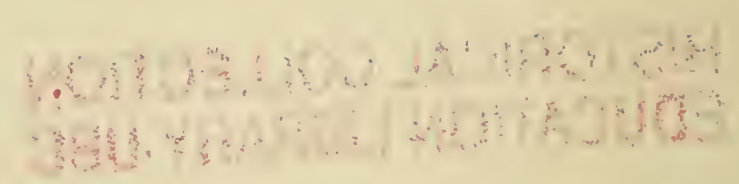




\section{ELEMENTARY PHYSICS AND}

CHEMISTRY 
s. 


\section{ELEMENTARY}

\section{PHYSICS AND CHEMISTRY elloc}

\section{EIRST STAGE}

IY

\section{R. A. GREGORY}

PROFESSOR OF ASTRONOMY, QUEEN'S COLLEGE, LONDON ; OXFORD UNIVERSITY EXTENSION LECTURER

AND

A. T. SIMIMONS, B.SC. (Lond.)

ASSOCIATE OF THE ROYAL COLLEGE OF SCIENCE, LONDON

迎ondon

MACMILLAN AND CO., Limited

NEW YORK: THE MACMILLAN COMPANY

1906 
First Edition 1S9?.

Reprinted 1900, 1902 (twiee).

Reprinted witl corrections, 1905, 1006 .

\$LASGOW: PRINTED AT THE UNIVERISTY PRESS BY HUBEKT MACLEHOSE AKD CO, LTD, 


\section{PREFACE.}

THE course of elementary physics and chemistry commenced in this book is based upon a syllabus of work approved several years ago by the Board of Education as suitable for the upper standards of elementary schools. The syllabus was divided into three parts, and the first of these is here dealt with.

'The course is well adapted for experimental work by individual children, and, as it forms a satisfactory introduction to the study of science, it is suitable for the lower forms of secondary schools as well as for pupils in the upper standards of elementary schools.

Every teacher now understands the importance of practical exercises in all scientific instruction, however elementary. Unfortunately, it is not as yet always possible to provide accommodation and apparatus sufficient to enable individual pupils to experiment. This difficulty has been borne in mind in designing the form of the following lessons, each of which is divided into two parts - the first consisting of instructions for the performance of simple experiments, the second of explanations of the principles taught by the practical work.

When circumstances permit, every child should perform the experiments, but when this is impossible the teacher should 
use the practical wo $k$ as demonstrations before the class. The descriptive text will provide suitable reading lessons in class, or can be studied by the pupil at home.

Our object has been to arrange a practicable and instructive first course of science based upon sound educational principles. Most of the illustrations are new, and all of them have been inserted with the object of simplifying the text.

For the advice readily given us, before we decided upon the plan of the lessons, by the late Mr. T. G. Rooper, M.A., one of His Majesty's Inspectors of Schools, Mr. J. A. Humphris, and Mr. Chas. Davis, we gladly take this opportunity of recording our thanks.

R. A. GREGORY.

A. T. SIMMONS. 


\section{CONTENTS.}

LESSON

PAGE

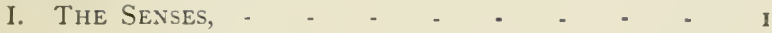

II. Matter and Hardiess, - - . . . 6

III. Solids, Liquids, ANd Gases, - - - - IO

IV. Properties of some Commun Things, - - 13

V. Properties of some Common Things-Continued, i6

VI. Measureinent of Leigth, - - - - 20

Vil. Measurement of ARea, - - - - $\quad 24$

Vili. Measurement of Volume, - - - - 28

IX. Mass aNd Weight, - $\quad$ - $\quad$ - 33

X. Measuremext of Mass, - - - $\quad 37$

XI. The Principle of the Balance, - - - - 42

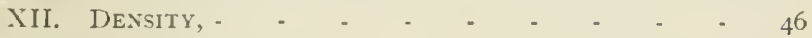

XIII. Dexsiti-Continuel, - $\quad$ - $\quad$ - $\quad$ - 51

XIV. Determination of Dexsity, - - - - 54

XV. THINGS WHICH SINK IN WATER, - - . - 56

XVI. ThINGS Which FloAT IN WATER, - - - - 60

XVII. Prixciple of ARCiIMEdes, - - - - - 64

XIJII. Determination of tile Density of a Solid, - 68 vii 
LESSON

SIX. THE AIR AROUND US, -

XX. The Pressure of THE AIR,

XXI. BAROMETERS,

XXII. Why the Heigit of the Barometer Alters, S3

XXIII. EFFECTS OF IIEAT, - - - - - - S8

IXIT. THERMOMETER, - - - - - - 93

XXY. Graduation of Thermoneters. Fixed Points, 98

XXVI. Soluble and Insoluble Solids, - - - 102

XXVII. Soluble Liquids ANd Gases, - - - 107

XXVIII. THERE IS NO LOSS DURING SOLUTION.

EVAPORATION゙, -

XXix. Saturated Solutions, - - - - - $\quad$ - 114

XXX. Solubility of Things in Acids, - - - 116

XXYi. Changes of Mass when Chemical action ACCOMPANies SOLution, - - - - - - I20

XXXil. Crystals and Crystallisation, - - - 124

XXYiII. Crystals and Crystallisation-Continued, - I28

XXXiv. Grapilic Representation, - - - - - $\quad$ - I33

XXXV. Graphic Representation-Contimued, - - 142 


\section{LESSON I.}

\section{THE SENSES.}

\section{PRACTICAL WORK.}

Things required.-A book. School bell. Bunch of flowers. Piece of sugar or salt. Smelling salts, or bottle of ammonia solution. A peeled onion, or any convenient substance with a strong smell.

\section{What to do.}

Notice the things on the table. You know they are there because you can see them. You could not see them in the dark. Eyes and light are necessary to see.

Shut your eyes, You can now tell the things are on the table by feeling or touch.

Stand away from the table and shut your eyes. You can now neither see nor feel the things, but you can smell some of them, and therefore know they are in the room.

Shut your eyes and let someone ring the bell. You cannot see or feel the bell, and cannot smell it, but you hear the sound and know that it comes from a bell.

Taste the sugar and salt. You could tell one from the other by this means even if both looked and felt the same.

\section{REASONS AND RESULTS.}

How Science is Studied.-Before beginning any piece of work it is always best to find out all the things there are which we can use to help us in our task. If we neglect to do this it is quite possible we may find, when we have half finished our 
labour, that had we remembered something which has escaped our notice, our task would have been easier and the result more satisfactory.

It will be best for us, then, before we begin our study of this new subject, science, to make sure that we know all the ways of learning which it is possible to use. This may seem at first very difficult ; but, really, it is nothing of the kind, as we shall soon find out. Every boy or girl in the class will notice that there are several things on the table. How do you know that this is so? Everyone of you has learned the fact in the same way. You say that you know there are things on the table because you see them, or, as some of you said, by seeing. But you must go a little farther.

Seeing.-When can you see? You are able to see when it is light and when your eyes are open. Even if it is light and your eyes are shut you cannot see. Or, if your eyes are open and it is dark you cannot see. Seeing is only possible when there is light and you have open eyes. But your eyes must be in a healthy condition. Some people with open eyes cannot see, because their eyes are unsound or diseased. They are called blind people.

Feeling.-But though blind people cannot see they could still tell there were things on the table. Even when your eyes are

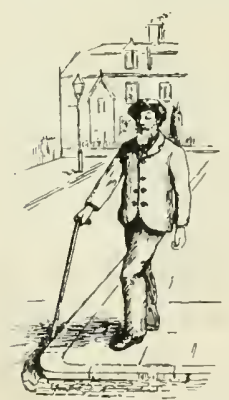

Fig. I.-Blind people can find their way by feeling. shut you can quite easily find out the things you can no longer see. How do you manage it? By feeling them or touching them. It would take you very much longer to learn all there is to be learnt about one of the substances on the table by feeling it than it does by seeing it. But if you were to practise this way of learning what a thing is like you would after a time become very clever at it. Blind people are clever enough to recognise their friends by feeling all over their faces. Though you generally feel with your fingers, the skin of all parts of your body is able to tell you when an object touches it.

Smelling.-There are still other ways of learning about things. 
Even when you are in your places, away from the table, and not iooking at it, you know that there is something unusual near you. You say there is a smell in the room. Two or three things on the table have a strong smell or odour, and by means of this you could be quite sure of their presence. Smelling is another power you have which you will use in your studies of science. When you want to learn exactly what a smell is like you sniff the air up your noses from near the object which gives rise to the smell, and evidently it is by

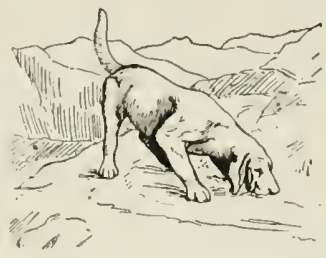

Fig. 2.-Bloodhounds are very clever in finding people by smell. means of your noses that you are able to smell. Some animals, like the bloodhound, have this power to a great degree, and are very clever in finding the whereabouts of objects from their smell. In this way they used to be employed to find runaway slaves.

Hearing. - If the bell on the table is struck you become aware of its presence through your ears. You hear the sound to which the bell gives rise. Or, if you drop the piece of sugar, or one of the other objects, after raising them from the table, the noise which results when the object strikes the table is quite enough to tell you that something is there. Hearing, a power which all people have who are not deaf, is another way of learning facts. Every day of your lives you make use of hearing in this way. Perhaps you know it is time to get up, because you hear the milkman shouting in the street, or because the alarum clock goes off, or someone calls you. You know a letter has arrived because of the postman's knock. You are sure there are birds in the trees because you hear them singing. You will be able to think of many other ways for yourself.

Tasting.-Even yet you have not found all the ways by which you learn facts about the objects around you. A boy, who could neither see, nor feel, nor smell, nor hear an object, might still be able to tell there was such a thing. This last power is very popular with boys and girls. Though you may shut your eyes and not be able to see, smell, or hear a lump of sugar, you could taste the sugar. 
It is difficult to imagine anyone tasting the sugar without feeling it, for while you taste the sugar you would also feel it on your tongue. But if you consider a little you will think of cases where tasting is possible without feeling. In some towns, near factories or gasworks, it is often possible to taste things in the air though you cannot feel them. Some of you have tasted the salt in the air at the seaside. If you are very careful you may be able to taste the something in the air which causes the smell when the bottle of ammonia upon the table is opened. Often tasting and smelling go together; many substances which have a taste also make themselves known by their smell.

Seeing, Feeling, Hearing, Smelling, and Tasting are called "Senses." - These five ways of gaining knowledge, or of getting to know things, are called the senses. All ordinary persons possess them, and you must be sure to learn what they are. The first depends upon the eye, feeling upon the skin, hearing upon the ear, smelling upon the nose, and tasting upon the tongue.

\section{FIVE SENSES.}

I. Seeing depends upon the Eye.

2. Feeling depends upon the Skin.

3. Hearing depends upon the Ear.

4. Smelling depends upon the Nose.

5. Tasting depends upon the Tongue.

The senses are sometimes called the five gateways of knowledge; and this is a very good name, for everything which you know has been learnt through one or other of these gateways.

All the facts of science are learnt in the same way, and you cannot understand too soon that there is no difference between ordinary knowledge and science. In learning science you are only successful when you use your five senses very carefully, and this is only possible after they have been practised a great deal or trained sufficiently. You must learn to see properly or accurately, and to use each of your other senses without making mistakes.

You have, perhaps, when somebody has asked you how you know a certain thing, answered "By common sense." You have meant by this that you knew the thing by the use of your senses. 
When you use your senses properly, without mistakes, what you learn is a fact of science. Or, as a great man once said, "Science is organised common sense."

TO BE ReMEMBERED.

\section{How Facts about Things are learnt.}

1. By Seeing. Eyes and light are necessary to see.

2. By Feeling. Blind people can examine things by touch.

3. By Hearing. When a boy hears the school bell he knows that there is a bell, though he may not see it.

4. By Smelling. Smelling is assisted by sniffing. Bloodhounds can find men by following their scent.

5. By Tasting. Usually accompanied by feeling; often by smelling.

\section{These Powers are called "Senses."}

The parts of the body they depend upon are: (1) Eyes, (2) Skin, (3) Ear, (4) Nose, (5) Tongue.

They are sometimes called "gateways of knowledge."

There is no difference between science and ordinary knowledge.

Everyone should train his senses carefully.

Organised common sense is science.

\section{EXERCISE I.}

1. Name the five senses and the part of the body upon which each depends.

2. Write down five things you can see, five things you can feel, five things you can smell, five things you can hear, and five things you can taste.

3. What thing do you know ot which you can feel but not see?

4. Name some things you can see but which you can neither hear, feel, smell, nor taste. 


\section{LESSON II.}

\section{MATTER AND HARDNESS.}

PRACTICAL WORK.

Things required-Pieces of flint, rock-crystal, a tumbler, chalk, lead, pocket-knife, iron, copper, brass, wood, soap, wax, a turnip, carrot, potato, or apple.

\section{What to do.}

Notice that the things upon the table differ from one another, and consider in what ways they are different. They differ in hardness, shape, size, and colour.

Select one of the things, and notice that it will scratch some substances but not others. Test the things which the knife will scratch or cut and the things it will not cut. Test in the same way the things the finger-nail will scratch and those it will not scratch.

Arrange the substances in pairs as below, so that one is scratched by the other. In this way a continuous table in which the substances are arranged according to their hardness can be drawn up thus:

$\begin{array}{lllll}\text { Flint scratches } & \text { glass. } & \text { Copper scratches lead. } \\ \text { Glass } & \text { iron. } & \text { Lead } & \text { chalk. } \\ \text { Iron } & & \text { copper. } & \text { Chalk } ~ " & \text { wax. }\end{array}$

\section{REASONS AND RESULTS.}

What is meant by Matter?-You must notice again to-day that there are several things on the table. You now know that you are sure of this fact by the help of your senses. Some of these things are recognised by more than one sense; indeed some appeal to all of them. Many names are given to things which are studied by the help of the senses. Besides the name things, you can use the word substances, or the word which is perhaps most commonly employed, namely, matter. 
You must not confuse this meaning of the word 'matter' with other meanings you have learnt. Most children, when the word is used, first think of the yellow fluid which pours out of a boil or gathering, but you must in these lessons, when the word matter is used, say to yourselves, that is the name given to all those things which are studied by means of the senses.

There are many Kinds of Things.-There are many kinds of things about which you know through your senses. You would have no trouble in naming a great many of them. There are desks, books, wall-maps, slates, apples, bricks, and so on. When you begin to think about these things, it soon occurs to you that they are very different from one another, and that it would be much easier to study them if they were arranged in classes, putting those together which are alike and separating those which differ from one another.

This is just what the headmaster does with the children who come to school. Because the boys who come differ from one another in many important ways, he cannot teach them altogether. Some can read very nicely, while others scarcely know their letters. Some can work out difficult sums, but others hardly know their tables.

For these reasons, among others, the boys are arranged in classes or standards. So, if you wish to study all the kinds of things about you, you will find it best to learn how things differ from one another. You want, in fact, to learn the properties or qualities of at least the common things about you Then, when it becomes necessary, you will be able to imitate the headmaster and arrange things into classes in the manner already spoken about. This plan is called classifying things. You must, therefore, try to learn some of the properties of very common things.

Things differ in Hardness. - If you were asked to say how the things on the table differ from one another, you would probably say that they differ in size, shape, colour, hardness, and in other ways. Now consider exactly what you mean by the property of hardness. A stone is hard, so is a piece of wood, and so is a piece of iron, but they are not of the same hardness. Some things, then, are harder than others. 
It is often easy to decide which is the harder of two things. For instance, you know that a knife is harder than a piece of wood ; for you can often dig your thumb-or finger-nail into the

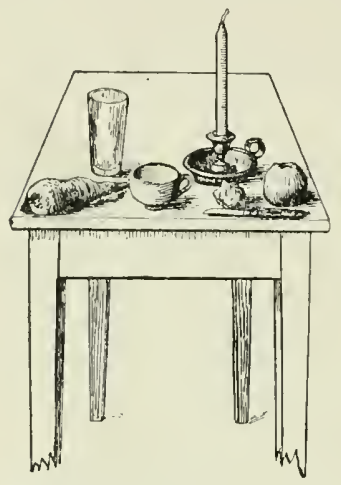

Fig. 3.-The things on the table differ in hardness as well as in other ways.

wood, but you cannot dig your nail into a steel knife. Also, you can cut wood with a knife, but you cannot cut it with a piece of india-rubber, because the india-rubber is softer than the wood. All things which a knife will cut or scratch are softer than the knife, and all things which it will not cut or scratch are harder than it.

In the same way, things like potatoes, some woods, chalk, bread, blotting paper, and soap can be scratched by the finger-nail, and are therefore softer than the fingernail. Things like iron, glass, and flint cannot be scratched or cut by the finger-nail, and are therefore harder than it.

The Test of Hardness. - You will now understand the way to find out which is the harder of two things. What has to be done is to test which will scratch or cut the other. If you were asked whether glass or flint was the harder, you should try if the flint will scratch the glass. It does. Will the glass scratch the flint? It will not. Which is the harder then? The flint, of course.

In the same way, if you were given a large number of different things and told to arrange them in the order of their hardness, you would take any one of the substances and find which of the others it would scratch and which it would not scratch. Then another would be taken, and the same tests made, and so a list like the one below would be made. This is the method always adopted to find out if one thing is harder than another.
1. Diamond.
5. Iron.
2. Rock-crystal.
6. Copper.
3. Glass.
7. Lead.
4. Steel.
8. Wax. 
The hardest substance is first in the list, the next hardest is second, and the softest is last. Any of the substances will scratch a substance lower in the list, and can be scratched by substances higher in the list. Diamond is seen to be the hardest substance; it will scratch every other thing. Emery is also very hard, and is therefore used for polishing many things.

The arrangement of things in the order of their hardness is similar to the arrangement of boys in a class. The top boy can beat all the other boys of the class in school-work; and a boy in any position in the class can beat those below him, but can be beaten by those above him.

TO BE REMEMBERED.

Matter is the same as substances or things, and we learn about it by means of our senses. There are many kinds of things, but the same properties are possessed in a different degree by different things.

Things differ in $(a)$ hardness, $(b)$ shape, $(c)$ size, $(d)$ colour.

The hardness of a thing is its ability to resist being scratched or worn by another thing.

\section{EXERCISE II.}

I. Name six things around you. What name could you give them instead of things.

2. What have you learnt about the meaning of 'matter'?

3. Why is it a good plan to divide things into classes?

4. Name as many ways in which things differ from one another as you can.

5. What plan should you follow if you wished to arrange three substances in the order of their hardness?

6. Which is the hardest thing you know? What is it used for? 


\section{LESSON III.}

\section{SOLIDS, LIQUIDS, AND GASES.}

\section{PRACTICAL WORK.}

Things required.-Some of the solids used in the last lesson. Tea-cup, tumbler, salad-cream bottle, round medicine phial, piece of india-rubber tubing, and a large basin or pan of water. Water, milk, quicksilver, and any other liquids available.

What to do.

Notice that the solid things upon the table are of different shapes, and that the shapes do not alter.

Show by pouring the same amount of water or other liquid into different vessels that the shape of the water depends upon the shape of the vessel.

Collect a bottle of ordinary gas, and use it to show that a gas has no surface and spreads itself through as much space as it can. The following is a way to do this :-

Fill a bottle with water, and invert it in a basin of water; then displace the liquid with gas led from a jet by a piece

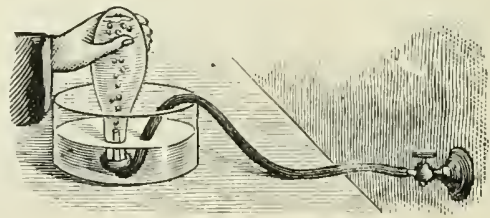

FIG. 4.-Gas is issuing from the twbe and bubbling up through the water in the bottle.

of india-rubber tubing (Fig. 4). Now insert a cork into the neck of the bottle while it is still under water, or cover the mouth with a glass plate, and lift the bottle out of the water and place it on the table. The gas has the size and shape of the bottle.

Open the bottle and wave it about; you immediately notice 
the smell of gas throughout the room, and know from this that the gas is everywhere in the room, and therefore has the size and shape of the room.

\section{REASONS AND RESULTS.}

Solids.-Most of the things you see around you have a certain size and shape of their own. The table in front of you and the desk you sit on have the same shape now as when they were first brought into the school, if no one has done anything to them. In the same way, a stone, a brick, a piece of india-rubber, or a tumbler keep their own shape unless someone breaks them. Things of this kind, which have a size and shape of their own, and remain of the same size and shape so long as they are not interfered with, are called solids. Some solids, as you have seen, are harder than others, and some can have their shape altered more easily than others. But none of them change by themselves. You know this very well in your own mind, though you may not have thought much about it. If you place a tumbler upon a table, and leave it for a while, you expect to find it there when you come back, and not changed into a bottle, because you know the shapes of solids do not alter unless someone alters them.

Liquids.-If you put a stone into a tea-cup, then into a tumbler, and then into a basin, you know that the size and

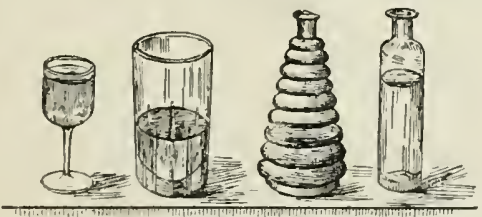

FIG. 5.-The shape of the liquid in these vessels is different, but the amount of liquid is the same, and the surface is horizontal in each.

shape of the stone remain the same in all the vessels. This is also true of any solid. But if a certain amount of water, say a wine-glassful, is taken and poured into a tumbler, you know that the water will not keep the same shape that it had at first. The water could be poured successively into vessels of different sizes and shapes, and finally into the wine-glass again; but though 
the shape would keep on altering, being in every case the shape of the containing vessel, the size would remain unaltered. Things which behave in this way are called liquids. You can think of many liquids in use day by day. For instance, vinegar, oil, milk, beer, and lemonade are all liquids.

There are other properties of liquids with which you are familiar. In the first place, the surface of a liquid at rest is always horizontal. You may shake the liquid up into a heap by jerking the vessel containing it, but as soon as you leave it alone it settles down again until its surface is horizontal. The fact that liquids can be poured from one vessel to another shows another property, namely, that liquids flow. A liquid can also be broken up into small round drops, such as the drops of water which form rain.

Gases.-When a gas is spoken of, you think of the gas used to light rooms and streets. There are, however, many other gases, and you will perhaps learn about them some day. Some gases smell and some do not; some are poisonous and some are harmless ; some, like coal-gas, will burn, and some will not. But all gases are alike in one respect ; they spread out and fill completely the vessel which holds them. A bottle of gas cannot be kept unless it is tightly corked, for after a while the gas escapes into the surrounding air.

Comparison of the Size and Shape of Solids, Liquids, and Gases.-Solids, liquids, and gases are not alike as regards size and shape. Solids have a size and shape of their own, which differ for each solid, but remain the same for one particular solid.

Liquids have a size of their own, but always take the shape of the vessel in which they are contained.

Gases have no definite size or shape; both these properties depend upon the space in which the gases are confined. However small a quantity of gas may be, it always spreads out until something prevents it from taking up more space.

TO BE REMEMBERED.

Solids are things which keep their own size and shape.

Liquids are things which take the shape of the vessel containing them, and have a horizontal surface when at rest. 
Gases are things which completely fill any space into which they may be put.

\section{EXERCISE III.}

I. What do you know about the size and shape of solid things?

2. What experiment would you do to show that while the size of a liquid remains the same its shape can keep on altering?

3. What do you know about the size and shape of gases? Describe an experiment which shows what you say is true.

4. State in your own words what a solid is, what a liquid is, and what a gas is.

5. How do solids and liquids differ from one another?

6. In what important respects do liquids and gases differ?

\section{LESSON IV.}

PROPERTIES OF SOME COMMON THINGS.

PRACTICAL WORK.

Things required.-Piece of glass, transparent liquids, sealingwax, roll-sulphur, slate, lead, feathers, cork, sponge, sheet-lead, india-rubber, cane, air-ball, or pop-gun.

What to do.

Examine each of the things thoroughly, and consider what you would want to know about it in order to describe it to a person who had never seen it.

Notice, for instance, that glass can be seen through (transparent), and breaks easily (brittle).

Lead, and most other things, cannot be seen through (opaque). Lift the lead. It is heavier than pieces of the other substances of the same size (dense). Beat it into a thin sheet (malleable). Bend or twist it and it remains in the shape it is made (pliable).

Stretch, bend, compress, or twist the india-rubber, and then release it. It goes back to the original shape (elastic). 
Compress an air-ball or a pnetmatic tyre. Release it. It also springs back to the original shape; hence air is elastic. Bend cane or whalebone (flexible).

\section{REASONS AND RESUI,TS.}

Common Things - Glass.-You must now take a few common things, and examine them to learn some of the properties things may possess. We will begin with Glass. What do you know about this substance? You can see through it, you say. Yes ; and what do we call substances which can be seen through? Transparent; that is right. All things you can see through are called transparent. Glass, then, is transparent. Some other things which are transparent are rock-crystal, air, water, and many other liquids.

Now, if the plate of glass is dropped, what happens? It breaks into pieces. What is a thing which breaks into fragments in this way called? Brittle. Some other brittle things are cast-iron, sticks of sealing-wax, roll-sulphur, slate. In being brittle all these things are like glass. In what way do they all differ from glass? You cannot see through them, or, as is usualiy said, they are opaque. Opaque things, then, are those you cannot see through.

Lead.- Now examine lead. What do you know about this substance? You say it is very heavy. But it is not enough to say that, for if you take a sufficient quantity of feathers they will weigh as much as the piece of lead. There is, of course, no difference between the weight of a pound of lead and a pound of feathers. What you meant to say was that a small piece of lead was very heavy. Because of this we speak of lead as being very compact or dense. Some other dense things are copper, gold, slate, etc. If a very large thing has but a small weight, it is not dense. Such things as cork, sponge, camphor, are not dense.

What else do you know about lead? You learnt in your last lesson that it is not very hard. It can be hammered out into sheets. Sheet lead is used for lining tea chests and other boxes. Solicls which can be beaten out into sheets are called malleable. Copper, gold, platinum are all of them malleable, but gold has more malleability than any other solid. 
Can you learn anything more from your piece of lead? Yes, it can be bent and does not spring back; its shape after bending or twisting remains just as you left it. All things which remain just as they are left after bending or twisting are called pliable. Copper, paper, and sheet-tin are also pliable.

India-rubber.-Everybody knows the chief property of indiarubber, for the name of this property is actually given to india-rubber, which is made into long threads. These are called elastic. What is it about india-rubber which makes you say it is elastic? Though you pull it, squeeze it, or bend it, it returns to its original shape and size when you leave it alone. It is the property of going back to its first shape and size after being forced out of it that is called elasticity.

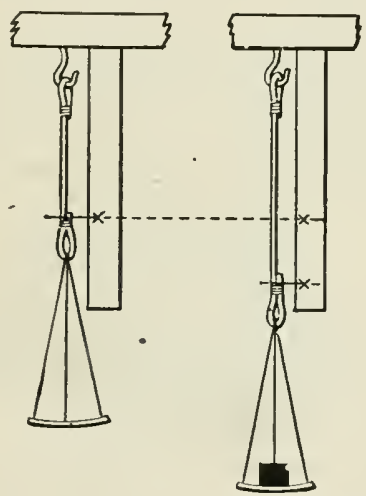

FIG. 6.-The india-rubber is stretched, but it goes back to its original lengtb when it can, and is therefore said to be an elastic substance.

What other elastic things do you know? If you squeeze an air-ball or push upon a pneumatic tyre, when you remove your fingers they spring back to the shape they had at first. These experiments tell you that air is very elastic. Cane, steel, and whalebone all spring back when forced out of shape, that is, they also are elastic. But some things, such as a strip of whalebone and a cane, are only elastic to a great degree in one direction. Elastic things of this kind are generally called flexible. 


\section{TO BE REMEMBERED.}

Glass can be seen through, or is transparent; is easily broken, or is brittle. Opaque things cannot be seen through.

Lead is heavy in comparison with the same bulk of many other substances, or is dense ; is malleable, or can be beaten into thin sheets; is pliable, or can be bent or twisted into different shapes.

India-rubber is elastic, or returns to its original shape after the shape has been changed. Flexible things also return to their original shape after being bent.

\section{EXERCISE IV.}

1. What do you mean by a transparent substance and what by an opaque thing? Name six transparent things and six opaque things?

2. Write down all you have learnt about lead.

3. Explain as carefully as you can what you understand by a dense substance. Name several dense substances.

4. What things are said to be malleable? Write down the names of as many such things as you san.

5. Why are india-rubber, air, whalebone, etc., said to be elastic? How would you show that air is elastic?

\section{LESSON V.}

\section{PROPERTIES OF SOME COMMON THINGS-} CONTINUED.

\section{PRACTICAL WORK.}

Things required.-Sponge, clean white blotting-paper, glassfunnel, a cane. Crystals of rock salt and sugar candy, powdered salt and sugar. Several crystalline substances, such as washingsoda, borax, and rock-crystal. Some flour and soot. Matches, magnesium ribbon, and a taper. Some clay.

What to do.

Notice the holes or pores in sponge (porous). Place a sponge in a saucer of water, and notice that the water dis- 
appears; it goes into the pores in the sponge, and can be squeezed out again. Filter water through blotting-paper, folded to form a cone, and placed in a funnel. Show that clay will hold water (impervious).

Observe the regular shape of particles of salt and sugar (crystalline). Particles of flour or soot have no regular shape (amorphous).

Add salt or sugar to water, and notice that it disappears (dissolves, or is soluble).

Show that sand, slate-pencil, and many other substances are insoluble.

Burn a match, paper, magnesium ribbon, etc. (combustible). Find some things which will not burn (incombustible).

\section{REASONS AND RESULTS.}

Sponge.-By squeezing a sponge you at once find out that it is elastic. But the first fact you notice about the sponge is that

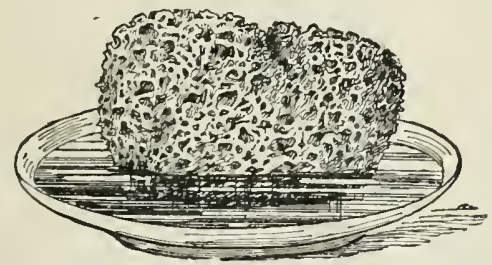

FrG. 7.-A sponge is very porous. Water will go into the pores when the sponge is placed in it.

it has lots of holes in it. What other thing which is upon the table has holes in it? The cane. But the holes in the cane are smaller than those in the sponge. What name do you give to the little holes spread over your skin? Pores. A thing which is full of holes or pores is called porous. The sponge, therefore, is very porous. But for a thing to be porous it is not necessary to be able to see the holes.

If you take a piece of blotting-paper, and fold it as shown in Fig. 8, put it into a glass funnel, and pour some water on it, the water finds its way through the paper because, though you cannot see them, there are holes in the paper, or it, too, is porous. 
Even iron is porous to a small extent, and water is sometimes filtered through a certain kind of iron. Pumice, charcoal, sand.
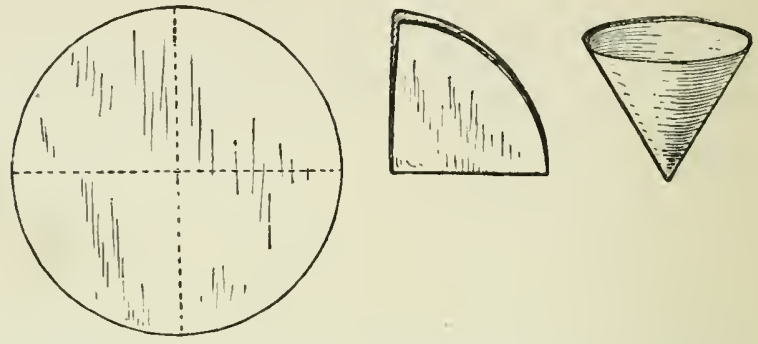

Fig. 8. - If a circular piece of paper is folded as shown by the dotted lines, it can be made into a cone which may be placed in a funnel for filtering.

stone are also porous. In the kind of filter shown in Fig. 9 the water soaks through a block of carbon, and is thus purified.

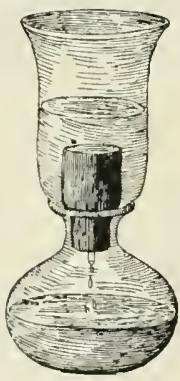

FIG. 9. - A Filter in which the water passes through a block of carbon, owing to the porosity of the carbon.

Things which will not allow water to pass or filter through them are called impervious. Clay is an impervious thing; so is glass and india-rubber.

Salt and Sugar.--Salt and sugar are crystalline substances, that is, each small piece has a certain regular shape, which for a particular substance is always the same. Solids which take a regular shape like this are called crystals. You will learn more about these in a later lesson. Other common things which occur in crystals are washing-soda, borax, diamonds and some other precious stones, rock-crystal, and many other substances.

Things which are not crystalline are called amorphous, a word which is made up of two Greek words meaning 'without shape.' Flour, soot, etc., are examples of amorphous things.

Now, if you put the salt or sugar into a glass or bottle of water, and shake or stir the water, you will notice that the salt or sugar disappears, and if you taste the water you easily recognise the presence of the salt or sugar. You may say the salt or sugar has 
dissolved or is soluble. Do you know any other soluble things? Try some. You will find you can dissolve washing-soda, nitre, and borax in water, and in this way you prove they are soluble.

Substances which will not dissolve in water are said to be insoluble. Many things are insoluble in water; for instance, sand, gravel, slate-pencil, coal, chalk. However long you leave these in water they will not dissolve.

Things which burn.-Many things easily burn in the air when made hot enough. If you hold a match in a gas-flame you can easily show that it continues to burn after taking it out. Similarly, you can make a piece of magnesium ribbon burn. Tapers and pieces of paper also burn quite easily. Things which burn in this way are said to be combustible. What are the common combustible tnings used? Coal, coke, coal-gas, tallow, wood. Those substances which will not burn are called incombustible. Slate, iron, bricks, glass, etc., will not burn, and are therefore called incombustible things.

\section{- To be Remembered.}

Sponge is porous, or contains numerous small holes or pores. All things are more or less porous. Things through which water will not pass are impervious.

Salt and Sugar are crystalline, or are made up of little crystals, each having a certain regular shape ; they are soluble, or disappear when put in water. Particles of soot and flour have no regular shape, or are amorphous.

Things which burn are combustible, and things which will not burn are incombustible.

\section{Exercise V.}

I. Many substances allow water to pass through them very readily. Why is this? What experiment would you perform to show this in the case of blotting-paper?

2. Write down all you know about sugar.

3. What things are said to be soluble? Name six soluble things. What is the opposite to soluble?

4. What is the difference between combustible and incombustible things? Name five things of each kind. 


\section{LESSON VI.}

MEASUREMEN'T OF LENGTH.

PRACTICAL WORK.

Things required.-Foot-rule divided into inches on one edge, and into decimetres, centimetres, and millimetres on the other. Tape measure (or long rule) divided into inches and centimetres.

What to do.

Notice the divisions upon the rule. Measure a few lengths, such as the width of a sheet of paper, or of a table, in feet and inches. Consider how confusing it would be if inches and other standards of length had not a constant size.

Notice the fractions of an inch, and find by measurement the number of inches in $1 \frac{1}{3}$ feet, $2 \frac{1}{2}$ feet, $2 \frac{2}{3}$ feet, I yard, 2 feet 9 inches, and any other lengths which may occur to you.

Examine the metric divisions upon the rule. The smallest are millimetres; ten millimetres make I centimetre, ten centimetres make I decimetre, ten decimetres make I metre. Notice that all these go in steps of ten.

Find the number of inches which are equal to the length of I metre, the number of millimetres equal to an inch, and the number of centimetres equal to an inch.

Measure a distance in inches and centimetres, and from the results determine the relation between the two.

\section{REASONS AND RESULTS.}

Measurement of Length.-Whenever you measure a length, what you do is to compare it with another length which is called the standard or unit. Every boy knows, from his lessons in arithmetic, that British people, when they speak of a length, express it as yards, feet, inches, or one of the other measures 
which have been learnt in Long Measure or Measures of Length.

Most thoughtful boys have said to themselves at one time or another-What are these yards, feet, and so on? How does the maker of a rule know how long a yard has to be? And how is it that if you buy a yard measure in London, Manchester, or any other town, it is always the same length? These are all very important questions, and you must try to answer them.

What a Yard is. - In the strong room of the Board of Trade in London there is a fire-proof iron chest which contains a bar of bronze. Into this bar, near each end, are sunk two golden studs, and across each stud fine lines are drawn. The distance between these marks (when the bar is at a certain temperature, called sixty-two degrees Fahrenheit, which you will understand before you get to the end of your book) is what is called the Imperial Standard Yard. Several exact copies of this bar have been made and are securely kept in different places. There is consequently very little danger of all the bars being burnt or lost at the same time. All yard measures should be the same length as the distance between these marks. The yard is divided into three equal parts, and each of these is called a foot. A foot is divided into twelve equal parts, and each part is called an inch.

The Metre.-Lengths are not measured in yards, feet, and inches in all countries. In France, and most other countries, the standard length is what is called a metre. In Sèvres, a bar of a similar kind to that kept by our Board of Trade is carefully preserved. The distance between the two marks in the golden studs is the standard known as the metre. The metre is longer than the yard. You know there are thirty-six inches in the ya.d, but the metre measures about thirty-nine and one third inches, or three feet, three and one-third inches ( 3 feet $3 \frac{1}{3}$ inches). This number is easily remembered because it only contains the figure 3 .

Divisions of the Metre.-The metre is not divided in the same way as the yard. A much better plan is adopted. First the metre is divided into ten equal parts, each of which is called a decimetre, so that you may write:

Io decimetres make one metre. 
The distance from one end to the other of Fig. Io is a decimetre.

Next, each of these decimetres is divided into ten equal parts, each of which is a centimetre, and it takes one hundred of them to make a metre, consequently you may say :

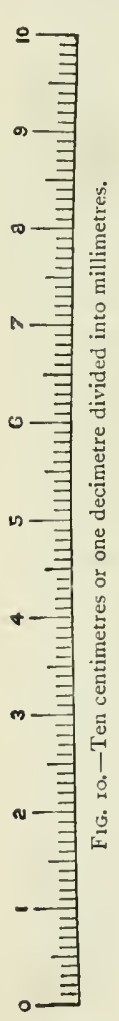

Io centimetres make I decimetre.

Ioo centimetres, I metre.

The distance from one number to the next in Fig. Io is a centimetre.

Then, each centimetre is clivided into ten equal parts, and each of these is called a millimetre, and it takes one thousand of them to make a metre. The smallest divisions in Fig. Io are millimetres.

Thus, you see that you may write a table for the sub-divisions of the metre which you will have no trouble in remembering :

Io millimetres make 1 centimetre

Io centimetres,, 1 decimetre.

10 decimetres ", 1 metre.

For lengths greater than a metre the same simple plan is used. A length which contains exactly ten metres is called a dekametre; one which just contains a hundred metres is called a hektometre; and one which is exactly a thousand times as long as a metre is called a kilometre. These can be put together in another little table :

Io metres make I dekametre.

Io dekametres " I hektometre.

Io hektometres " $"$ I kilometre.

Comparison of British and Metric Measures.-On the Continent the metric system of measurement is used almost entirely. The sign posts on the roads do not show how many miles it is to the next village or town, but the number of kilometres. Linen and silks and such materials are not sold by the yard, but by the metre, and shorter lengths are measured in centimetres. You will find it useful to remember that about $2 \frac{1}{2}$ or 2.5 centimetres 
are equal to I inch, $30^{\circ} 5$ centimetres are equal to I foot, and eight kilometres are about five miles.

Inches.

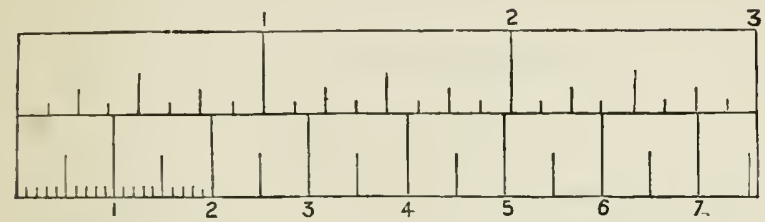

Millimetres.

Centimetres.

Fig. 11. - An inch is very slightly longer than $2 \frac{x}{2}$ centimetres.

TO BE REMEMBERED.

A Standard Length is required before lengths can be measured. The table of Long Measure shows how British standards of length are related to one another.

The Standard Yard is the distance between two lines upon a bronze bar kept by the Board of Trade. One third $\left(\frac{1}{3}\right)$ of a yard is 1 foot, and one twelfth $\left(\frac{1}{12}\right)$ of a foot is $I$ inch.

The Metre is the French or metric standard of length. It is divided into tenths or decimetres, hundredths or centimetres, and thousandths or millimetres. The length of a metre is roughly 3 feet $3 \frac{1}{3}$ inches.

\section{EXERC1SE VI.}

I. What is meant by the Imperial Standard Yard? Name the parts into which it is divided.

2. What is a metre? Compare its length with that of a yard.

3. Explain how the metre is divided and write down the names which are given to these parts.

4. What are some of the advantages of dividing the standard of length according to the metric system?

5. How many millimetres are there in each of the following :centimetre, decimetre, and metre?

6. How many dekametres are there in a kilometre? And how many retres in the same length? 


\section{LESSON VII.}

\section{MEASUREMENT OF AREA.}

PRACTICAL WORK.

Things required.-Square foot cut out of cardboard, and having square inches marked upon it. Square inch cut out of cardboard. Square decimetre of cardboard, having square centimetres marked upon it. Square centimetre of cardboard.

\section{What to do.}

Compare the square inch with the square foot. Count the number of square inches in one row marked upon the square foot; there are 12. Count the number of rows; there are 12. The total number of square inches is therefore $12 \times 12=144$.

Compare the square centimetre with the square decimetre in the same way, and find the number of square centimetres there are in a square decimetre.

Notice the difference of size of the square inch and the square centimetre.

Find, by measurement, the number of square inches in any rectangular surface (such as a drawing board), and also the number of square centimetres. This is done by multiplying the length of one side by the length of the side at right angles to it

By comparing the two results, determine roughly the number of square centimetres in a square inch.

\section{REASONS AND RESULTS.}

Measurement of Area.-Most of the boys who read this book will probably already know the difference between lengths and areas. But to make quite certain we will take a few simple examples.

Provided with a rule, it would be easy to measure the length of the room and its breadth or width. If we had a ladder 
we could, in the same way, measure its height. Now, if we were going to have a carpet put down, we should give the upholsterer the order, and he would pay us a visit to measure the floor. You know very well it would not be enough for him to measure the length of the room only, or its width only; because both of these are measures of length. To know how much carpet he wants the workman must find out the amount of surface the floor has, or what is called its area. To do this he measures both the length and width of the floor, and when he multiplies them together he gets the area, if the room is a square or oblong one. If he measures the length and width in feet, then by multiplying them together he gets the area of the floor in square feet; if the measurement of the length and width were taken in inches, the area in square inches would be obtained by multiplying them together.

Whenever areas are measured in this country, square inches, square feet, square miles, or some other unit from square

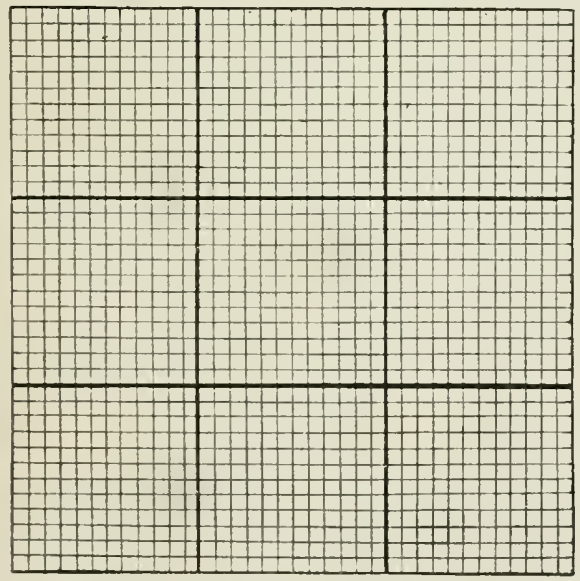

FIG. 12. - This shows how a square yard can be divided into square inches. Fach small square represents a square itich, and the large squares bounded by thick lines represent square feet.

measure is employ'ed. 'Square measure' is obtained from 'long measure' by multiplying. Thus, as there are $\mathbf{1 2}$ inches in a 
foot, there are $12 \times 12$ square inches in a square foot. You will understand this by examining Fig. 12. Each of the large squares bounded by thick lines represents a square foot, but it is of course smaller than a real square foot.

Square Measure.-By referring to Fig. I2, which illustrates how a square yard may be divided into square feet and square inches, and examining the squares of cardboard divided into square inches or square centimetres, it is easy to see how square measure is obtained from long measure. We will write what we have learnt in the form of a table :

$$
\begin{aligned}
& 144(=\mathrm{I} 2 \times 12) \text { square inches make I square foot. } \\
& 9(=3 \times 3) \quad, \text { feet } \quad, \quad \text { I }, \text { yard. } \\
& 30 \frac{1}{4}\left(=5 \frac{1}{2} \times 5 \frac{1}{2}\right) \quad \text { " yards ", I } " \text { pole. }
\end{aligned}
$$

How many square inches are there in a square yard? You can find out by counting the squares in Fig. 12, or by counting the squares in one of the areas representing a foot and multiplying the number by nine.

Square Metric Measures.-If instead of measuring the length and breadth of the floor in feet the workman had measured them in metres or decimetres, what would the area obtained by multiplying be measured in? Not in square feet, but in what is called square metres, square decimetres, etc. Square measure in the metric system is obtained from long measure in just the same way as we used in the case of inches. All we mean by the metric system is the plan of using metres, etc., instcad of yards, etc., in measurements of all kinds. We can now write down the measures of area or surface in the metric system :

$100(=10 \times 10)$ square millimetres make I square centimetre.

$100(=10 \times 10) \quad$ " centimetres " I " decimetre.

$100(=10 \times \mathbf{I 0})$ " decimetres ", I ", metre.

A square decimetre is too large to be shown on this page. Fig. I 3 shows two complete rows of square centimetres, but there are ten rows of this kind in a square decimetre. The square centimetre $A G F E$ in the top left-hand corner is divided into square millimetres. As I square centimetre contains 100 square milhimetres, I square decimetre or 100 square centimetres contains $100 \times 100$ square millimetres, that is 10,000 square millimetres. 
The size of a square centimetre is compared with the size of a square inch in Fig. I4. You will see that a square inch is much larger than a square centimetre. Each side of the square inch is 2.54 centimetres in length, so the number of square centimetres in a square inch is $2.54 \times 2.54=6.45$ or nearly $6 \frac{1}{2}$ square centimetres.

\section{TO BE REMEMBERED.}

Area is found by measuring length in two directions. A foot square is a square which has each side one foot in length. Square Measure is derived from Long Measure; it tells the standards which must be used in measuring areas.

Square Inches and square Centimetres. -As $2.54 \mathrm{~cm} .=\mathrm{I}$ inch, the number of square centimetres in I square incls is $2 \cdot 54 \times 2 \cdot 54=6.45$, or $x$ ery nearly $6 \frac{1}{2}$ square centimetres.

\section{Exercise VII.}

1. What measurements of a wall must we know before we can tell how much paper will be required to cover it?

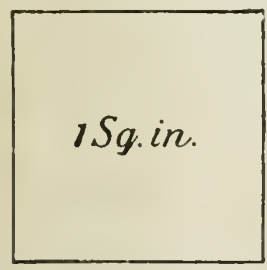

FIG. I4. $-\Lambda$ square inch contains $6^{\circ} 45$ square centimetres.

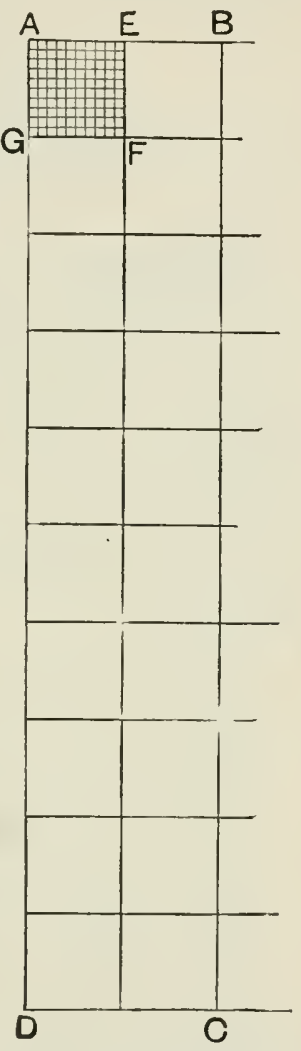

FIG. 13. - Square centinietres and square millimetres. Ten rows of ten square centimetres make one square decimetre.

2. How many square inches are there in a square foot, and how many in a square yard?

3. How many square centimetres in a square metre, and how many in a square decimetre?

4. How many square millimetres in a square decimetre? How many square millimetres in a square metre? 


\section{LESSON VIII. \\ MEASUREMENT OF VOLUME.}

\section{PRACTICAL, WORK.}

Things required.-A box one cubic foot in size, and having a lid one inch thick. The box should be a cubic foot with the lid closed. The top of the lid should be divided into square inches, and lines round the edge should mark off cubic inches (Fig. 15). Lines should be drawn round the box at every inch from the bottom edges. Cubic inch of wood. Cubic centimetre of wood. Slab of wood $10 \times 10 \times 1 \mathrm{~cm}$. Rod of wood $\mathrm{I} \times \mathrm{I} \times 10 \mathrm{~cm}$. A box measuring inside exactly I decimetre high, I decimetre wide, and I decimetre long, that is, I cubic decimetre internal volume (Fig. 16). Litre and half-litre measures; also pint and half-pint.

\section{What to do.}

Notice that the area of each face of the cubic foot is one square foot. Count the number of square inches marked on the top of the lid. Notice that the cubic inch has the same thickness as the lid, and that 144 cubic inches could be cut out of the lid. Shut the lid and stand the box upside down on the table. You know how many cubic inches there are in the slab which forms the lid. How many slabs of the same thickness are marked upon the box, and how many cubic inches are there altogether in a foot cube?

How many cubic centimetres are there in the rod of wood? How many such rods would be required to make a slab of wood the same size as that supplied? How many cubic centimetres, therefore, does the slab contain? How many slabs would be required to fill the box? How many cubic centimetres would go into the box?

Compare the cubic centimetre with the cubic inch and the cubic decimetre with the cubic foot. Knowing that $2.54 \mathrm{~cm} .=\mathrm{r}$ inch, calculate the number of cubic centimetres in one cubic inch. 
Notice the difference between one litre (the capacity of one cubic decimetre) and one pint, and determine roughly the number of pints in one litre.

\section{REASONS AND RESULTS.}

Measurement of Volume.-If we examine Fig. I5, which represents a cubic foot, and bear in mind what we have already

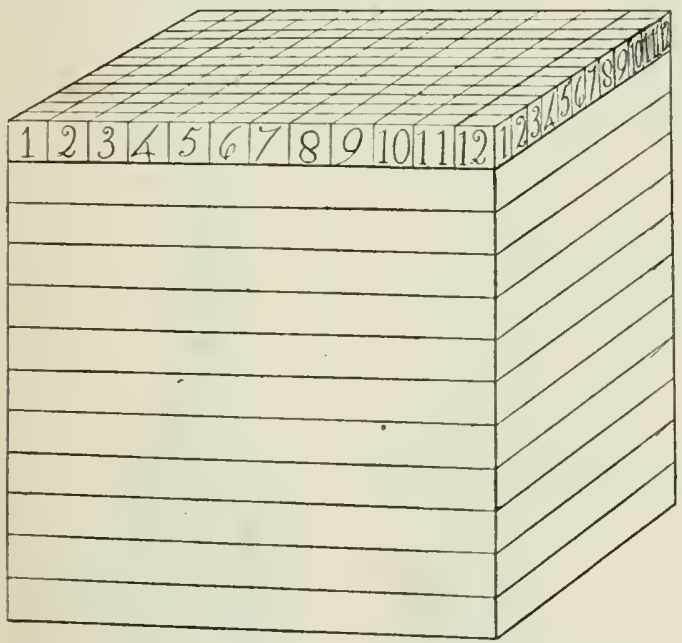

FIG. 15.- Each little cube at the top may be imagined to be r cubic inch. There are 144 of them. Twelve such layers of cubic inches make I cubic foot.

learnt, we shall easily understand that each edge of the solid there represented is measured as a length. Each of its faces has an area, which can be obtained by multiplying together the lengths of two of the edges which meet at a corner. But the size of the solid, or the amount of room it takes up, or the space it occupies, is quite a different thing. This new measurement is what is called its volume.

The volume of a solid body is obtained by measuring in three directions. Just as to find the area of a surface we measure its length and breadth, so to measure the volume of 
a solid we must find in addition to measurements of length and breadth, another distance called the thickness. If we multiply length, breadth, and thickness together we obtain a volume or cubical content.

Returning to our cubic foot for a moment, let us find how many cubic inches it contains. We know already that any one of its faces covers 144 square inches of surface. In the cube we can think of a layer of 144 cubic inches, or little cubes each edge of which is an inch, and each face of which is a square inch. How many such layers are there in the whole cubic foot? Evidently there are twelve layers.

Consequently, in the whole cube we have $144 \times 12=1728$ little cubes whose edges are one inch long and whose faces are each one square inch in area. Or one cubic foot contains 1728 cubic inches.

We could reason in the same way to find out how many cubic feet are required to build up a cubic yard. We may write down, therefore,

I $7.28(=12 \times 12 \times 12)$ cubic inches make I cubic foot.

$27(=3 \times 3 \times 3)$," feet " I " yard.

Metric Measures of Volume.-We proceed in a similar way when we wish to measure volumes by the metric system. Ten
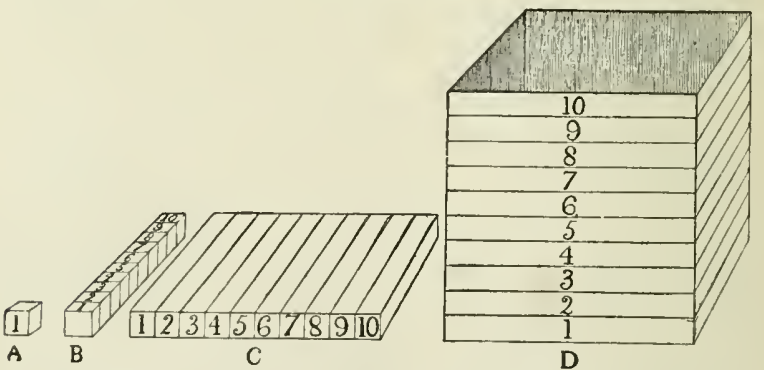

Fig. 16.-Ten cubes like $A$ would make a rod like $B$. Ten rods like $B$ would make a slat like $C$, and ten such slabs would go into the box $D$.

cubic centimetres in a row would make a rod as at $B$ in Fig. I6. Ten such rods would make a slab as at $C$, which would therefore contain $10 \times$ Io cubic centimetres, that is, Ioo cubic 
centimetres. Ten such slabs would go into a box such as is shown at $D$; so the number of cubic centimetres in a box this size would be $100 \times 10$ cubic centimetres, that is 1000 cubic centimetres.

The box measures 10 centimetres each way, and its volume is a cubic decimetre. You know there are 10 centimetres in a decimetre, so you may say the edge of the decimetre box is 10 centimetres in length; the area of one of its faces is $10 \times 10=100$ square centimetres; its volume is $10 \times 10 \times 10=$ $100 \times 10=1000$ cubic centimetres.

The Litre.-If a hollow cube is made I decimetre long, I decimetre broad, and I decimetre deep, it will hold 1000

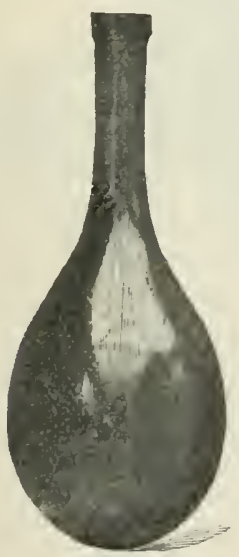

LITRE.

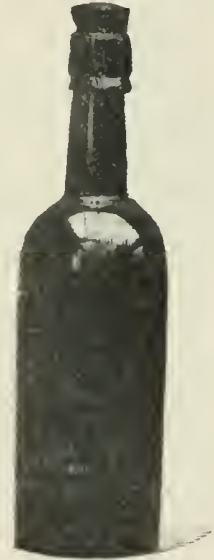

Pint.

FiG. 17. - A litre bottle will hold $1 \frac{3}{4}$ pints. These two bottles look nearly the same size, but the glass of the litre hottle is much thinner than that of the pint bottle.

cubic centimetres of liquid. This capacity is called a litre. All liquids are measured in litres in countries where the metric system is adopted. Thus in France, wine, milk, and such liquids are sold by litres instead of by pints. A litre is equal to about one and three-quarters English pints. A litre bottle and a pint bottle are shown side by side in Fig. I7. 
We may now write some of the measures of volume in the metric system :

ro centilitres make I decilitre.

Io decilitres " I litre (I000 cubic centimetres).

Io litres

Io dekalitres

Io hektolitres

, I dekalitre.

" I hektolitre.

" I kilolitre or I cubic metre.

Cubic Centimetres and Cubic Inches.-It has already been found that one inch is 2.54 centimetres long. The area of one

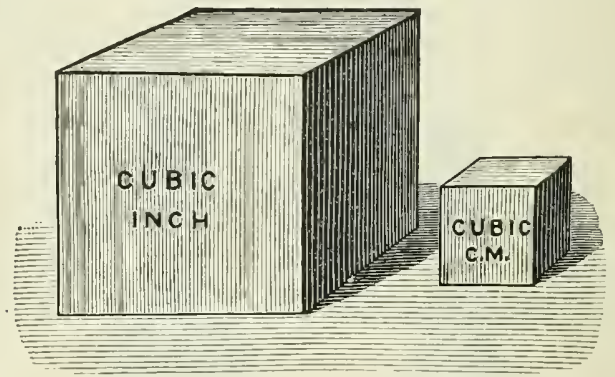

FIG. 18.-It takes $16 \frac{1}{3}$ cubic centimetres to make 1 cubic inch.

square inch, that is of a surface I inch long and I inch broad, is therefore $2.54 \times 2.54$ or 6.45 square centimetres. The volume of a cubic inch, if the measurements are made in centimetres, is $2.54 \times 2.54 \times 2.54$ cubic centimetres, that is 16.38 cubic centimetres. It would thus take 16.38 cubic centimetres, or roughly I $6 \frac{1}{3}$ cubic centimetres, to make one cubic inch. Sixty-one cubic inches are about equal to the volume of one decimetre.

TO BE ReMEMBERED.

Volume is cubical content. Length, breadth, and thickness have to be measured in determining volume. Cubic Measure is derived from Long Measure.

A Litre is a volume or capacity of 1 cubic decimetre, that is, 1000 cubic centimetres; I litre $=1 \frac{3}{4}$ pints.

As 2.54 centimetres $=1$ inch, the number of cubic centimetres in 1 cubic inch is $2.54 \times 2.54 \times 2.54=16.38$. 


\section{EXERCISE VIII.}

I. If you were told the number of inches in a foot, how would you calculate the number of cubic inches in a cubic foot?

2. What is meant by a litre? What would be the length of the side of a cube which contained 1000 litres?

3. Write down the names given to the parts of a litre.

4. Which would hold more water, a litre jug or a pint bottle?

\section{LESSON IX.}

\section{MASS AND WEIGHT.}

\section{PRACTICAL, WORK.}

Things required.-The two pieces of iron or brass which in ordinary language are called a "pound" and a "half-pound" weights; or a "pound" and a "two-pound" will do. Also set of ounce "weights." Pair of scales. Spring balance. A yard of thin iron wire. Strong magnet. Equal masses of lead and cotton wool.

\section{What to do.}

Lift the two pieces of metal. One feels heavier than the other, that is, the masses are different.

Place a certain amount of lead in one pan of a balance, and counterpoise it with cotton-wool in the other pan. The masses are equal but the volumes are different (Fig. 19).

Drop one of the pieces of metal ; it falls to the ground on account of the earth's pull upon it. I.

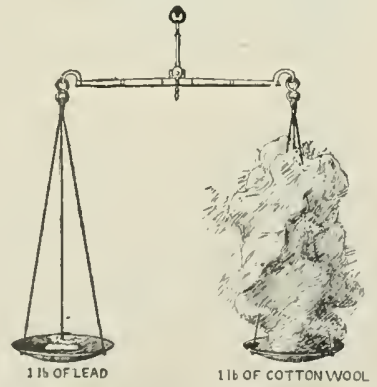

FIG. 19. - $r$ lb. of lead has the same mass as $\mathrm{I} \mathrm{lb}$. of cotton wool. 
doubled when you held the piece of metal, what difference would you feel? If the attraction suddenly ceased, what would happen when you released your hold of the piece of metal?

Wind a piece of iron wire round a smooth walking stick or a round ruler, and so make a coil. Hang one end of the coil on a support, and to the other attach the iron pound. Observe that the spring is made longer by the downward pull of the iron (Fig. 20).

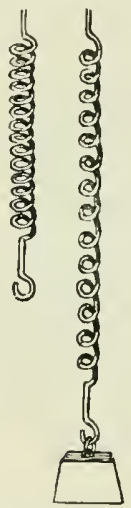

Fig. 20. - The coiled spring is pulled out by the mass hung from it.

Examine the parts of a spring balance ( $F$ ig. 2I). Attach one ounce to the balance and show that the marker is pulled down to the division I. The pull of the spring upwards and of the ounce downwards are equal.

If possible, using a delicate spring balance, such as is used for weighing letters, show that the downward pull of a mass of iron can be increased by holding

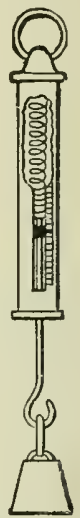

FIG. 21, - To show the spring inside a spring balance. a strong magnet beneath it (Fig. 22).

\section{REASONS AND RESULTS.}

What Mass is.-Before we attempt to learn how mass is measured we must know what is meant by this word. When we say that the mass of one piece of metal is twice as great as the other, we mean that one of them contains twice as much iron, brass, or othe: material as the other. And always when we speak of the mass of a body we mean the amount of stuff or matter, of whatever kind, it contains. Though the masses of two lumps of material may be equal, as can be shown by making one balance the other in a pair of scales, their volumes 
may he very unequal. This is very well seen by comparing equa! masses of lead and cotton-wool.

The mass of a thing is not the same as its weight, though one is often confused with the other. Keeping in mind what is meant by mass, we can, by doing one or two experiments, find out exactly what should be meant when the word weight is used.

Mass is not Weight.-If the mass of a pound is dropped from the hand it falls to the ground. If the same mass is hung upon the end of a coil of iron wire, the coil is made longer by the downward pull of the mass fixed to its end. The amount by which a steel spring is lengthened, as the result of such downward pull of masses attached to its end, is used to measure their weights in the instrument called a spring balance. If we use a very delicate balance of this kind, like those used in weighing letters, we can make the weight of a small piece of iron hung on to the balance appear greater by holding a strong magnet beneath it. But though the weight may appear greater, the mass or quantity of matter is, of course, the same whether the magnet is under the iron or not.

If you have understood these experiments you will have no trouble in seeing clearly what exactly is meant by the weight of a body. Unsupported things fall to the

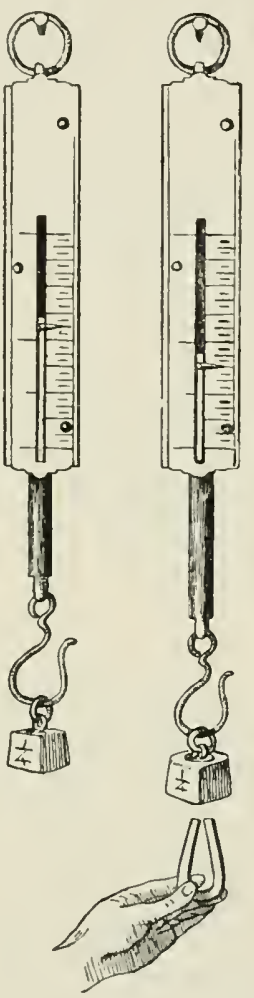

FIG. 22. - The piece of iron may be made to appear heavier by a magnet, but the mass does not change. ground; a fact which can also be expressed by saying that they are attracted to the earth. Now, even when they are supported, like the objects on the table, the earth attracts them just as much, only the table prevents them from falling, 
as they would do if there were no table there. The force with which a body is attracted by the earth is its weight. But it must be remembered that this force is just the same whether they actually fall to the ground or not. You become aware of the weight of a heavy thing when you hold it on the outstretched hand. You feel that it is only by using your strength, or as it is sometimes said, by exerting force, that you prevent it from falling. This force which you exert is equal to the weight of the heavy object. If you have understood this, and it is necessary that you should, you will never confuse mass and weight, for while mass is the amount of substance in a thing, weight is the force with which the thing tries to get to the earth.

\section{To Be REMEMBERED.}

The mass of a thing and its weight are not the same.

The mass of a thing is the quantity of matter in it, and this remains the same wherever the body is placed.

The weight of a thing is the strength of the earth's pull upon it. In other words, it is the force with which the thing is attracted by the earth.

\section{EXERCISE IX.}

I. What do you mean by the mass of a thing? Is there any difference between the mass of a pound of cotton-wool and the mass of a pound of iron?

2. Which is larger in size, the mass of a pound of cotton-wool or the mass of a pound of iron?

3. What experiments would you perform to show that masses are attracted by the earth?

4. What do you mean by the weight of a mass? Write down the difference in the meaning of $(a)$ the mass of a book; $(b)$ the weight of a book.

5. It is possible to make the weight of a piece of iron appear greater than it really is. How would you do it? 


\section{LESSON $X$. \\ MEASUREMENT OF MASS.}

PRACTICAL WORK.

Things required.- Examples of British masses, e.g. an ounce, a pound, a half-hundredweight. Box of metric masses, generally spoken of as a box of "weights." A kilogram. Spring balance.

\section{What to do.}

Compare the pound and the kilogram. Hang the roo gram mass from a spring balance, and notice that the downward pull or its weight is equal to the weight of $3 \frac{1}{3}$ ounces.

What then is the British equivalent of the weight of a kilogram? It is evidently equal to the weight of $3 \frac{1}{2}$ ounces $\times 10=$ weight of 35 ounces $=$ the weight of $2 \frac{1}{5}$ lbs. (roughly).

\section{REASONS AND RESULTS.}

Measurement of Mass.-Just as in measuring lengths we found it was necessary to have a standard with which to compare, so in measuring mass we must also have a standard or unit. Then we can say how many times the mass of a given body is greater or smaller than our unit. In this country the standard of mass is the amount of matter in a lump of platinum which is kept with the standard yard by the Board of Trade. This lump of platinum is called the imperial standard pound avoirdupois (Fig. 23). The divisions, etc., of the imperial pound you have already learnt in your arithmetic lessons, under the name of "avoirdupois weight."

A mass of $\mathrm{I} \mathrm{lb}$. avoirdupois is kept at a weights and measures office in every city, so as to test the lb. 'weights' used by tradesmen, and see whether they really have the mass of $I \mathrm{lb}$. or are too light. A local standard lb. used for this purpose is shown in Fig. 24 


\section{AVOIRDUPOIS WEIGHT. ${ }^{1}$}

\begin{tabular}{|c|c|}
\hline 6 drams & make I ounce. \\
\hline ounces & $" \quad$ I pound. \\
\hline 8 pounds & I quarter. \\
\hline $\begin{array}{l}4 \text { quarters } \\
\text { o hundredweights }\end{array}$ & $\begin{array}{l}\text { I hundredweight. } \\
" \quad \text { I ton. }\end{array}$ \\
\hline
\end{tabular}

The Kilogram and Gram.--The standard of mass which is adopted in France, and in other countries where they use the

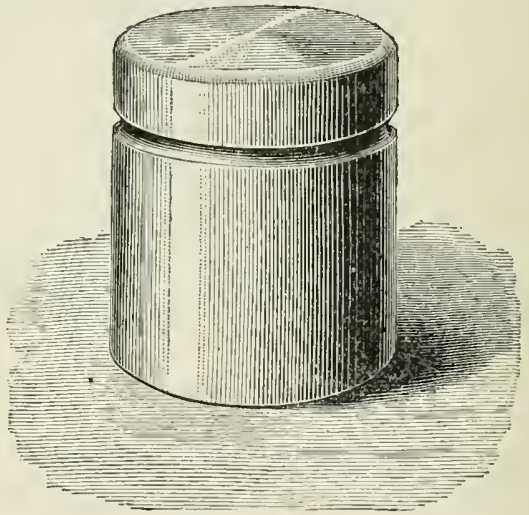

FIG. 23.-Exact size and shape of the British standard pound, made of platinum. From Aldous's Course of Physics (Macmilian).

metric system, is called the kilogram. The kilogram is the amount of matter in a lump of platinum which is kept in safety at Sèvres. This standard is bigger than the British pound; indeed it is equal to about two and one-fifth of our pounds. It is very interesting to know how the mass of a kilogram was obtained. It was agreed to give the name gram to the mass of water which a little vessel holding one cubic centimetre would contain. $^{2}$ The lump of platinum was made equal to the mass

1 Remember this is a wrong use of the word weight. What ought it to be?

2 The temperature being $4^{\circ} \mathrm{C}$. But it is unnecessary for the beginner at this stage to consider why the temperature must be mentioned. 
of one thousand cubic centimetres of water; it would therefore have the same mass as one thousand cubic centimetres of water, or, as you know this amount is called, a litre of water. The

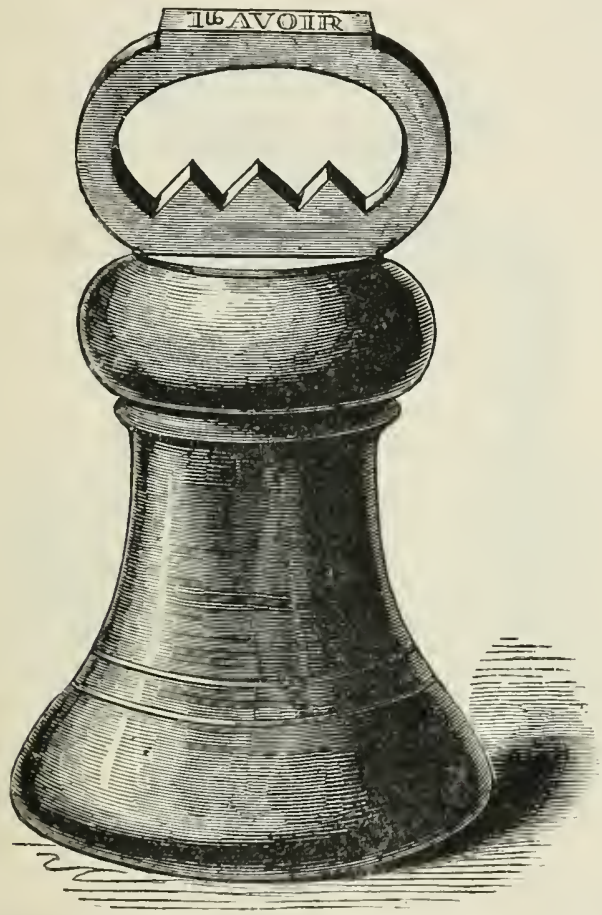

Fic, 24.-Size and shape of the avoirdupois I Ib. kept by Inspectors of W'eights and Measures. Made of brass. From Aldous's Course of P'hysics (Macmillan).

names used for the divisions, etc., of the gram are obtained in the same way as in the case of the metre, thus:

\section{METRIC MEASUREMENT OF MASSES.}
Io milligrams = I centigram.
10 grams = 1 dekagram.
Io centigrams = I decigram.
Io dekagrams = I hektogram.
Io decigrams $=$ I gram.
Io hektograms = I kilogram. 
How to remember Metric Measures.-As we have now described the metric measures of length, volume, and mass. this is the place to explain how they can all be easily remembered.

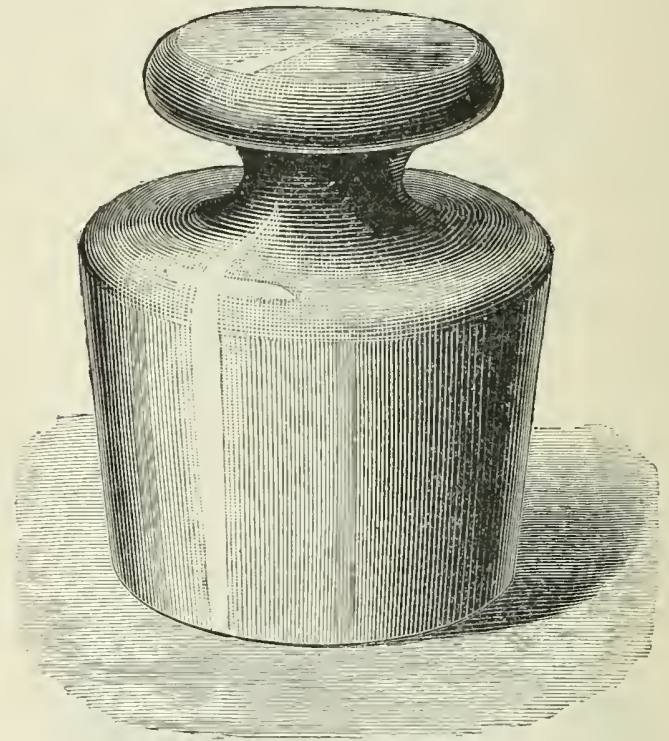

Fig. 25.-Exact size and shape of the metric standard of mass-the kilogram-made of platinum. From Aldous's Course of Physics (Macmillan).

You should bear in mind that in metric measures

milli- means thousandth.
centi- " $\quad$ hundredth.
deci- "
deka- $\quad$ tenth.
hekto- "
kilo- a hundred times.

By putting these words in front of the words metre, litre, and gram, all the metric measures of length, volume, and mass are obtained, as shown in the following table: 


\begin{tabular}{|c|c|c|c|}
\hline & Length. & Volume. & Mass. \\
\hline $\begin{array}{r}\frac{1}{1000} \\
1 \frac{1}{100} \\
1 \\
10 \\
1 \\
10 \\
100 \\
100 \\
1000\end{array}$ & $\begin{array}{l}\text { Milli-metre } \\
\text { Centi-metre } \\
\text { Deci-metre } \\
\quad \text { Metre } \\
\text { Deka-metre } \\
\text { Hekto-metre } \\
\text { Kilo-metre }\end{array}$ & $\begin{array}{l}\text { Milli-litre } \\
\text { Centi-litre } \\
\text { Deci-litre } \\
\quad \text { Litre } \\
\text { Deka-litre } \\
\text { Hekto-litre } \\
\text { Kilo-litre }\end{array}$ & $\begin{array}{l}\text { Milli-gram } \\
\text { Centi-gram } \\
\text { Deci-gram } \\
\text { Gram } \\
\text { Deka-gram } \\
\text { Hekto-gram } \\
\text { Kilo-gram }\end{array}$ \\
\hline
\end{tabular}

You see from this that what you have learnt to call the metric system of weights and measures is much simpler than ours, and the boys in countries where it is used have not to learn so many different tables as they have in England when they begin "weights and measures" sums.

\section{TO BE REMEMBERED.}

The British standard of mass is the imperial pound avoirdupois.

The metric standard of mass is the kilogram ( $=2 \frac{1}{3} \mathrm{lbs}$.), or the mass of 1000 cubic centimetres of water at a certain degree of temperature. A gram is the mass of I cubic centimetre of water.

To remember metric measures bear in mind the words milli (thousandth), centi (hundredth), deci (tenth), deka (ten), hekto (hundred), kilo (thousand).

\section{EXERCISE $X$.}

1. What is the standard of mass in British countries and what in France?

2. Write out "avoirdupois weight."

3. State exactly what a kilogram is. How much water by volume has a mass of a kilogram?

4. Write down the table you have learnt of the metric system of masses. 


\section{I.ESSON XI.}

\section{THE PRINCIPLE OF THE BALANCE.}

\section{PRACTICAL WORK.}

Things required.-Lath with a ring or eye screwed into one edge, above the centre, and a similar ring at each end the lath should be marked in equal divisions of about I centimetre, starting from the centre. Two pill boxes, or shallow trays, having threads for suspending them from the lath. I lb. of very small nails. Set of "weights."

\section{What to do.}

Hang the lath from a smooth round nail by means of the ring above its centre, so that it turns easily about the nail and hangs horizontally, as it will do if properly suspended. Hang a mass by means of thread upon the lath at any convenient distance on one side of the nail, and balance it with a mass of the same amount on the other side. Measure and prove that the distance of the masses from the middle division is the same in each case.

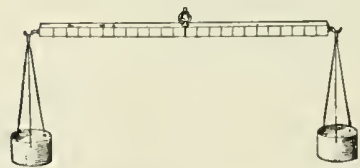

Fig. 26.-A balance made with a lath and pill-boxes.

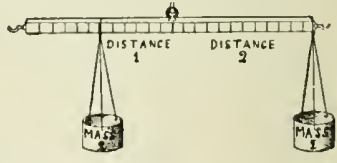

FIG. 27. - The mass multiplied by the distance from the turning point gives the same result on both sides.

Using the lath as before, hang over it, at equal distances from the nail, two pans (which you can make out of pill boxes and thread), one on each side of the nail. Put a known mass, say 20 grams, or, if more convenient, an ounce, in one pan and find out what mass must be placed in the other for the lath to be horizontal, or, as we say, for the lath to be equilibrium. Prove in this way that when 
the pans are at equal distances from the support there is equilibrium when the masses are equal.

Hang two masses, one twice as great as the other, on opposite sides of the turning-point of the lath. Move them along until they balance one another; then notice that the smaller of the two masses is twice as far away from the centre as the larger. Experiment with other masses, and show that in every case

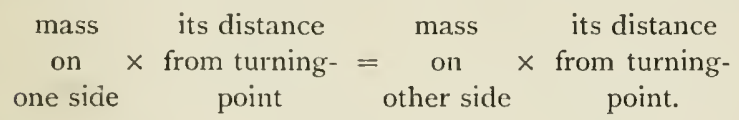

Find in this way the masses of a few things, such as half-a-crown, penny, etc.

\section{REASONS AND RESULTS.}

The Principle of the Balance.-When two boys are going to bave a see-saw they first place the plank upon a $\log$ or some

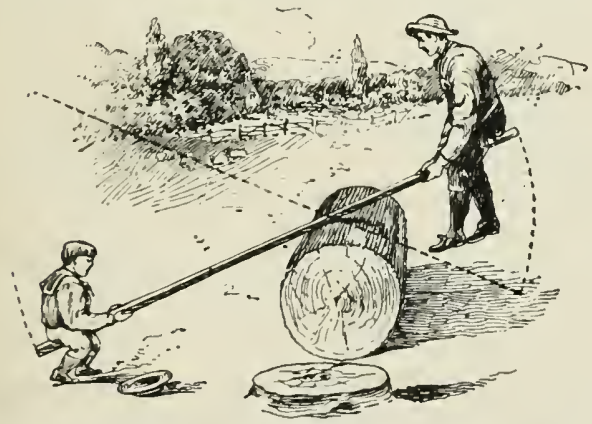

F1G. 28.- The bigger boy sits nearer the log than the smaller boy to make the balance right.

other support, so that it balances, half of it being on one side of the log and half on the other. If the boys have the same mass they sit at equal distances from the log, and then the see-saw moves easily up and down. If one boy is bigger than the other, he sits nearer the log than the smaller boy in order to make the balance right. A small boy at one end of the see-saw can 
balance a big and heavy boy sitting near the log upon the other side.

A small lath balanced upon a ring above the centre, as shown in Fig. 26, is similar to a see-saw, and, like it, will swing up and down. If a certain mass is hung from one side, then the same mass must be hung at the same distance from the centre on the other side in order to balance the lath. When the lath is supported at the middle, equal masses are always balanced at equal distances from the point of support. This fact is made use of in constructing ordinary balances or scales. A simple form of balance can be made by hanging two pill boxes from hooks at the ends of the lath, as shown in the picture (Fig. 26).

The Balance.-The form of balance shown in Fig. 29 is evidently similar in principle to the supported lath with pill

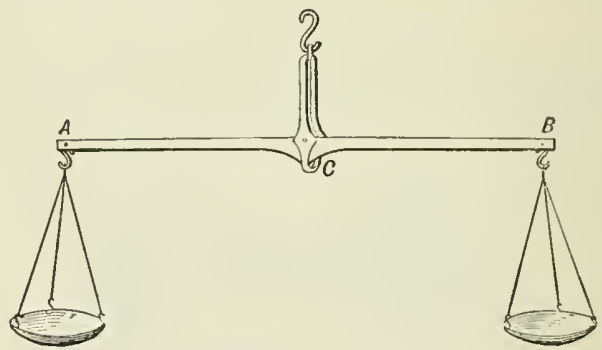

FIG. 29. - A simple balance, or pair of scales.

boxes. This kind of balance is good enough for ordinary purposes, but when exact weighings are wanted, a better form, such as that shown in Fig. 30, is used. All the parts in this balance are very carefully made, and the greatest possible pains are taken to have very delicate supports and accurate adjustments. Instead of the wooden lath described just now, a brass beam, $A B$, is employed. This is supported at its middle line on a knife edge of hard steel, which, when the balance is in use, rests on a true surface of similar steel. The hooks to which the pans are attached are likewise provided with a $\mathbf{V}$-shaped groove of hard steel, which also, when the balance is in use, rests upon knife edges on the upper parts of the beam. To the middle of the beam is attached a pointer, $F$, the end of which moves in 
front of an ivory scale, $G$, fixed at the bottom of the upright which carries the beam. When not in use, the beam and hooks are lifted off the knife edges by turning the handle $C$.

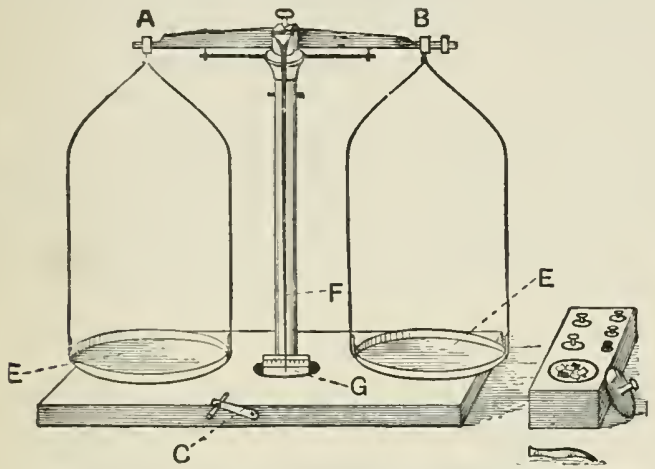

FIG. 30.-A delicate balance for the accurate determination of masses.

The Balance is used for comparing Masses. - When we wish to know the mass of any body we place it in one pan of the balance (for the sake of convenience the left one is generally used), and then we counterpoise it with known masses. From our second experiment with the suspended lath we know that when the body whose mass is required is balanced by one or more masses from a box of standard masses, called a box of "weights," we can find the unknown mass by adding together that of all the masses in the right hand pan.

\section{TO BE REMENBERED.}

A balanced lath remains in equilibrium when the mass on one side, multiplied by its distance from the turning-point, is equal to the mass on the other side, multiplied by its distance from the turning-point.

The balance is used to compare masses. The principle upon which it depends is, that when two masses placed at the same distance on opposite sides of the turning-point balance one another, they are equal.

\section{EXERCISE XI.}

I Describe an experiment to illustrate the principle of the halance, and give a sketch of the things you use. 
2. Describe, with a sketch, the construction of the balance, and explain its use.

3. If a boy whose mass is $56 \mathrm{lbs}$. sits on one side of a balanced seesaw, at a distance of 6 feet from the $\log$ upon which it rests, how far from the log must a boy whose mass is 112 lbs. sit in order to keep the see-saw level?

4. Why is it necessary to be sure that the pans of a balance are suspended at the same distance from the turning-point?

5. Suppose a tea merchant uses a pair of scales having a beam not supported from the centre, but from a point a little distance nearer the pan in which he puts his "weights." Do his customers get fair weight? If not, explain whether they get less or more than they ought.

\section{LESSON XII.}

DENSITY.

PRACTICAL WOKK.

Things required.-Cubic centimetres of oak, lead, cork, and marble. Two $4 \mathrm{oz}$. flasks, or small bottles of the same size. Balance and box of "weights." Graduated glass jar, marked in cubic centimetre divisions (Fig. 3I), pipette. Small beaker.

\section{What to do.}

Determine, by means of a balance, the mass of each of the cubic centimetres supplied, and record the results thus :

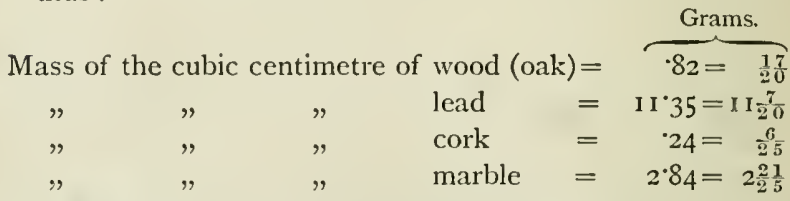

Counterpoise two small bottles of the same size. Fill one with water and the other with methylated spirit. Notice that the bottle of water is heavier than the bottle of spirit, though the volume of each liquid is the same.

Place a glass vessel in one pan of the balance, and counter. poise it with shot or small nails in the other. Measure out 
Ioo cubic centimetres of water into the glass vessel, and find the mass of the water in grams. Determine the mass of one cubic centimetre by dividing this number by Ioo. It will be found that the mass of one cubic centimetre is one gram very nearly. It would be exactly if the water were at a certain temperature.

A convenient way to add or take away small quantities of liquid is by means of a pipette, used as shown in Fig. 32.

Counterpoise a pint measure or bottle with some sheet lead. Fill the bottle with water, and place iron weights in the opposite pan to balance it. Notice that the size of the iron is much less than the size of the pint of water.

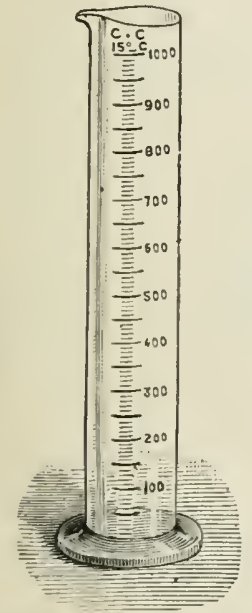

Fig. 3r. - Measuring jar, graduated in cubic centimetres.

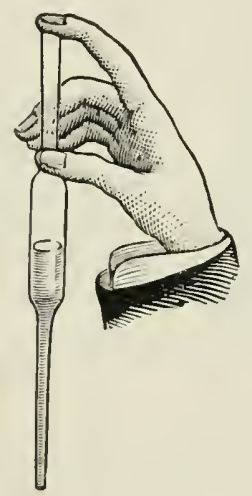

Fig. 32.- How a pipette is used.

\section{REASONS AND RESULTS.}

The Meaning of Density.-In an earlier lesson an explanation was given of the meaning of the word dense, and lead was mentioned as an example of a dense substance. You must now learn more exactly what the word dense, or density, means.

If different solids are obtained, of the same size or volume, every boy knows that they will have different masses. Suppose, 
for instance, we determine the mass of a cubic centimetre of wood, lead, cork, and marble, one after the other. The lead will be found to have the greatest mass, or be heaviest, the marble will come next, and then will follow the wood and cork in order. We thus find that equal volumes of these different solids have different masses.

By filling two bottles of the same size with different liquids, it can also be shown that equal volumes of different liquids have different masses. And when different gases are compared in the same way, equal volumes of these, too, are found to have different masses.

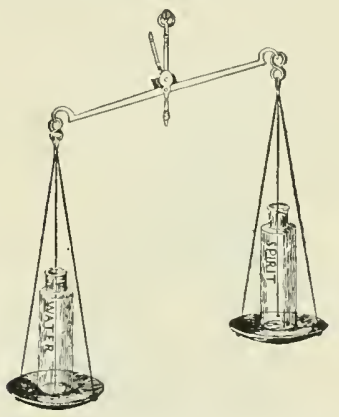

FIG. 33.- A bottle of water is heavier than a bottle of spirit of the same size.

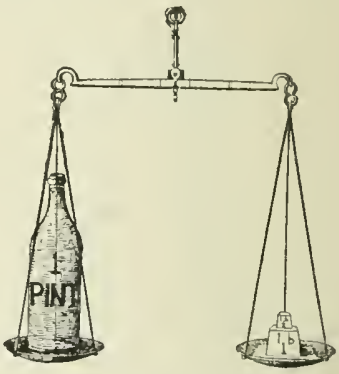

FIG. 34. - A pint of water has a mass of a pound and a quarter. Notice the piece of lead under the $1 \frac{3}{4}$ lbs. to counterpoise the empty bottle.

Or, if we compare the size of a pint of water with that of one and a quarter pounds of iron, we find that, though as shown by weighing, the masses of these things are equal, yet their sizes are very unequal. Hence we may say that equal masses of iron and water have very different sizes.

Two facts, which should never be forgotten, are taught by experiments of this kind. They are :

I. Lumps of different substances of the same size or volume may have unequal masses.

2. Lumps of different substances which have equal masses may have very different sizes or volumes.

It is usual to speak of these facts by saying that things have different densities. Referring again to an example we have 
already used, a pound of feathers or cotton-wool has exactly the same mass as a pound of lead, but, as you know, both the feathers and cotton-wool take up much more room, or have a larger volume, than the piece of lead (Fig. 19). The matter in the lead must be packed more closely than in the cotton-wool, which accounts for it taking up less room. The shortest way of saying all this, and the way in which you must express it for the future, is to say that lead is denser than either cottonwool or feathers.

If the size of a thing whose mass is great is very little, then it is called a dense thing, or is said to have a high density. If, on the other hand, the size of a thing is very great and its mass very small, it is said to have a low density. Lead is a substance with a high density, because, as you know, a small piece of it has a large mass. Pith and cork, on the contrary, have a low density, because a very large lump of either of them has a small mass.

How Densities are compared.-It is easy to compare densities when lumps of exactly the same size are used. Since the volumes are the same, it is quite clear that the thing with the greatest mass is the densest, and that which has the smallest mass is the least dense, so that we can compare the densities of these things by their masses. If we arrange them in order, putting the heaviest at the top, thus,

lead
marble
wood
cork

we can say that lead is denser than marble, marble than wood, and so on. Moreover, the densities of these things having the same size are in the same proportion as their masses.

Standard of Density.-But to compare densities it is better to have a standard, just as we have a standard of length, the yard, with which to compare other lengths; or a standard of size with which to compare other sizes. The density of water at a certain fixed temperature is taken as the standard. [This temperature is called four degrees centigrade, and written 
$4^{\circ} \mathrm{C}$., which you will understand after you have studied the thermometer.]

The mass of one cubic centimetre of water at $4^{\circ} \mathrm{C}$. is one gram, and its density is taken as the standard of density, and is called 1. Similarly, a substance, the mass of a cubic centimetre of which is two grams, would be said to have a density of 2 , for it must contain twice as much matter as water does, packed into one cubic centimetre. The mass of a cubic centimetre of quicksilver is $13 \frac{3}{5}(13.6)$ grams, i.e. it contains $13 \frac{3}{5}$ times as much matter in one cubic centimetre as there is in one cubic centimetre of water. Its density is therefore $13 \frac{3}{5}$ or 13.6 .

\section{To be Remembered.}

Equal volumes of different substances may have different masses. Equal masses of different substances may have different volumes. Density is shown by the proportion of mass to volume.

The standard density is the density of water at a temperature of 4 degrees on the centigrade thermometer.

The mass of a cubic centimetre of water at a temperature of $4^{\circ} \mathrm{C}$. is 1 gram, and the mass in grams of a cubic centimetre of any substance at this temperature is the density of the substance.

\section{Exercise XII.}

I. How would you show that equal volumes of different substances may have different masses?

2. If you had equal masses of iron and water, which would have the larger size? What conclusion would you draw from the difference?

3. What is meant by the density of a substance? Name several things with a high density and several things with a low density.

4. The density of what substance is taken as the standard? How would you proceed to find the mass of a cubic centimetre of water? What result would you expect to obtain? 


\section{LESSON XIII.}

\section{DENSITY-CONTINUED.}

\section{PRACTICAL WORK.}

Things required. - Small bottle, or medicine phial, with glass stopper having a groove, made by means of a file along the part which fits into the bottle; also a bottle with a file mark across it near the top. Balance and a box of weights. Small nails for counterpoising.

\section{What to do.}

Clean and dry the bottle having a mark across it. Counterpoise the bottle with a pill box containing very small nails or lead foil. Now fill the bottle with water up to the mark; and find, by weighing, the mass of the water.

Empty out the water and fill up to the mark with the liquid whose density is required, such as methylated spirit or milk. As before, find by weighing the mass of spirit or milk in the bottle. The masses of equal volumes of the two liquids are thus obtained.

Consider the use of the grooved stopper in the second bottle, and use the bottle to determine the masses of equal volumes of two different liquids.

\section{REASONS AND RESULTS.}

How the Density of a Thing is measured.-This becomes very easy when water is taken as a standard. All we want to do to know the density of any substance is to ascertain the mass of a cubic centimetre of the substance. This number tells us, since the mass of a cubic centimetre of water is I gram, how many times heavier or lighter the substance is than the standard, water; and this, as you know, is the density of the substance. 
We can now think of density in two ways. We can either regard it as

(1) The number of times a substance is heavier or lighter than water, or, as

(2) The mass of a cubic centimetre of the substance.

Let us go one step further. What is true of one centimetre of each of the things we are considering, namely, the standard water and the substance whose density is required, will also be true of two centimetres, or any other number of centimetres. So long as we keep the sizes or volumes the same, then, we can comparc the densities in just the same way, for the number of times the substance is heavier or lighter than water can be cietermined at once by a simple division sum. But we need not measure the volume in cubic centimetres. ${ }^{1}$ Cubic inches or cubic feet would do just as well. All we want to be quite sure of is that their volumes are the same.

Experimental Determination of Density of Liquids.-Since we only have to be quite sure that the volume of the water and

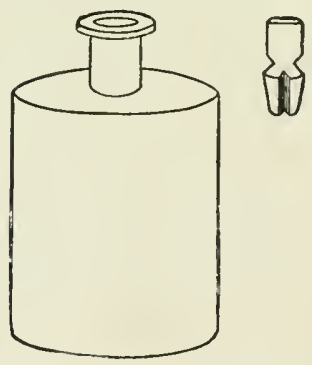

F1G. 35.-A buttle with a groove in the stopper, for determining relative density. the other substance are exactly the same in order to compare their densities at once, it is a very easy matter to find the density of a liquid. All we have to do is to take a bottle and scratch a mark on it, and fill it up to this mask with the various liquids, and we shall be quite sure this gives us the same volume of each of the liquids. Or, we can completely fill a bottle with one liquid after another, and so obtain equal volumes of them. A convenient way to do this is to use a bottle like the one shown in Fig. 35, having a stopper with a groove cut on it, or a hole bored through it. When such a bottle is filled with a liquid, and the stopper is put in, some of the liquid passes up through

1 At this stage it is assumed that the substance is at $4^{\circ} \mathrm{C}$. , but this has not been insisted on too much lest the reader should get confused. 
the groove to make room for the stopper. A bottle of this kind may be named a density bottle.

Suppose the mass of water in a density bottle was found to be 50 grams, and the mass of the same volume of methylated spirit was found to be 40 grams. Then these numbers show the relative densities of the two liquids, and as we take the density of water as the standard or unit, the density of the spirit is equal to 40 divided by 50. It is thus seen that the density of spirit is represented by the fraction $\frac{40}{50}$ or $\frac{1}{5}$, which written as a decimal fraction is 0.8 .

The density of many liquids is greater than that of water. Thus milk has a density represented by the number 1.03 , or $\mathrm{I} \frac{3}{100}$, so that equal volumes of water and milk would have masses in the proportion of 100 to 103 . In all cases, whether solids or liquids are used in the experiments, we can say

$$
\text { Density of substance }=\frac{\text { mass of substance }}{\text { mass of equal volume of water }} \text {. }
$$

TO BE, REMEMBERED.

Density may be considered as ( 1 ) the mass of a cubic centimetre of a substance, or (2) the number of times a substance is heavier or lighter than an equal volume of water.

Relative density is equal to the mass of a substance divided by the mass of an equal volume of water.

To find the relative density of a liquid a density bottle is used, and the mass of liquid which fills it is divided by the mass of water which fills it.

\section{Exercise XIII.}

1. State clearly the two ways in which you have learnt density may be spoken of.

2. If a cubic foot of any liquid has a mass ten times greater than that of a cubic foot of pure water, what would be its density?

3. Draw a density bottle, and explain how it is used.

4. The density of quicksilver is $13 \frac{3}{6}$; what does this mean?

5. Explain fully how you would determine the density of vinegar. 


\section{LESSON XIV. \\ DETERMINATION OF DENSITY.}

PRACTICAL WORK.

Things Required. $-U$-tube mounted upon a strip of board. This U-tube can be made by bending a piece of glass tubing, or by connecting two pieces of tubing of equal bore with a piece of india-rubber. Quicksilver, milk, vinegar, and similar common liquids.

What to do.

Pour quicksilver into one of the branches of the U-tube until it reaches a horizontal line drawn on the board (Fig. 36).

Now introduce water into one of the tubes, and notice that the mercury on which the water rests is pushed down; afterwards introduce enough water into the other tube to bring the mercury back to its original level. By measuring you find the length of each column of water is the same. Repeat the experiment with different quantities of water.

Remove the water and dry the tubes, and see that the mercury is up to the mark. Nearly fill one of the tubes with some liquid, such as methylated spirit, and balance it with water introduced into the other tube. Measure the lengths of the columns of liquid.

\section{REASONS AND RESULTS.}

Balancing Columns of Water.-A convenient way to balance liquids against one another, and so determine their relative densities, is by means of a glass tube bent in the form of a $U$.

When we arrange a $U$-tube, as in Fig. 36 , the mercury in the bend acts just like a pair of scales, and we are able to balance a column of water in one of the upright arms with a column of the same length in the other. We are then able to argue thus : the 
columns of water are the same size, or have the same volume, and they balance one another, and consequently their masses must be the same; and, finally, since their masses are equal and their volume the same, they must have the same density.

\section{Balancing Columns of Different} Liquids. - But suppose we put water in one arm of the U-tube, and enough methylated spirit into the other to make the mercury stand at the same height in the two arms.

Here we have a different state of affairs. The column of spirit which balances the column of water will be the longer, hence its size or volume is greater, since the tubes are the same width. But because they balance, their masses must be the same. Which is the denser? Evidently the water is. But how much denser? We can, since the masses are equal, easily calculate this. We may say

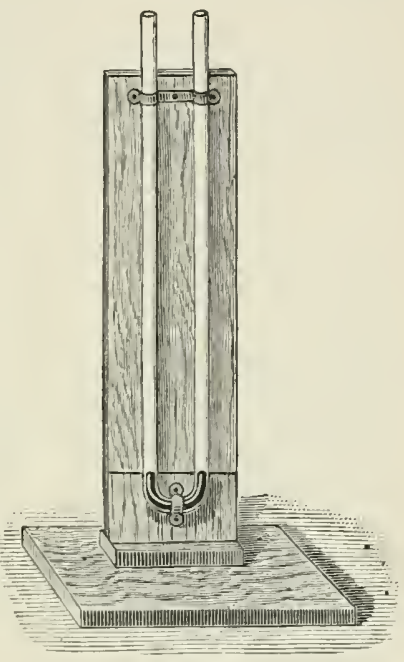

Fig. 36.-An arrangement for balancing columns of liquid. Mercury is in the bend of the tube, up to the line on the upright board.

$$
\text { Density of spirit }=\frac{\text { length of water column }}{\text { length of spirit column }} \text {. }
$$

This is a very good way to compare the densities of liquids.

How the Density of a Solid is found.-The rule in the case of a solid is just the same as with a liquid; but the plan of getting the mass of a volume of water exactly equal to the v'lume of the solid depends upon several things, which you have yet to learn about, as to the way in which solids float or sink in water. It will be wisest to first study this subject, and then to try and learn how to measure the density of any solid. This we shall try to do in the next lesson. 


\section{TO BE REMEMBERED.}

When columns of liquid balance one another, the denser the liquid the shorter is the column. If spirit and water are used

$$
\text { Density of spirit }=\frac{\text { length of water column }}{\text { length of spirit column }} \text {. }
$$

The density of any other liquid can be determined by balancing a column of it against a column of water.

\section{Exercise XIV.}

I. Two glass tubes of equal width are connected by india-rubber tubing and arranged in the shape of a $U$. The bend is filled with quicksilver. If water is poured into one tube, and spirits of wine into the other, until they exactly balance one another, which liquid will stand higher, and why?

2. Water is poured into one of the tubes in the apparatus described in the last question until it half fills the tube. How much water must be poured into the other tube to just balance it? Why?

3. Which liquid has the greater density, water or milk? Describe a method by which you would find out the density of milk.

4. In an experiment with a $U$-tube, it was found that a column of olive oil ro inches in lengin balanced a column of water 9 inches long. What is the relative density of olive oil?

\section{LESSON XV.}

\section{THINGS WHICH SINK IN WATER.}

\section{PRACTICAL WORK.}

Things requirea.-A fish-globe, such as are sold to keep gold fish in, or a large clear glass finger-bowl; pieces of lead, iron, oak, pine, cork. Glass cylinder divided into cubic centimetres. Irregular solid, such as a glass stopper or a pebble. Mercury in a saucer or tumbler.

\section{What to do.}

Fill the fish-globe or finger-bowl with water, and carefully place lumps of different things, e.g. pieces of lead, 
iron, oak, pine, and cork, one after another, into the water. Observe that ( $\mathrm{r}$ ) some sink and others float, (2) of those which float some sink further into the water than others. Take the objects which sink in water and place them in mercury. Notice that they float.

Partly fill a glass cylinder, divided into cubic centimetres, and record the level of the water therein. Drop in one of the cubic centimetre solids which sinks, and again read the level of the water; put the others in in order, recording the level of the water after each such addition. It will be found that the level increases by I cubic centimetre division in each case.

Take any solid, such as a glass stopper or a marble, and drop it gently into water contained in the graduated glass cylinder. Read the level of the water before and after dropping the solid in; the difference between these readings will give you the rolume of the solid in cubic centimetres.

\section{REASONS AND RESULTS.}

Some Things sink, others float in Water.- When you throw a stone into water what happens to it? It sinks to the bottom. But if you throw a piece of wood into water does it also sink? No, it floats. By noticing what happens when different substances are put in water you can easily divide them into two classes. Those in one division all sink, while those in the other all float. And, in water.

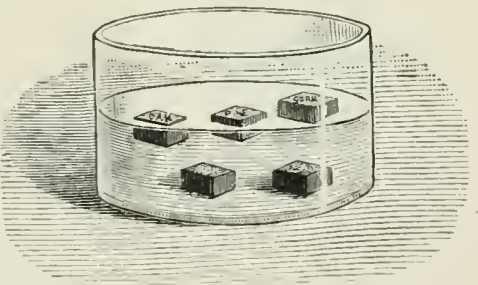

Fig.37.-Some things sink, and others float, of those that float, some sink further into the water than others.

But you must not suppose that substances which sink in water will sink in every liquid. As a matter of fact, solid iron, or even lead, will float upon mercury.

Volume of Water displaced by Bodies placed into it.-If we put water into a narrow glass cylinder, and then add lumps of material of such a size and shape that they will go into 
the vessel easily, we can, by first making a mark on the cylinder at the level of the water and then dropping in the things one at a time, show that, no matter whether they sink or float, the water stands higher when the solids are in it than it did before. Or, as it is usually stated, the solids in every case displace a certain amount of water. How much water is thus displaced? Evidently the amount depends upon the volume of the part of the solid under water.

How to determine the Volume of an Irregular Solid.-If a solid one cubic centimetre in size sinks in water it pushes aside one cubic centimetre of water to make room for itself. If its size is two cubic centimetres, it makes two cubic centimetres of water rise above the level the water had at first. Whatever the size of the solid, it must have room, and this room is obtained by displacing an amount of water of exactly the same size.

This is a very useful fact to remember. For suppose you wish to find the volume of a stone having an irregular shape.

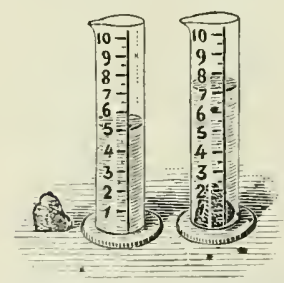

FIG. 38. - The rise of level of the water when the stone is put in show's the volume of the stone.

It would be difficult to do this by measuring the stone, but the stone could be placed in a vessel of water and the rise of level produced by it noticed. The water displaced could then be poured into a cubic inch box or into a cubic centimetre box, and the number of cubic inches or cubic centimetres could be thus found. Or, we could get a glass measure having cubic inches or cubic centimetres marked upon it, and pour the displaced water into it. But the best plan of all is to use a vessel having cubic centimetres marked upon it. Water can be put in such a vessel up to a certain mark, and the number of cubic centimetres of water displaced by the solid can be seen at once by noticing the number of divisions between the levels of the water before and after the solid is put in.

The Volume of Water displaced may be measured in Cubic Inches.-Though in every one of the experiments in our lessons on the displacement of water we have usually spoken 
of the volume of water displaced as being a certain number of cubic centimetres, there is no reason why, if we preferred it, we should not measure this and other volumes in cubic inches, cubic feet, or any other measure of volume. The principle is the same, and the choice of the unit of volume quite a matter of convenience. Cubic centimetres are generally used to measure such rolumes as these, because of the simple relation which exists between the unit of volume and the unit of mass in the metric system. As we have learnt, the mass of a cubic centimetre of water at a certain fixed temperature is exactly one gram.

To be Rememberen.

When an object sinks in a liquid the volume of liquid displaced by the object is equal to its own volume.

To determine the volume of an irregular solid it is immersed in water, and the volume of water displaced is observed.

\section{EXERCISE NV.}

1. Pieces of iron, cork, wood, pith, and lead are thrown into a trough of water. How will the different substances behave?

2. How would you find out the volume of water displaced by a solid which sinks?

3. You are given a large glass marble and told to find its volume without measuring or calculating. How would you do it?

4. Does it make any difference whether the graduated glass vessel into which solids are put when we want to find their volumes by immersion in water is divided into cubic centimetres or cubic inches?

5. The level of water in a graduated jar with cubic centimetre marks upon it is noted. A pebble is placed in the water, and it causes the level to rise 19 divisions. What is the volume of the pebble? 


\section{LESSON XVI. \\ THINGS WHICH FLOAT IN WATER.}

PRACTICAL WORK.

Things required.-Rectangular rod of wood, I square $\mathrm{cm}$. in section and about $15 \mathrm{~cm}$. long, with lines around it $1 \mathrm{~cm}$. apart. A small piece of the wood is gouged out of one end, and lead is put into the hole; and the end is then made flat by filling in with wax. Graduated jar. A lactometer. Narrow test tube with mercury or shot in it. Balance and box of weights.

\section{What to do.}

Put some water in the graduated jar, and notice its level. Find the mass of the rectangular rod, and then place the

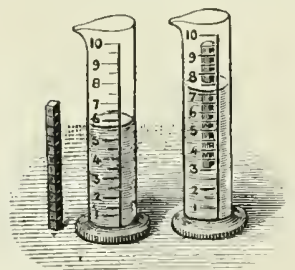

FIG. 39.-The number of cubic centimetres in the part of the rod under water is equal to the number of cubic centimetres of the water dis. placed.

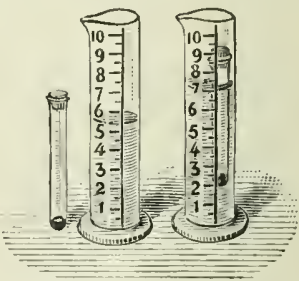

Fig. 40. - The mass of the test-tube and contents is equal to the mass of water displaced.

rod in the jar with the leaded end downwards. Notice how many cubic centimetres of the rod are immersed, and also how many cubic centimetres of water are displaced. Since the mass of I cub. cm. of water is I gram, the number of cubic centimetres of water displaced is also the mass in grams of the water displaced. This mass will be found equal to the mass of the whole rod.

Fill the divided glass cylinder with water up to a certain mark. Notice the level of the water. 
Make a mark across a test-tube about two-thirds of the distance from the bottom of the test-tube. Float the testtube in the water and put mercury or shot into it until the mark upon it is on a level with the surface of the water. Notice the number of cubic centimetres of water displaced when the test-tube is thus immersed.

Then take out the test-tube, dry it, and determine its mass together with the mercury it contains. The total mass of the test-tube and contents will be found equal to the mass shown by the number of cubic centimetres of water displaced. Repeat the experiment with the test-tube immersed to a different mark.

Float the test-tube and contents in spirits of wine and milk in succession. Notice that in the former case it sinks deeper than the mark, while in the other not so deep.

Place the loaded test-tube or a lactometer (I) in milk, (2) in water, (3) in a mixture of milk and water. Observe the depth to which it sinks in each case.

\section{REASONS AND RESULTS.}

Water displaced by Solids which float.-You have learned that a solid which sinks in water or any liquid displaces a volume of liquid equal to its own volume. When a solid floats, the case is slightly different. Part of the solid is in water and part out of the water, and, of course, only the part immersed is pushing the water aside in order to make room for itself. In the case of a floating object, therefore, the volume of liquid displaced is equal to the volume of the part of the solid below the surface.

What decides the Depth at which an Object floats in Water? -When any object is floating in water, a certain volume of it is under water and a certain volume is above the surface. You know very well that the depth at which it floats depends upon its heaviness, or, in more exact words, upon its density. A rod of heavy wood sinks deeper in water than a rod of light wood of the same size. The water displaced by the heary wood has therefore a greater volume, and consequently a greater mass, than that displaced by the light wood. But there is one important fact which applies to both cases, and should be kept 
well in mind. It is that the mass of the water displaced by the immersed part of a floating object is equal to the whole mass of the object. If therefore you are asked how far does an object which floats sink into water, the answer is -it goes on sinking until it has displaced an amount of water whose mass is equal to that of the whole mass of the floating object.

How far will an Object sink in other Liquids in which it floats? -Since the depth at which an object floats in water is decided by the rule we have just learnt, namely, that it goes on sinking until the mass of the water displaced by the

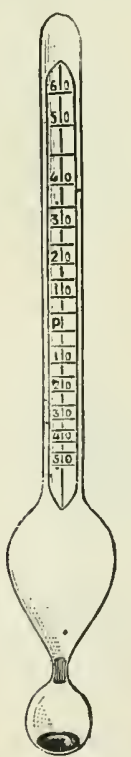

FIG. 41.-A lactometer, for testing the quality of milk. It sinks to the mark $P$ when put in pure milk. inmersed part of it is equal to the mass of the object itself, we have a ready way of deciding whether an object will sink further in another liquid or not so far. If the liquid into which it is put is less dense than water, like spirits of wine, it is clear that to make up a given mass we shall want more of the liquid. Consequently, to make up a mass equal to the mass of the floating body, the object will have to sink further into the spirit than into the water. If, on the other hand, the object is placed in a liquid such as mercury, which is denser than water, it will not sink so far, because it will not take so much of this denser liquid to have a mass equal to that of the floating body.

The Lactometer. - This fact is made use of in the construction of the simple instrument called a lactometer (Fig. 4I), used to test the density of milk. When placed in pure milk a lactometer should float with the mark $P$ (Fig. 4I) on a level with the surface of the liquid. In a mixture of milk and water the lactometer floats with some other division level with the surface of the liquid. Thus, in milk Io per cent. below the average density, the ro above the mark $P$ is level with the surface.

An experienced observer is able, therefore, from the readings of a lactometer to tell whether a sample of milk has a correct 
density, or whether it is heavier or lighter than it should be. At the same time it nust be clearly understood that it is not possible to decide at once from the reading of a lactometer whether a sample of milk has been adulterated or not. There are other considerations to be taken into account.

TO BE REMEMBERED.

When an object floats in a liquid, the volume of liquid displaced is equal to the volume of the immersed portion of the object.

The mass of the water displaced by a floating object is equal to the whole mass of the object.

An object which floats in water sinks deeper into a liquid which is less dense than water, and not so deep into one which is denser than water.

A lactometer is an instrument for testing the proportion of water which may have been added to milk.

\section{EXERCISE XVI.}

I. What is the volume of water displaced by an object which floats in it?

2. How far will a given object sink into water?

3. Will a lead pencil sink further into spirits of wine or into water when floated in these liquids? Give reasons for your answe1.

4. Why does a piece of oak sink further into water than a piece of deal the same size? 


\section{LESSON XVII.}

\section{PRINCIPLE OF ARCHIMEDES.}

\section{PRACTICAL WORK.}

Things required.-Brick with string tied to it. Pail of water. Metal cube or other heavy object. Spring balance. Tumbler. Balance with one pan having short suspension cords or chains
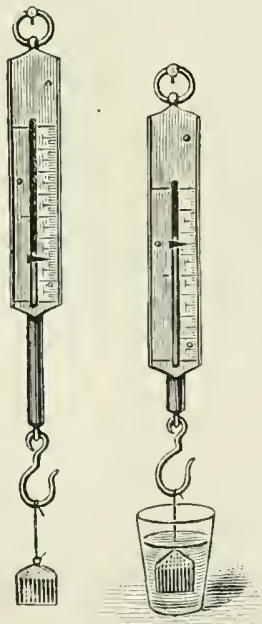

FIci. 42. - The block weighs less when immersed in water than when suspended in air. and a hook soldered to the bottom. Box of weights. Graduated jar. Small tin canister. Small nails or shot. Methylated spirit or turpentine.

\section{What to do.}

Hold a brick by a string having one end tied round it. Keeping the string in your hand, lower the brick into a pail of water, and notice that the brick seems to become lighter when it is immersed in the water.

Suspend a metal cube, or any other fairly heavy object, from a spring balance, and notice the reading of the balance. This indicates the weight of the object in air. Immerse the cube in water, as in Fig. 42, and again notice the reading of the balance. It is less than before, and the loss of weight shows the buoyant power of the water.

Find the volume of the cube, or other object used in the last experiment, by noticing the volume of the water it displaces in the graduated jar. 
Hang the object from one pan of the balance, as shown in Fig. 43 , and determine its mass in grams. Now bring a vessel of water under the pan so that the object is immersed in it, as in Fig. 44. The pan rises, indicating a loss of weight. Put gram weights in the pan until the balance sets horizontally as before. You thus find the apparent loss of mass due to the buoyancy of the water. Notice that the number giving this loss in grams is the same as that giving the rolume of water in cubic centimetres displaced by the object.

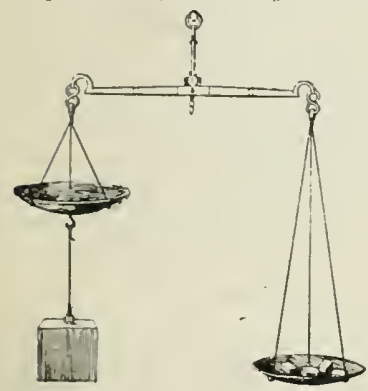

FIG. 43.-Weighing an object in air.

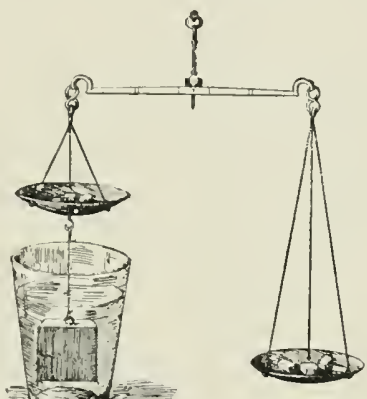

Fig. 44.-The same object weighed in water. Notice that weights are in the short pan to make up for the huoyancy of the water.

If time permits, repeat the experiment with another object, and find again that the number giving its volume in cubic centimetres is the same as that showing the loss of weight (measured as before) when immersed in water.

Procure a small tin canister about half the diameter of the graduated jar. Put some water into the jar. Notice the level Place the canister in the water and gradually put shot or small nails into it until it just sinks in the water when the cover is on. Pour the water displaced by the canister into a beaker counterpoised upon a balance; then take out the canister, wipe it, and place it in the other pan of the balance. You will find that the mass of the canister and shot is practically the same as the mass of the water displaced. 
Repeat the experiment, using another liquid, such as methylated spirit, or turpentine, instead of water.

\section{REASONS AND RESULTS.}

Buoyancy.-Most boys and girls have noticed when in a bath that if there is water enough, and they take hold of no support, the water buoys them up, or they experience a tendency to rise up through the water. In the case of things which float, such as a wooden rod or a lead pencil, you can easily see the results of this buoyancy which the water exerts, by pushing either the rod or pencil down into the water and then letting go, when the solid floats up through the water. Even in the case of bodies which sink, there is the same buoyancy on the part of the water, but it is not enough to float them. The effect which the water has upon such bodies can, however, be seen in the loss of weight which they experience if they are weighed by a spring balance when hanging in water (Fig. 42).

Loss of Weight of Things immersed in Water.-It is easy to prove by experiment that an object weighs less in water than out of it. If a cubic centimetre of lead, or any other heavy material, is hung from a spring balance and then suspended in water, it will be found to weigh the weight of one gram less in water than out. If two cubic centimetres are suspended from the balance, the loss of weight is the weight of two grams. In every case the loss of weight measured in this way is equal to the number of cubic centimetres of the solid immersed in the water. The loss is thus equal to the weight of the water displaced. This fact brings us to a highly important conclusion, known after its discoverer as the Principle of Arckimedes.

The Principle of Archimedes-When a Body is immersed in Water it loses Weight equal to the Weight of the Water displaced by it.-- If the body be immersed in any other liquid, then, the loss of weight is equal to the weight of an equal volume of that liquid. It does not matter what substance a thing is made of ; the amount of loss of weight depends upon the volume of the part immersed and not upon the material.

We can now understand many interesting facts. For instance, a ship made of iron, and containing all kinds of heavy 
things, is able to float in water although the material of which it is made is denser than water. This is because the ship and all its contents only weigh the same as the volume of the water displaced by the inmersed part of the hull. Or, the ship as a whole weighs less than a quantity of water the same size as the ship would weigh.

Now, ton, we can see why some solids float and some sink. When an object weighs more than an equal volume of water it sinks. When an object weighs less than an equal volume of water it floats. When an object weighs the same as an equal volume of water it remains suspended in the water.

A balloon rises in the air because the gas in the balloon, together with the bag and tackle, weighs less than an equal volume of air. If the balloon were free to ascend it would rise to a height where its weight would be equal to the weight of an equal volume of air.

\section{To BE ReMEMBERED.}

Buoyancy is the support given by liquids to objects immersed in them.

Objects immersed in water appear lighter than when they are out of water.

The Principle of Archimedes states that when an object is immersed in a liquid it experiences a loss of weight equal to the weight of the liquid displaced by it.

Iron ships float because they are lighter bulk for bulk than an equal volume of water.

The weight of the mass of water displaced by the part of a ship in water is equal to the weight of the whole mass of the ship.

\section{EXERCISE XVII.}

1. Why do thing; lose weight in water? How would you measure this loss of weight?

2. What is meant by the Principle of Archimedes?

3. A piece of iron sinks in water while a cork floats. What is the reason of this?

4. What do you understand by buoyancy?

5. Why will an iron ship float in water? 
6. An object having a volume of 27 cubic centimetres has a mass of 124 grams in air. What is its weight in water?

7. The mass of an object appears to be 19 grams less in water than in air. What is the volume of the object?

\section{LESSON XVIII.}

\section{DETERMINATION OF THE DENSITY OF A SOLID.}

PRACTICAL, WORK.

Things required.-Balance and box of weights. Pebbles, and other solids suitable for determination of densities. Beaker of water. Fine thread.

\section{What to do.}

Attach the solid the density of which you are going to determine to one side of the balance, as shown in

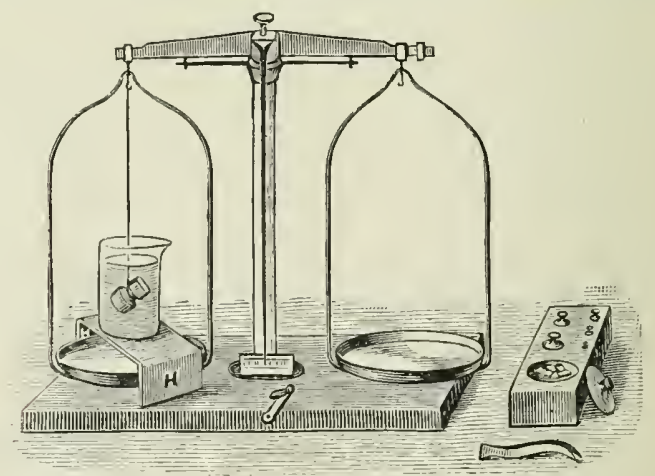

FiG. 45.-How to find the weight of an object suspended in water.

Fig. 45. By weighing, find its mass in air. Then Immerse the solid in water placed in a beaker standing upon a small platform $H H$, as shown in Fig. 45. Find 
its weight in water, and, by subtracting this number from its weight in air, determine the loss in weight of the solid when suspended in water.

Another plan of determining the weight of an object in water was explained in the last lesson (Fig. 44).

This loss of weight equals the weight of a volume of water equal to the volume of the solid. We can therefore write :

$$
\text { Density of solid }=\frac{\text { Weight of the solid in air }}{\text { Its loss of weight in water }} \text {. }
$$

\section{REASONS AND RESULTS.}

How the Relative Density of a Solid is determined.-We left this problem over from a previous lesson, in which we learnt how to determine the density of a liquid compared with water. Until you had studied what you have now learnt to call the Principle of Archimedes, it was not possible to understand the steps by which the relative density of a solid is obtained. But now that you have found out that when a body is immersed in water it loses weight equal to the weight of the water displaced by it, you are in possession of all the information necessary for determining the density of a solid compared with water.

All we want to know is:

1. The mass of the object, which we can determine by weighing it in air.

2. The mass of an equal volume of water.

And the Principle of Archimedes enables us to do this in the following manner :

We hang the object, by means of a fine thread, from one side of the beam of a balance in such a way that it is completely immersed in water. Then by weighing we observe that its mass appears less than when hanging in air. This is because it loses weight in the water. The buoyancy of the water acting upwards overcomes part of the pull of the earth downwards. The difference in the mass of the object in air and its apparent mass when immersed in water gives us the mass of a volume of water equal to the volume of the object. From these 
numbers we can at once calculate the density of the solid compared with water as a standard:

$$
\text { Density of the solid }=\frac{\text { Mass of the object in air }}{\text { Mass of an equal volume of water }} \text {. }
$$

But the weight of an object at any particular place depends directly upon the mass, consequently we can substitute the word weight for mass in this case, and can therefore write as follows :

$$
\text { Density of the solid }=\frac{\text { Weight of the object in air }}{\text { Weight of an equal volume of water }} \text {. }
$$

Another way to find the Mass of an Equal Volume of Water.-To find the mass of an equal volume of water, the object could be placed in a graduated jar and the amount of water displaced could be taken out and its mass determined by weighing. Or, if the number of cubic centimetres of water displaced is observed, the same number tells us the mass of the displaced water in grams.

Example.-A piece of lead was found to have a mass of Ioo grams in air, and when suspended in water its mass appeared to be 90 grams. What is its density compared with water?

What must we do with these numbers to find out the density of the lead compared with water? We want to know two things, you remember-first, the weight of the object in air. We know the mass by weighing, and the weight is directly proportional to this. Secondly, we want to know the loss of weight in water, as this gives us the weight of an equal volume of water. We get the loss of weight by subtraction, thus :

Loss of weight $\left.=\begin{array}{c}\text { The weight of } \\ \text { the lead in air }\end{array}\right\}-\left\{\begin{array}{c}\text { The weight, or its } \\ \text { apparent mass, in water }\end{array}\right.$ =weight of 100 grams - weight of 90 grams =weight of 10 grams.

$\therefore$ Density of the lead $=\frac{100}{10}=10$.

Since the density of this piece of lead is ro, we know that one cubic centimetre of it will have a weight equal to that 
of 10 grams. What is the volume of the piece of lead used in the example? Evidently, since its weight is equal to that of 100 grams, its volume must be ten cubic centimetres.

\section{TO BE REMEMBERED.}

To determine the density of a solid, we determine (1) its mass in air ; (2) its apparent mass in water. From these numbers we can find the loss of weight which the solid experiences in water, and can say :

$$
\text { Density of solid }=\frac{\text { Weight of solid in air }}{\text { Loss of weight in water }} \text {. }
$$

\section{Exercise XVIII.}

I. Describe fully, with a drawing, what weighings you would perform to determine the density of a solid.

2. Why does the mass of a solid weighed in water appear to be less than in air?

3. A solid was weighed in air and found by a balance to have a mass of 120 grams: When suspended in water and again weighed its mass seemed to be 100 grams. What is its density?

4. How does the Principle of Archimedes assist in the determination of the density of a solid?

\section{LESSON XIX.}

\section{THE AIR AROUND US.}

\section{PRACTICAL WORK.}

Things required.-Glass trough full of water. Bottle. Flask or bottle fitted with funnel and tube, as in Fig. 48. Balance. Weights. Two 8 oz. flasks, one fitted with tubing and clip, as in Fig. 49.

\section{What to do.}

Try to force an empty bottle, held upright with its mouth downwards, into a vessel of water (Fig. 46). When you leave go,

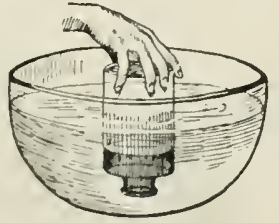

Fig 46.-. The air in the bottle cannot escape, and is compressed as the bottle is pushed down into the water. 
the bottle jumps up again. There is something in it which acts like a spring.

Tilt an empty bottle, held mouth downwards, in a

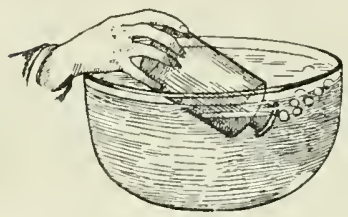

FIG. 47.-As the water goes into the bottle, air bubbles out. trough of water, and notice the bubbles of air which pass up as the water enters the bottle (Fig. 47).

Take a funnel with a narrow tube, and fit it firmly into a bottle by means of an indiarubber stopper with two holes in it. Through the second hole pass a short piece of glass tubing bent at right angles (Fig. 48).

Place a finger over the open end of the tube, pour water into the funnel, and notice that, so long as you keep your finger upon the end of the glass tube, the water is prevented from getting into the bottle by some-

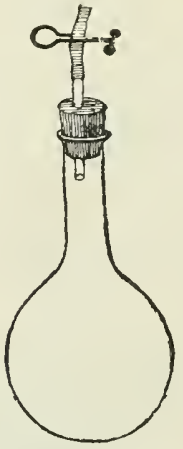

Fig. 49. - When air is sucked out of the bottle, the bottle weighs less than before.

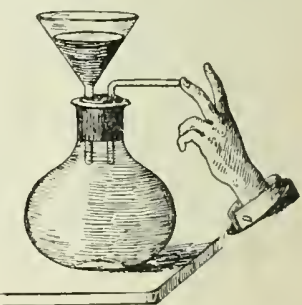

FiG. 48. - The bottle only contains air, but the water will not run in until the finger is taken from the tube, and then the air can be felt coming out.

thing - air-already there (Fig. 48). Take your finger away. The water now runs into the bottle, and air escapes from the tube. The escaping air may be felt, or its effect upon a lighted match may be seen.

The following experiment needs to be carefully done with a good balance in order to be successful. Obtain two large flasks. Fit one with a closely-fitting india-rubber stopper, having a hole in it through which a short piece of glass tubing passes. Upon the 
india-rubber a clip is fastened (Fig. 49). Hang the flasks over the two pans of the balance, the fitted one having the stopper and tubing with it, and counterpoise them (Fig. 50).

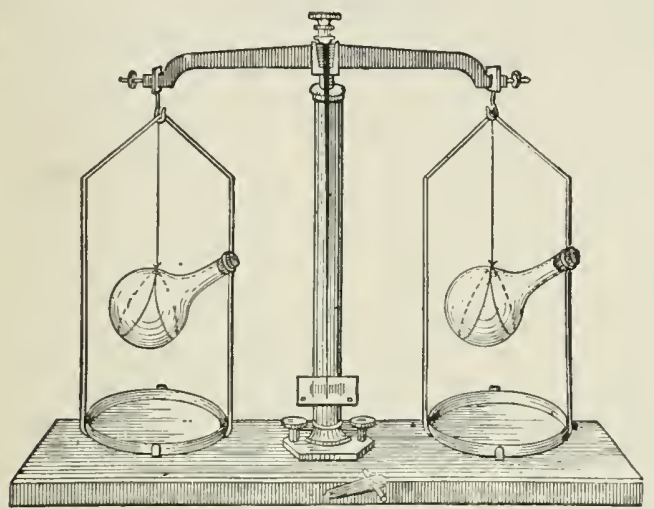

Fig. 50.-Counterpoised flasks. When air is sucked out of one flask, this flask becomes lighter than the other.

Now insert a short glass mouthpiece in the india-rubber, open the clip, and suck air out of the stoppered flask, without touching the flask. Fasten the clip while you are sucking out the air. Take out the mouthpiece, and you will find that the flasks no longer counterpoise, the one from which air has been withdrawn being lighter than before. Admit air by opening the clip, and it will be found that the flasks again counterpoise one another.

\section{REASONS AND RESULTS.}

There is Air all round us.-Though we can neither see, smell, hear, nor taste it, there is air all round us wherever we go. We can feel it when it is blown against us in a wind, and see the results of its motion when it moves trees or loose objects on the ground. It drives windmills and blows sailing ships across the seas; at times its force is so great that it blows down great 
houses and produces mighty billows upon the ocean. When these things happen we become quite sure that there is air. And even on the calmest day the air can be felt by swinging an open hand to and fro, or by using a fan.

Empty Vessels contain Air.-When a boy has used all the ginger beer or lemonade out of a bottle, he says the bottle is empty. This, however, is not exactly true. What is usually called an empty bottle is really a bottle of air. If the bottle is dipped under water with the mouth downwards and then tilted, the air will be seen bubbling out of it to make room for the water which runs in. Or, if water is allowed to run into it through a funnel passing through the cork, the air can be felt as it escapes through a hole in the cork. There can be no doubt, then, that the bottle contains air even when it looks empty, and the same is true for other so-called empty vessels.

Air has Mass.-As air really exists and can be felt it must have mass, though the mass of a small quantity, such as a bottle of air, is very slight. We sometimes say that things are as light as air, but there are gases which are lighter still. The gas we burn in our houses, for instance, is lighter than the same volume of air. Compared with water, however, air is very light. A cubic foot of water has a mass equal to 1000 ounces, but a cubic foot of air, at the ordinary temperature and pressure, only has a mass of a little more than an ounce. Water is, in fact, about eight hundred times heavier than an equal bulk of air.

To find the mass of the air in a pint bottle, the bottle must first be weighed full of air and then with the air sucked out by means of an air-pump. The difference between the two weighings shows the mass of a pint of air.

\section{To Be ReMEMBERED.}

Air surrounds us; it can be felt when winds are blowing or by waving a hand through it.

The bubbles which rise when an empty bottle is placed in water consist of air escaping from the bottle.

The mass of air can be found by weighing a tightly stoppered bottle first full of air and then with the air sucked out. 


\section{EXERCISE XIX.}

1. What reasons have we for saying there is air all around us?

2. Name some of the results caused by the morements of the air round us.

3. How would you show that a so-called empty bottle really contains air? Give a drawing.

4. In what way can air be shown to have mass?

\section{LESSON XX.}

\section{THE PRESSURE OF THE AIR.}

\section{PRACTICAL WORK.}

Things required.-Narrow glass tube or pipette. Leathern sucker. Flask fitted with tube as in Fig. 5I (the stoppered flask used in the experiment to determine the mass of air will do). Penny squirt or glass syringe. Cylinder or tumbler with ground glass edge. Piece of card large enough to cover mouth of cylinder or tumbler. Bellows.

\section{What to do.}

Dip a long tube-a pipette will do-into water. Place your finger over the top and lift the tube out of the water. Notice that the water does not run out of the tube although the bottom is open (Fig. 32).

Moisten a leathern sucker, press it upon a flat stone, and notice that it can only be pulled off with difficulty, owing to the atmosphere pressing upon its upper surface.

Fit a one-holed stopper into a flask of water. Push a piece of glass tubing through the stopper. Try tr suck up the water (Fig. $5 \mathrm{I}$ ). You cannot, unless you loosen the stopper so as to let the pressure of the air force the water up the tube.

Dip the open end of a glass syringe or squirt into a 
tumbler of water (Fig. 52); pull up the piston, observe that the water follows it, owing to the pressure of the atmosphere

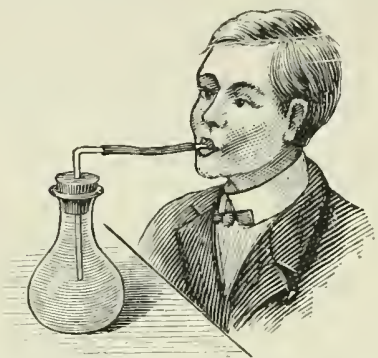

FIG. 5I, - The water in the flask cannot bc sucked out while the cork is tight. upon the surface of the water in the tumbler.

Take a tumbler or cylinder with ground edges and completely fill it with water. Place a piece of card-or stout writing paper across the top and invert the vessel. If the air has been carefully kept from entering the tumbler, the water does not run out (Fig. 53). Think what keeps the paper in its place.

Procure a pair of bellows. Notice that the valve at the bottom only opens inwards. Open the bellows, and observe that the valve is pushed up a little as the air enters (Fig. 56). Close the bellows; the valve is pushed down; and, as the air cannot escape any other way, it is forced through the nozzle (Fig. 57).

Tie a piece of thin india-rubber, such as is used in toy air-balls, over the mouth of a funnel. Suck air from the funnel, and notice that the india-rubber is forced inwards by the pressure of the outside air. Place your finger over the open end of the funnel while the indiarubber is in this condition, and turn the funnel in different directions. Notice that the india-rubber undergoes no change in shape, thus showing that the air pressure outside is the same in different directions (Fig. 54). 


\section{REASONS AND RESULTS.}

Air exerts Pressure.-Everything which has weight can exert pressure. The pressure depends first of all upon what we have

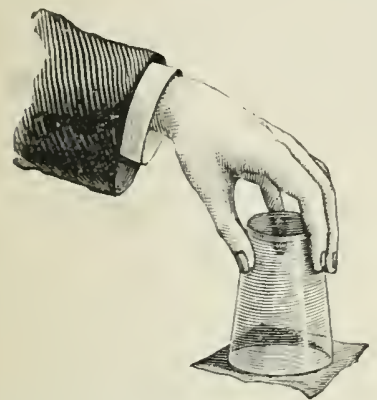

FIG. 53.- The paper does not fall off though the glass is full of water.

learned to call the density of a thing. For instance, if you carry a piece of iron upon your shoulder you are pressed down more than by a piece of wood of the same size. But the pressure also depends, of course, upon the amount of material you are bearing. Thus, a sack of wool borne upon your head would exert more pressure than an iron nail. You will be able to understand, then, that though

the air is so light compared with other substances, a large quantity of it would be very heavy and would exert a very great pressure.

Now, the air above us extends upwards from the surface of the earth for many miles; and in consequence of this it presses very heavily upon everything. You will see in the next chapter how this pressure is measured, but there are many simple ways which show that it is real.

The reason why a leathern sucker is difficult to pull off an object upon which it has been placed is that the air is pressing upon the outside of the sucker but not upon the inside (Fig. 55).

When a liquid is drunk through a

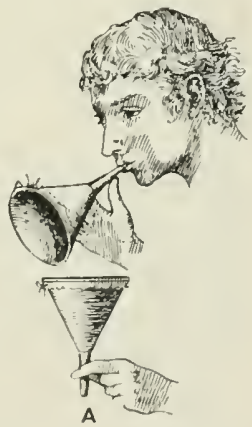

Firs. 54.- The funnel at $A$ has a sheet of india-rubber tied over the top. When air is sucked out of the funnel the india-rubber curves inwards as at $B$, owing to the pressure of the air outside. tube, the vessel containing the liquid must be open to the air or else it cannot be obtained. You may see that this is so by examining a baby's feeding bottle. If the stopper of 
the bottle is screwed in tightly, and there is no open hole in it, the baby cannot get his food, however hard he sucks.

Air presses in all Directions. - The pressure of air is not only downwards, but upwards and sideways; in fact, in all directions.

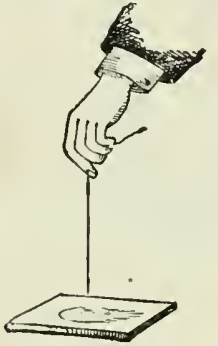

FIG. 55-The sucker cannot be pulled off easily because the air is pressing on the top of it, but not on the lower side.

If the pressure were only exerted downwards, then a sucker could be pulled off an object on which it is fixed by turning the object upside down or sideways. But you know that you cannot pull the sucker off any easier whatever way you turn it.

The upward pressure of the air is shown by means of bellows. As the top board is lifted up, the air forces up the valve at the bottom and enters the bellows (Fig. 56). If there were no upward pressure, this of course could not happen.

Why we do not feel the Weight of the Air above us. - Though our bodies are pressed upon by the whole weight of the air above us, we do not feel it. Why is this? The lungs, which fill up a large part of our chest space, are filled out with air, and this air is in free communication with the atmosphere through our throat and mouth. The result is that the air in the lungs presses them outwards from the inside just as much as the atmosphere presses

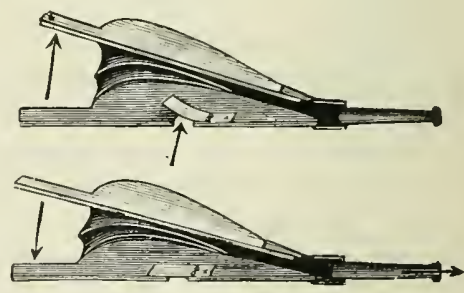

Figs. 56 and 57 .

When the bellows are being opened the valve rises and lets in air.

When the bellows are tieing closed the valve is pushed down, and air is forced out of the nozzle or spout.

them inwards from the outside, and so we feel no inconvenience. It is just as if two equally strong boys are pulling as hard as they can from opposite sides of a door. Though they are both exerting all their strength, the door does not move. 
TO BE ReMEMBERED.

The pressure of air is due to its weight, and is shown by the use of a sucker as well as in other ways.

When air is removed by suction from the inside of a tube dipping into a liquid, the pressure of the air outside forces the liquid up the tube.

The reason why the pressure of air is not felt is that it is equal in all directions around us as well as inside our bodies.

\section{EXERCISE XX.}

I. What is meant by saying that air exerts pressure?

2. Why cannot a baby get his food from a feeding bottle, if the stopper contains no hole and is tightly screwed down?

3. Why is it so difficult to pull off a leathern sucker from a damp stone?

4. Explain the action of a pair of bellows.

5. How does a squirt act?

6. Would a squirt act if there were no air around it? Give reasons for your answer.

\section{LESSON XXI.}

BAROMETERS.

PRACTICAL WORK.

Things required. $-\mathrm{A}$ barometer tube about 36 inches long. Piece of glass tubing about 6 inches long, and the same width as the barometer tube. Thick india-rubber tubing to connect barometer tube and short tube. Board having two lines; 28 inches apart, drawn upon it, and a strip of paper divided into tenths of inches, gummed to the top, as shown in Fig. 58. Mercury. Cup to hold mercury.

\section{What to do.}

Tie a short piece of thick india-rubber tubing upon the open end of a barometer tube. Tie the free end of the tubing to a glass tube about six inches long, open at both ends. Rest the barometer tube with its closed end downwards, and pour mercury into it (being careful to remove all air bubbles) until the liquid reaches the short tube. Then fix the arrangement upright as in Fig. 58. 
The air pressing upon the surface of the mercury in the short open arm of the $U$-tube balances a long column of mercury in the closed arm.

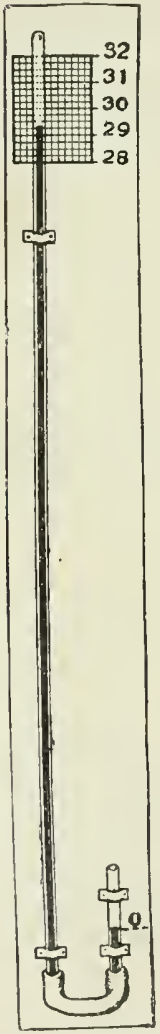

Fici. 58. -The pressure of the air on the mercury in the small tube is able to keep up the column of mercury in the long tube.

\section{REASONS AND RESULTS.}

How the Pressure of the Air is measured.It is very important that we should find a way of measuring how much the air presses upon things on the earth's surface. The instrument shown in Fig. 58 enables us to do this. The top of the long tube is sealed so that the air cannot press upon the mercury in it, but the small tube is open and the air can therefore press upon the mercury in it.

Balancing Columns of Air and Mercury.The instrument just mentioned is evidently very much like the $\mathrm{U}$-tube used in Lesson XIV. Now look at Fig. 58, it is clear that there is a column of mercury supported by some means which is not at first plain. If this were not so, the mercury would sink to the same level in the long and the short tubes, for liquids always find their own level. If a hole were made in the closed end of the tube this would immediately happen. There should be no difficulty, from what has been already said, in understanding that the column of mercury is kept in its position by the downward force of the weight of the atmosphere pressing upon the surface of the mercury in the short open tube. The weight of the column of mercury, and the weight of a column of the atmosphere of the same size through, or of the same area, is exactly the same. Both the column of mercury and the column of air must be reckoned from the level of the mercury in the short stem of the barometer shown in Fig. 58-the mercury column to the top in the long 
tube ; the air to its upper limit, which is at a great distance from the surface of the earth.

Air Pressure shown by a Barometer. - The height must, in every case, be measured above the level of the mercury in the tube or cistern open to the atmosphere; just as, in the case of the $\mathrm{U}$-tube in Lesson $\mathrm{XIV}$., the heights of the liquid columns had to be measured from a fixed line. In the arrangenent shown in the accompanying illustration (Fig. 58), a line is drawn at a fixed point $O$, and the short tube is shifted up or down until the top of the mercury in it is on a level with the line.

For an instrument of this kind to be accurate, great care has to be taken that no air enters the space at the top of the long tube. If air does enter, it will press upon the surface of the mercury in the long tube, and the height of the mercury will be less than thirty inches. In such a case, instead of measuring the whole pressure of the atmosphere, what we should really be measuring would be the difference between the pressure of the whole atmosphere and that of the air enclosed in the longer tube. In a properly constructed barometer, therefore, there is nothing above the mercury in the longer tube except a little mercury vapour.

An arrangement like that described constitutes a barometer. A barometer is an instrument for measuring the pressure exerted by the atmosphere.

A Common Form of Barometer.-You have probably seen a barometer, or weather-glass as it is called, of the kind shown in Fig. 59. In the inside of an instrument of this form there is a bent tube of exactly the same kind as has been described in this lesson. The only addition is a little weight which rests upon the mercury in the small tube, and therefore moves up and down as the mercury rises and falls. A cord attached to this float passes over a pulley connected with a hand which can turn like the hand of a clock. When, therefore, the mercury moves in the tube, the float moves up or down and the hand moves round. Marked upon the dial of the instrument are numbers corresponding to the number of inches in length of the long mercury column, measured from the level of the mercury in the small open tube. The length of the mercury column, or height of the barometer as it is termed, can thus be seen by noticing the 
number on the dial to which the hand points. The way in which the instrument works can easily be understood by an examination of Fig. 59 .
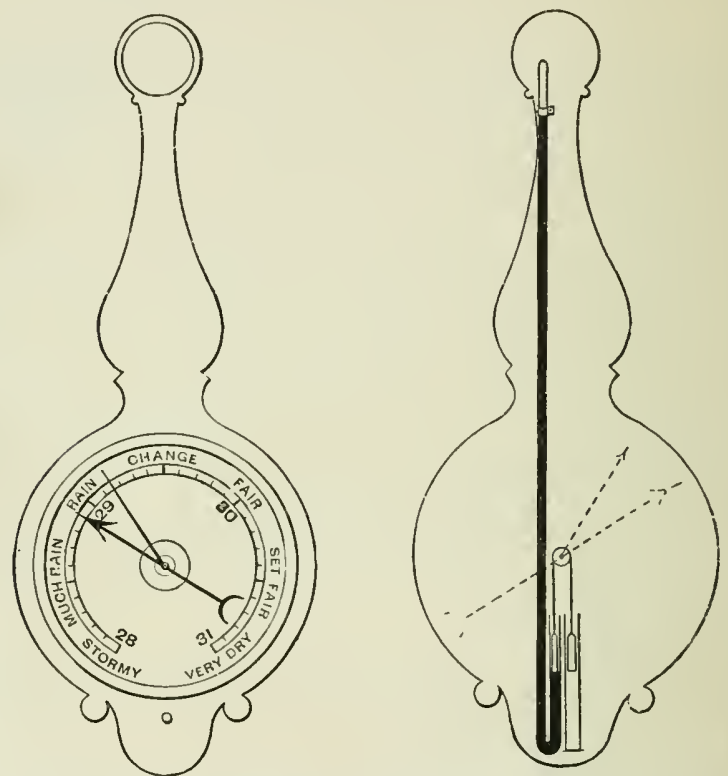

FIG. 59.-Front and back of a barometer or weather-glass used to show changes in the pressure of the air, and therefore changes of weather.

The short hand shown is useful for indicating how much the height of the barometer has changed It can be turned to point to any part of the dial. Suppose it is turned to point to the same number as the large hand on any day; then on looking again next day you could see how much the large hand of the barometer had moved from the place in which it was the day before.

\section{To Be ReMembered}

A barometer is an instrument for measuring the pressure of the air. The principle of a barometer is that a column of mercury in a tube containing no air is balanced by the pressure of the atmosphere outside the tube. 
The height of the mercury in a barometer is, on the average, 30 inches at sea-level. The height changes slightly from day to day on account of alterations in the pressure of the atmosphere.

\section{EXERC1SE XXI.}

I. How is the pressure of the air measured?

2. Describe fully and carefully how a harometer is made.

3. Make a drawing of a barometer and name its parts.

4. If a hole were made in the top of a barometer what would happen?

5. What is a barometer, and what is it used to measure?

\section{LESSON XXII.}

IVHY THE HEIGHT OF THE BAROMETER ALTERS. PRACTICAL WORK.

Things required. - The barometers made in the last lesson. Another barometer tube, some mercury, and a small basin.

What to do.

Slip a pjece of india-rubber tubing upon the open end of the barometer, and notice what happens when you blow vigorously down it. Suck air out of the tube, and observe the result.

Fill a barometer tube with mercury; place your thumb over the open end; invert the tube; place the open end in a cup of mercury, and take away your thumb.

The mercury in the tube will be seen to fall, so as to leave a space of a few inches between it and the closed end. Measure the distance between the top of the mercury column and the level of the mercury in the cup. It will be found to be about thirty inches. If a tube less than thirty inches ( 76 centimetres) long is used, there is no space at the top. Tilt the barometer tube, and notice that by and by the mercury fills the tube. 


\section{REASONS AND RESULTS.}

When the Height of the Mercury in a Barometer alters If, for any cause, the pressure upon the surface of the mercury in the open tube increases, the mercury in the long tube will evidently rise. If, however, the pressure becomes less, the

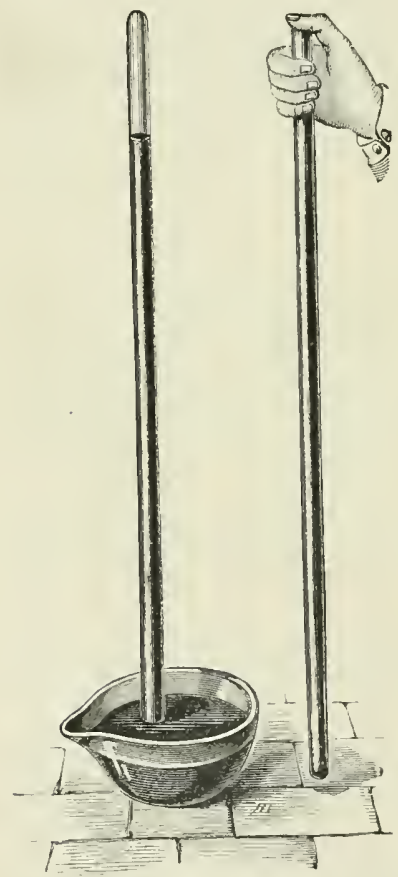

FIG. 60.-The tube is first filled with mercury, and then placed with the open end in a cup of mercury. A colunin of mercury about 30 inches iong remains in the tube. mercury column will get shorter. The effect of an increase of pressure can be shown by blowing into the small tube, and the effect of a decrease of pressure by sucking the air out of the small tube.

When you blow down the short tube of the barometer, you are helping the atmos. phere to press upon the mercury ; and the atmosphere and your breath both together press more, and the mercury is pushed higher. When you suck, you are acting against the atmosphere, and therefore reducing the pressure upon the mercury; so that, both together, there is not so much pressing done as when the atmosphere acts alone; this is why the mercury does not stand so high in the long tube.

\section{Another Form of Mercury} Barometer-Instead of using a barometer of the $U$-tube form, a straight tube sealed at one end may be filled with mercury, and inverted in a small cup of mercury, as shown in Fig. 60.

A column of mercury will then be supported in the tube by the pressure of the atmosphere. The distance between 
WHY TIE IIEIGHT OF THE BAROMETER ALTERS. S5

the top of the column and the surface of the mercury in the cup will be about 30 inches, or $76 \mathrm{~cm}$, when the tube is vertical, or in the position $A$ in Fig. 6r. If the tube is inclined to the position $B$, so that the closed end of it is less than this height above the mercury in the cup, the mercury fills the tube completely, showing that the space $C$ above the mercury, when the tube was in the position $A$, did not contain air. It will be clear from this that if the tube were less than 30 inches long, it would be entirely filled by the mercury. On an average, the atmosphere at the sea-level will balance a

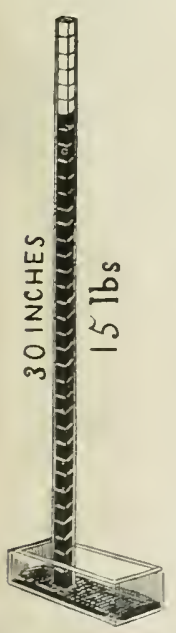

F1G. 62. - The mass of a cubic inch of mercury is $\frac{1}{2} l b$; therefore, that of 30 cubic inches is $t_{5} \mathrm{lbs}$.

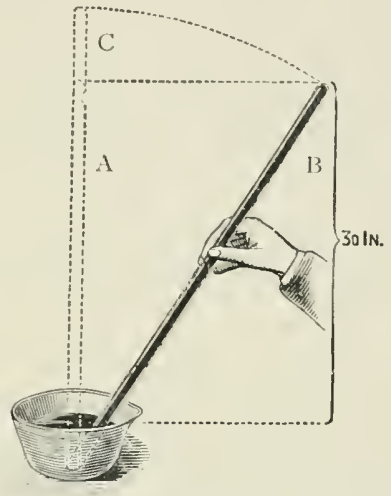

Fig. 6r,-The tilted glass tuhe is full of mercury, but if it is placed upright in the position $A$ the mercury will not fill it, and there will be nothing visible in the part $C$. 30 inches in length. column ot mercury No matter if the closed tube is 30 feet long, the top of the mercury column will only be about 30 inches above the level of the mercury in the cistern.

Weight of a Column of the Atmosphere.If the tube had an area of exactly one square inch, there would be 30 cubic inches of mercury in a column 30 inches long; and since the mass of a cubic inch of mercury is about half a pound, the whole column would have a mass of 15 lbs. This column would balance a column of air of the same area, so that we find that the weight of a column of air upon an area of one square inch, and extending upwards to the top of our atmosphere, is equal to the weight of 15 lbs. when the barometer stands at 30 inches.

Mercury is a Convenient Liquid for Barometers.-Mercury 
is used for barometers for convenience. Since the column of mercury which the atmosphere is able to support is 30 inches high, it is clear that if a lighter liquid is used, a longer column of it would be supported. For example, water is $13 \frac{3}{3}\left(13^{\circ} 6\right)$ times as light as mercury, therefore the column of water which could be supported would be $30 \times 13 \frac{3}{5}=408$ inches $=34$ feet, which would not be a convenient length for a barometer. The length of the column of glycerine which can be similarly supported is 27 feet. But in the case of lighter liquids like these, any small variation in the weight of the atmosphere is accompanied by a much greater alteration in the level of the column of liquid, and, in consequence, it is possible to measure such variations with much greater accuracy. For this reason barometers are sometimes made of glycerine.

Pressure of the Atmosphere at Different Altitudes.-Because the atmosphere has weight, the longer the column of it there is above the barometer, the greater will be the weight of that column, and the more it will press upon the mercury in the barometer. Hence, as we ascend through the atmosphere with a barometer, we reduce the amount of air above it pressing down upon it, and, in consequence, the column of mercury the air is able to support will be less and less as we ascend. On the contrary, if we can descend from any position, e.g. down the shaft of a mine, the mercury column will be pushed higher and higher as we gradually increase the length of the column of air above it. Since the height of the column of mercury varies thus with the position of the barometer, it is clear that the alteration in its readings supplies a ready means of telling the height of the place of observation above the sea-level, provided we know the rate at which the height of the barometer varies with an alteration in the altitude of the place.

At a height of $3 \frac{1}{2}$ miles from the sea-level, the mercury column only stands 15 inches high instead of thirty inches, thus showing that by rising to that height half the atmosphere is left behind. This does not mean that the atmosphere is only 7 miles high, for really there is air, though very thin or rarefied, at a height of Ioo or I 50 miles above the earth's surface. But the air below a height of $3 \frac{1}{2}$ miles is so much denser than that above this height, on account of its being compressed by the air above it, 
that it produces the same effect as the much greater thickness of lighter air.

To be ReMeMrered.

The pressure of the atmosphere at sea-level is equal to a weight of I 5 lbs. on every square inch. The higher we rise above sea-level the less is the pressure. At a height of $3 \frac{1}{2}$ miles, the mercury column in a barometer stands at 15 inches instead of 30 inches. The pressure is, therefore, equal to the weight of $7 \frac{1}{2}$ lbs. per square inch instead of the weight of 15 lbs. per square inch.

Mercury is used for barometers because it is a very dense liquid, does not leave a mark upon the tube, and can easily be seen.

\section{EXERCISE XXII.}

r. Why does the height of the mercury in a barometer change

(a) From day to day;

(b) When the instrument is taken up a mountain or down a mine?

2. What would happen if you were to blow down the small open tube of a barometer like that described in the last lesson?

3. What is generally about the length of the column of mercury in a barometer? If the area of the bore of the barometer tube were one square inch, what would be the weight of the column of the mercury supported by the air?

4. Would a barometer made with water as the liquid have to be longer or shorter than a mercury barometer? Give reasons for your answer.

5. If you took a barcmeter up a mountain, what effect would the change of level have upon the length of the mercury column? Why should there be any effect? 


\section{LESSON XXIII}

\section{EFFECTS OF HEAT.}

\section{PRACTICAL WORK.}

Things required.-An iron or brass rod about 6 inches long,

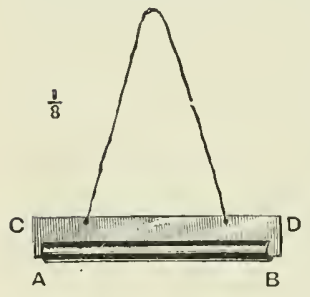

Fic. 63 - The $\operatorname{rod} A B$ will fit into the gauge $C D$ when it is cold, but it is too large when hot.

\section{What to do.} fitting into a "gauge" cut out of brass, as shown in Fig. 63. Spirit lamp or laboratory burner. Flat bar of iron about I foot long. Two wooden blocks. Heavy mass. A straw about 9 inches long, fixed at right angles to a sewing needle by means of sealing wax. $4 \mathrm{oz}$. flask fitted with stopper and glass tube. Jug of hot water. Air ball or paper bag. Ice. Porcelain dish or beaker. Tripod stand. Iron spoon. Wax (a piece of a wax candle will do) or butter.

Show that the metal rod just fits the gauge. Then heat the rod by a spirit lamp or laboratory burner. Show that it will not now go into the gauge.

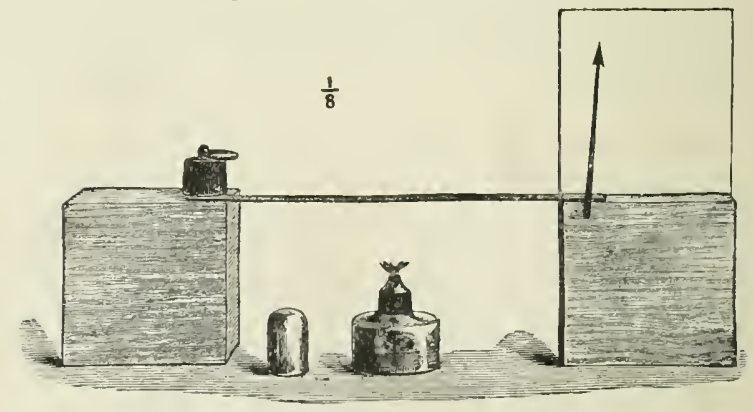

Fic. 64. - 1 flat bar of metal having one end kept from moving by a heavy mass is heated, and the other end moves the pointer, hecause the bar gets longer. 
Place the heavy mass on one end of the iron bar resting upon one of the blocks, as in Fig. 64. Let the other end bear upon the needle placed upon the other block and having the straw pointer fixed to it. Heat the bar with a flame, and notice that the pointer moves on account of the expansion of the iron.

Procure a $4 \mathrm{oz}$. flask and fit it with a cork. Bore a hole through the cork and pass through it a long glass tube which fits tightly. Fill the glass with water coloured with red ink. Push the cork into the neck of the flask and so cause the coloured water to rise up in the tube (Fig. 65). See that there is no air between the cork and the water. Now dip the flask in warm water, and notice that the liquid gets larger and rises up the tube. Take the flask out of the warm water, and see that the coloured water gets smaller as it cools and that it sinks in the tube.

Select an air ball or a well-made paper bag and tightly tie a piece of

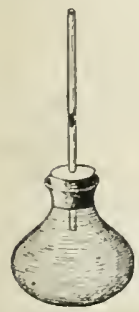

FIG. 66.-When the flask is warmed, the air in it gets larger and pushes up the drop of liquid in the tube. tape round the open end. Hold the ball

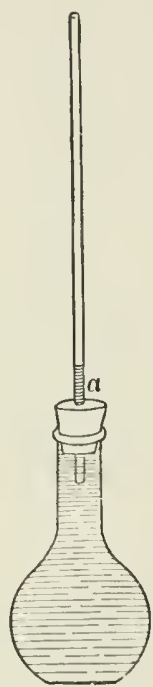

FiG. 65.- An arrangement for showing that liquids get larger when heated. or bag in front of the fire, and notice that the air inside gets larger and inflates the bag. Or, obtain the flask with a cork and tube, as in Fig. 66. Remove the cork and tube, and, by suction, draw a little red ink into the end of the tube near the cork. Re-insert the cork and gently warm the flask by clasping it in your hands. Notice that the air in the flask gets larger and pushes the red ink along the tube.

Melt wax or butter in an iron spoon.

Procure a lump of ice, and notice that it has a particular 
shape of its own, which, as long as the day is sufficiently cold, remains fixed.

With a sharp brad-awl, or the point of a knife, break the ice into pieces, and put a convenient quantity of them into a beaker. Place the beaker in a warm room, or apply heat from a laboratory burner or spirit lamp. The ice disappears, and its place is taken by what we call water. Notice the characters of the water. It has no definite shape, for by tilting the beaker the water can be made to flow about.

Replace the beaker over the burner and go on warming it. Soon the water boils, and is converted into vapour, which spreads itself throughout the air in the room and seems to disappear. The vapour can only be made visible by blowing cold air at it, when it becomes white and visible, but is really no longer vapour, but has condensed into smal! drops of water, or, as it is sometimes called, "water-dust"

\section{REASONS AND RESULTS.}

Effects of Heat.-If we make a thing hotter and hotter, we are able to notice several changes in it. These changes are of three kinds, which we may call :

(1) Change of size ;

(2) Change of state ;

(3) Change of temperature.

Change of Size.-As a rule, all bodies, whether solid, liquid, or gaseous, get larger when heated and smaller when cooled.

The change of size which a body undergoes is spoken of as the amount it expands or contracts ; or heat is said to cause expansion in the body. This expansion is regarded in three ways. When we are dealing with solids, we find we obtain expansion in length or linear expansion, expansion in area or superficial expansion, and expansion in volume or cubical expansion. In the case of liquids and gases, we have only cubical expansion. The same terms can be used with reference to contraction.

The expansion which substances undergo when heated has often to be taken into account. Railway lines, for instance, are 
not placed close together, but a little space is allowed between the ends of each length of the rails, so that the rails can expand in summer without meeting. Steam pipes used for heating rooms are also not firmly fixed to the walls at both ends, but left slightly loose or are loosely jointed, so that they can expand or contract without doing any damage. For the same reason the ends of iron bridges are not fixed to the supports upon which they rest. Iron tyres are put on carriage wheels by first heating the tyre and, while it is hot, slipping it over the wheel. As it cools it contracts and clasps the wheel very tightly.

Change of State.-It has been explained in Lesson 11I. that substances exist in three states, namely, solid, liquid, and gaseous. By the action of heat a substance may be changed from one state to another. WVax, for instance, is usually a solid, but by heating it it becomes a liquid. Butter can in the same way easily have its state altered from solid to liquid. Lead and zinc are also melted when heated, but they require a hotter flame than wax or butter.

A good example of the changes of state produced by heat is obtained by heating a piece of ice until it becomes water, and? then heating the water until it passes off into steam or water vapour. Here the same form of matter is by heat made to assume three states; in other words, ice, water, and steam are the same form of matter in the solid, liquid, and gaseous state respectively.

Change of state includes changes in the physical condition known as liquefaction or beconing liquid, and vaporisation or becoming converted into vapour. Thus, if we heat ice it first liquefies or becomes water, and is then vaporised or becomes steam.

Change of Temperature-Change of temperature is only another way of saying that the body gets hotter and hotter.

If the body is made colder and colder the same changes occur, but in the reverse order. We must learn more about each of these changes.

Measurement of Change of Temperature.-The change of size which takes place when a thing is heated gives us a good way of measuring the change of temperature which it undergoes. Think of the experiment with the coloured water in the flask 
with a long tube attached to it. Supposing we notice that the coloured water in the tube rises through a certain number of inches after the water has been heated somewhat; and that we then place the flask into some other liquid or some more water, and find the water rises up the tube to just the same place, we shall have every right to say that the second liquid is exactly as hot as the first was. This is measuring its temperature. The flask and tube with the water have become a “' temperature measurer,' or, as we always say, a thermometer.

\section{TO Be Rememberen.}

Effects of Heat.-(I) Change of size, shown by expansion and contraction of solids, liquids, and gases when heated or cooled.

(2) Change of state, as when ice is converted into water, and water into vapour or gas by heat.

(3) Change of temperature, which means the condition of bodies as regards heat, a hot body being at a higher temperature than a cold one.

Expansion means increase of size.

Contraction means decrease of size.

Vaporisation means the change of a liquid into a state of vapour.

Liquefaction means the change of a solid into the liquid state.

\section{Exercise XXIII.}

1. Write down the effects which can be noticed when a thing is made hotter and hotter.

2. Describe experiments which prove that things alter in size when heated.

3. What changes do you observe when a piece of ice is placed in a glass vessel and heated over a flame?

4. How would you show that a bar of iron gets longer when it is heated?

5. How would you show that liquids expand when heated?

6. Describe an experiment which proves that air expands when heated. 


\section{LESSON XXIV.}

\section{THERMOMETERS,}

PRACTICAL WORK.

Things required.-Three basins, containing hot, luke-warm, and cold water. Flask fitted with stopper and tube (Fig. 68),

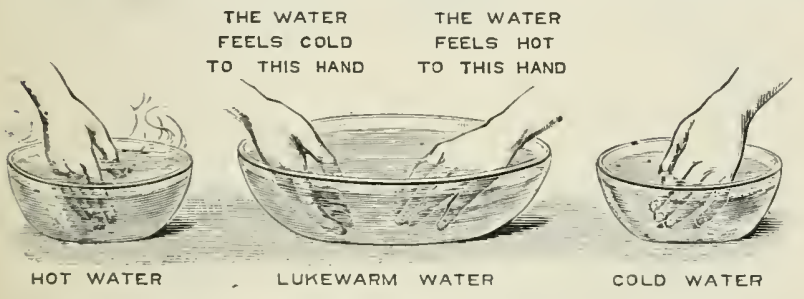

Fig. 67.-The sense of feeling cannot be depended upon to tell the temperature of anything.

Empty thermometer tube, with bulb. Small cup of mercury. Spirit lamp or laboratory burner. Beaker. Flask.

What to do.

Arrange three basins in a row (Fig. 67); into the first put water as hot as the hand can bear, into the second put luke-warm water, and fill the third with cold water. Place the right hand into the cold water and the left into the hot, and after half a minute put both quickly into the luke-warm water. The left hand feels cold and the right hand warm while in the same water.

Place the flask of water, with fitted tube, used in the last lesson, in hot water (Fig. 68), and notice the height of the liquid in the tube. Transfer it to

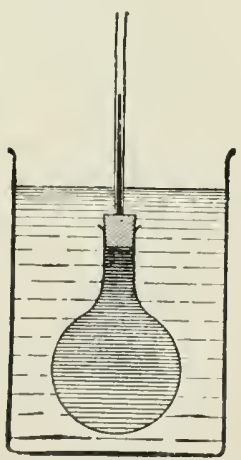

FIG. 68. - When the flask is put into warm water the liquid in it rises in the tube. cold water, and observe that the liquid in the tube sinks. 
Procure an empty thermometer tube, with a bulb at one end. (If a blow-pipe is available, a bulb can easily be blown

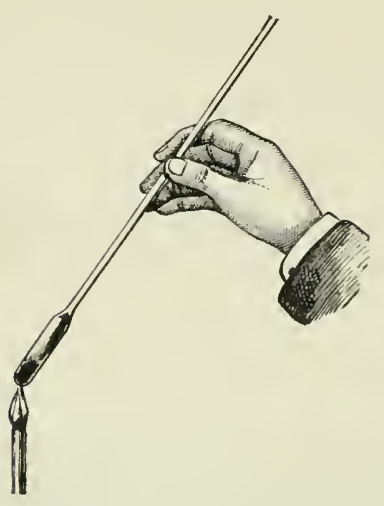

FIG. 69.-After beating the bulb as shown, the open end of the tube is placed in mercury, which rusnes in and fills the bulb and tube.

Repeat the operation until the mercury fills the bulb and part of the stem.

Place in hot water the bulb of the instrument just constructed, and make a mark at the level of the mercury in the tube. Now place the instrument in cold water, and notice that the mercury sinks in the tube. The mercury is thus seen to expand when heated and contract when cooled, and if the glass were marked the degree of hotness or coldness could be shown by the position of the top of the mercury.

Examine the thermometer supplied. Notice that it is similar to the simple instrument already described, but the top is sealed up, and divisions or graduations are marked upon it, so that the height of the mercury in the tube can be easily seen. 


\section{REASONS AND RESULTS.}

Feeling of Heat and Cold.-Some people feel cold at the same time that others feel warm. For instance, when a native of India, or any other hot part of the earth, comes to England he feels cold in ordinary weather, while an Eskimo who is here at the same time finds the weather warm. You can imagine an Indian and an Eskimo meeting an Englishman. The former says, "It is cold to-day," and the latter says, "It is hot to-day," while the Englishman thinks the weather is neither cold nor hot, but moderate. You can therefore easily understand that the sense of feeling cannot be depended upon to tell us accurately whether the air or any substance is hot or cold. Some instrument is needed which does not depend upon feeling and cannot be deceived in the way that our senses can. Such an instrument is called a thermometer.

How Expansion may indicate Temperature.-You have already learned that substances usually expand when heated and contract when cooled.- A flask filled with water, for instance, and having a stopper through which a glass tube passes, can be used to show the expansion produced by heat and the contraction by cold. But this flask and tube make but a very rough temperature measurer. The water does not get larger to the same amount for every equal adition of heat. Neither is it very sensitive, that to say, it does not show very small increases in the degree of hotness or coldness, or, as we must now learn to say, it does not record very small differences of temperature, and for a thermometer to be any good it must do this. Then, too, as everyone knows, if we make water very cold it becomes ice, which, being larger than the water from which it is made, would crack the tube. For many reasons, therefore, water is not a good thing to use in a thermometer.

\section{Choice of Things to be used in a Thermometer.}

I. We want a thing which exjaids a great deal for a small increase of temperature.

Gases expand most, and solids least, for a given increase of temperature. Liquids occupy a middle place. The most delicate thermometers are therefore those where a gas, such as air, is the thing that expands. But in common thermometers a liquid, 
either quicksilver or spirits of wine, is used. Both these things expand a fair amount for a given increase of temperature, and to make this amount of expansion as great as possible they are used in fine threads by making them expand in a tube with a very fine bore.

2. We want a liquid which does not change into a solid unless cooled very much, nor into a gas unless hated very much.

We cannot be sure of both these things in the same thermometer. When we want to use our thermometer for measuring great degrees of cold we use one containing spirits of wine, because this liquid has to be cooled a very great deal before it is solidified, that is made into a solid. But we cannot use this thermometer for any great degree of temperature, because it changes into a vapour when heated to only a comparatively small extent. If we wish to measure higher temperatures we use a quicksilver or mercury thermometer, because mercury can be warmed a good deal, or, as it is better to say, raised to a high temperature, without being changed into a gas.

3. IVe must have our liquid in a fine tube of equal bore with a comparatively large bulb at the end.

We all know that liquids have to be contained in some sort of vessel or else we cannot keep them together. We know, too, that we must have a fine bore, so that the iiquid may appear to expand very much for a small change of temperature. The bore must be equal all the way along, that is the width or diameter of the inside of the tube must be the same all the way along, so that a given amount of expansion in any part of the tube shall mean the same change of temperature, and, lastly, there must be a large bulb, so that there is a large surface to take the same temperature as that of the body the temperature of which we wish to measure.

The Marks on a Thermometer..-We will suppose an instrument has been made according to the rules just described. Before it is of any use it must have divisions marked upon it, or be graduated. Sometimes these divisions are marked upon the glass of the thermometer, and sometimes upon the wood or other material to which the glass is fixed.

By graduating a thermometer we mean obtaining marks upon it to which we can give numbers, so that we can refer to the hot- 
ness or coldness, that is, the temperature of any substance, by means of these numbers or degrees on our thermometer. If when a thermometer is plunged into water it makes the mercury thread rise up to the number 30 on the thermometer, we say the water had a temperature of thirty degrees, which we should write thus, $30^{\circ}$. We shall learn in the next lesson how these marks are obtained in different kinds of thermometers.

TO BE REMEMBERED.

The sense of feeling does not tell us accurately how hot or cold a substance is.

A thermometer is an instrument for measuring the degree of temperature of a substance.

The liquid in a thermometer should ( 1 ) expand a great deal for a small increase of temperature, (2) not easily change into a solid or gaseous

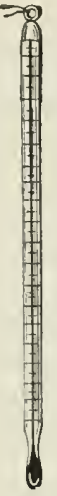

FiG. 7 I.-A thermometer with tempera. ture divisions marked upon the stem. state, ( $\hat{j}$ ) be in a tube of equal bore having a comparatively large bulb at one end.

\section{EXERCISE XXIV.}

I. What is a thermometer, and what is it used to measure?

2. If you were going to make a thermometer, which liquid should you use, and why?

3. What kind of tube would you select in making a thermometer, and why?

4. Iow would you get mercury into a narrow glass tube having a bulb at one end?

5. Describe a simple instrunent used to measure temperature.

6. What is the use of a thermometer?

7. Why is it not accurate to judge temperature by the sense of feeling? 


\section{LESSON XXV.}

\section{GRADUATION OF THERMOMETERS. FIXED POIN'TS.}

\section{PRACTICAL WORK.}

Things required.--Beaker. Flask. Test-tube fitted with stopper and exit tube, as in Fig. 72. Ice. Salt. Unmounted thermometers, with Centigrade and Fahrenheit graduations.

What to do.

Take some pieces of clean ice in a beaker or test-tube and plunge a thermometer amongst them. Notice the reading of the thermometer; it will be either no degrees $\left(0^{\circ}\right)$ or very near it. ${ }^{1}$ Warm the beaker or test-tube, and observe that as long as there is any ice unmelted the

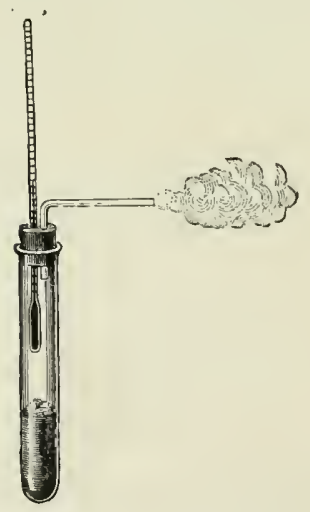

Fis. 72.- The water in the test. tube is boiling. Steam is coming out of the tulie, and the thermo. meter is being heated by it. reading of the thermometer remains the same.

Repeat the experiment with some other pieces of ice, and observe the important fact that the temperature of clean melting ice is the same in all your tests.

Add salt to the melting ice, and notice that the mercury indicates a lower degree of temperature.

Boil some distilled water in a flask, test-tube, or beaker, and plunge a thermometer in the boiling water. Notice the temperature. Raise the themometer until the bulb is just out of the water and only warmed by the steam. Again record the temperature. In both cases

1 A Centigrade thermometer is supposed to be used. If a Fahrenneit thermometer is used the reading will be $32^{\circ}$. 
the reading is the same. It is either one hundred degrees $\left(100^{\circ}\right)$, or very near it, if you use a thermometer with Centigrade divisions.

Repeat the experiment with a second lot of pure water, and note that the temperature of boiling water is again $100^{\circ}$.

Add salt to the water. Hold a thermometer in the steam of the boiling water, and notice that the temperature is the same as before, namely $100^{\circ}$. Push the thermometer into the water, and notice that a higher degree of temperature is indicated.

Again place the thermometer in clean ice in a test-tube or flask. Gently heat the vessel, and notice the following changes :

(I) The mercury remains at $0^{\circ}$ until the ice is all melted.

(2) When the ice is melted, the mercury rises gradually until it reaches $100^{\circ}$.

(3) The mercury remains stationary at $100^{\circ}$ until all the water is boiled away.

Arrange three basins of cold, luke-warm, and hot water side by side. Place the thermometer in the cold water and then in the luke-warm water. Notice the temperature indicated in the luke-warm water. Now place the thermometer in the hot water, and when it has been there a minute or two put it into the luke-warm water. Notice that the temperature indicated is practically the same as before. It is thus seen that, unlike our sense of feeling, a thermometer is not deceived by being made hot or cold before using it to indicate temperature.

Notice the temperature of the room indicated by the thermometer.

Place the thermometer in your mouth, and notice the temperature indicated by it at the moment it is removed.

\section{REASONS AND RESULTS.}

The Fized Points on a Thermometer. - It has been proved by numerous experiments that the mercury, or other liquid, in a thermometer always indicates the same temperature when placed in ice which is just melting. This temperature, then, 
is fixed, and provides us with a fixed point from which the divisions upon a thermometer can commence.

A second fixed temperature, or fixed point, is the temperature of the steam of boiling water. The steam of boiling water always has the same temperature when the water is boiling, and the height of the barometer is 30 inches. It is iniportant to remember that this temperature depends upon the pressure of the atmosphere, though you may not yet understand why this is the case. It is sufficient for the present to know that the temperature of the steam of boiling water is a fixed temperature, and provides the second fixed point upon a thermometer.

How the Numbers on a Thermometer are arranged.-It has now been explained how two fixed marks, or points, are obtained upon a thermometer. The place where the mark near to the bulb must be made is found by putting the thermometer into melting ice. The mark nearer the other end is got by plunging the thermometer into the steam from boiling water. Any numbers could be given to these marks. But so that everyone shall understand the readings of the temperatures of different things, it is best to make the numbering according to an agreed plan.

Centigrade Thermometers.-In scientific work the thermometer used is called the Centigrade thermometer. This name refers to the way in which the fixed points are spoken of and the distance between these marks divided. The plan in thermometers like these is to call the temperature at which ice melts, no degrees Centigrade (written $0^{\circ} \mathrm{C}$.), and the temperature at which water boils, one Inundred degrees Centigrade (written $100^{\circ} \mathrm{C}$.). The space between the fixed points is then divided into one hundred equal parts, and each division called a Centigrade degree.

Fahrenheit Thermometers.-Thermometers in this country are generally divided in a different fashion, and so that we may know exactly what their readings mean, we must learn how the numbers on them are got. The mark obtained by putting the thermometer into melting ice is called thirty-twe degrees Fahrenheit (written $32^{\circ} \mathrm{F}$.), and the mark found by plunging it into the steam from boiling water, two hundred and twelve 
degrees Fahrenheit $\left(212^{\circ} \mathrm{F}\right.$.). The space between these fixed points is divided into one hundred and eighty (1So) parts. The illustration (Fig. 73) shows a thermometer having Fahrenheit divisions on one side and Centigrade divisions on the other, so that the two scales can be compared.

More Remarks on the Boiling Point of Water.-We have up to the present purposely said very little about an important fact which must be taken into account when marking the boiling point of water upon the thermometer. Before water or any other liquid can boil when heated in a vessel exposed to the air, it must give off vapour which presses upwards strongly enough to overcome the pressure of the atmosphere. But as we have learned, the air presses down at one time more than at another, and more in a valley than up a mountain. Consequently, we shall have to heat a liquid more when the atmosphere presses down very much than when it is not so heavy, in order to make it boil. Water boils at the temperature mentioned in our lesson only when the mercury in a barometer is standing 30 inches high. If the barometer shows a higher reading than this, water will boil at a higher temperature than $100^{\circ} \mathrm{C}$., and if the reading is less, the waterwill boil at a temperature less than $100^{\circ} \mathrm{C}$.

TO BE REMEMBERED.

The fixed points on a thermometer are (I) the temperature at which ice melts or water freezes;

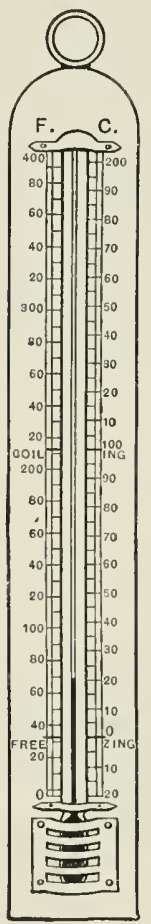

Fig. 73.-The num. bers on the left of the thermometer are Fahrenheit degrees of temperature, and those on the right are Centigrade degrees.

(2) the temperature of the steam issuing from boiling water when the barometer stands at 30 inches.

Two common kinds of thermometers are (1) the Centigrade and (2) the Fahrenheit thermometers, the different graduations being:

Centigrade.

Boiling point, Freezing point, $100^{\circ}$

$0^{\circ}$
Fahrenheit.

$212^{\circ}$

$32^{\circ}$ 


\section{EXERCISE XXV.}

1. IVhat marks do you find on a thermometer, and how are they obtained?

2. What do you mean by a "fixed point" on a thermometer? How many are there?

3. Explain how the numbers on a thermometer are obtained. Write down the temperature at which ice melts, and that at which water boils.

4. Some salt water is boiled. What temperature will a thermometer, placed in the steam given off, register? Will there be any difference in the reading if the thermometer is placed in the liquid?

5. What do you know about the temperature of a mixture of ice and salt?

\section{LESSON XXVI.}

\section{SOLUBLE AND INSOLUBLE SOLIDS.}

PRACTICAI, WORK.

Things required.-Sugar. Salt. Washing-sola. Flasks or tumblers with water in them. Spoon. Sand. Camphor. Shellac. Spirits of wine. Flowers of sulphur. Carbon bisulphide.

\section{What to do.}

Place a piece of sugar in water ; note that it soon disappears and gives a sweet taste to the whole of the water, so that in some way the sugar must have spread throughout the water.

Repeat the experiment with salt, and similarly notice that the salt can be recognised everywhere in the water by its taste.

Add sand to water and stir it up with the water. Let the water stand for a short time, and notice that the sand sinks to the bottom.

Stil up camphor with water. Notice that the camphor does not disappear; it is insoluble in water. Shake up a small lump of camphor with some spirits of wine in a small 
bottle. It gradually disappears just like sugar does in water.

Shake up flowers of sulphur with carbon bisulphide, and notice that it disappears. Be careful to keep the stopper in the bottle of carbon bisulphide, and do not bring the bottle near a light.

Fold a piece of clean white blotting paper or a filter paper in the manner already explained (Fig. S). Insert the folded paper into a glass funnel and place the funnel into a flask.

Make some muddy water by stirring inud into a tumbler of water, or by putting powdered charcoal into it. The mud or charcoal remains suspended in the water for a long time.

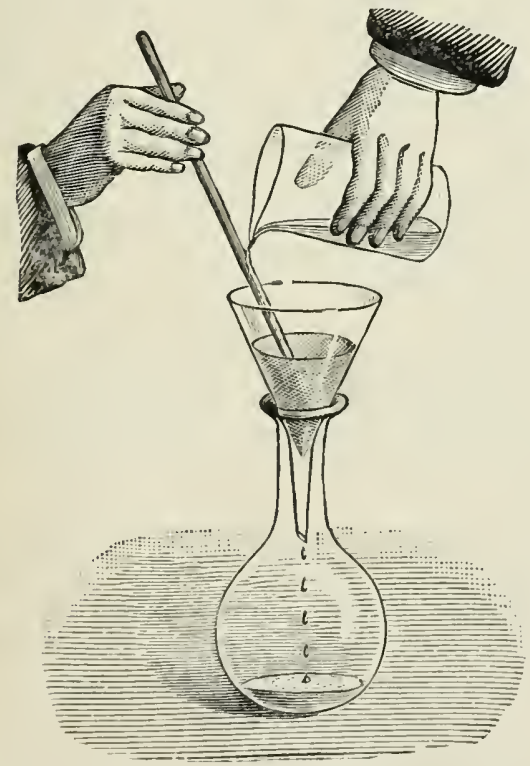

Fig. 74.- How to pour water into a paper filter in a glass funnel

Pour the muddy water carefully on to the filter paper in the funnel in the manner shown in Fig. 74 , and observe 
that the water which drops through is quite clear. The mud is left on the paper.

Similarly, filter a solution of sugar or salt, and observe that the solution is unaltered by passing through the paper.

\section{REASONS AND RESULTS.}

What Soluble and Solution mean.-When you put sugar into a cup of tea and stir it, you know that the sugar disappears. How would you find out whether sugar had been put in a cup of tea or not? By tasting the tea. Every child knows that sugar gives a sweet taste to tea, water, or milk. If salt is added instead of sugar, a salt taste is given to the tea, milk, or water. Whenever a substance disappears in a liquid in this way, and yet can be recognised by suitable means everywhere in the liquid, $i$ : is said to dissolve or to form a solution. Those substances which disappear in this way are said to be soluble. Many things besides salt and sugar are soluble in water. For instance, washing-soda, borax, and nitre (saltpetre) easily dissolve, or are soluble in water. Many other things, on the contrary, will not dissolve in water, and these are spoken of as insoluble substances.

Substances insoluble in Water.-Among many substances insoluble in water are sand, gravel, coal, camphor, and sulphur. If you try to dissolve sand, camphor, and sulphur in succession in water, you will find that they do not disappear; hence they are insoluble.

But though camphor will not dissolve in water, yet it disappears when skaken up in spirits of wine. We consequently say that camphor is soluble in spirits of wine, or that we can make a solution of camphor in spirits of wine. Another substance which will dissolve in spirits of wine and not in water is shellac. In fact, some of the varnish which is used for our furniture consists of shellac dissolved in spirits of wine. Again, if powdered sulphur is shaken up with the bad-smelling liquid called carbon bisulphide it dissolves. Though sulphur will not dissolve in water, and to only a small extent in alcohol, it forms a solution very easily in carbon bisulphide. 
Substances held in Suspension in Water.-Substances which are insoluble in water will, if they are very finely powdered and stirred up with some water, often take a very long time to settle. Or, as it is more commonly expressed, such finc particles remain suspended in the water for a long time. The lighter the particles are, of course, the longer time it takes for them to settle down and for the water to become clear. If on a rainy day you take a glassful of muddy water from the gutter, and then place it on one side, you will be able to watch the particles settling down. Those substances which, like the mud, are spread throughout the water without being dissolved in it are said to be held in suspension. The rate at which these suspended particles settle down on the bottom of the tumbler or other vessel to form a sediment depends upon their density. Light particles take a long time, heavy particles only a short time to sink.

We get rid of Suspended Substances by Filtering.-It is easy to separate suspended impurities from water. The process by which this is done is called filtration, or filtering. Many substances are used through which to filter water containing particles in suspension. Chemists most commonly use paper which has not been glazed. As you have learnt, such paper is porous. The holes through it are large enough to let water pass, but not large enough to let the suspended substances through. In consequence, these particles are left on the paper in the funnel, and the water which trickles through is quite clear. It must be carefully remembered, however, that it is impossible to get rid of substances in solution by filtering the liquid. I)issolved material passes through the holes in the paper with the liquid in which it is lield in solution.

Other substances besides unglazed paper are sometimes used in filtering. Thus the water supply of a town is often filtered through beds of sand. Household filters are made with pieces of charcoal for the water to trickle through, and in some others a particular kind of porous iron or porcelain is employed. Every filter requires to be cleaned frequently, or it gets clogged with impurities from the water which has filtered through it. 
TO BE REMEMBERED.

Solution is the process by which some substances, when placed in water or other liquids, disappear, and their particles spread through the entire mass of the liquid.

A substance is said to be soluble in a liquid when it disappears in the liquid and forms a solution. Examples : sugar, salt, and soda are soluble in water.

A substance is said to be insoluble in a liquid when it will not dissolve in the liquid. Examples: sand, gravel, camphor, sulphur are insoluble in water.

Substances which will not dissolve in water will often dissolve in other liquids. Examples : camphor and shellac are soluble in spirits of wine; sulphur is soluble in carbon bisulphide.

Insoluble substances may be spread thronghout water or held in suspension. Suspended impurities can be got rid of by filtering.

\section{EXERCISE XXVI.}

I. What do you mean by a soluble thing? Give examples.

2. Explain how you would proceed to make a solution of table salt.

3. Give a list of as many things as you can which will dissolve in spirits of wine and not in water.

4. How would you obtain clear water from muddy water?

5. What do you mean by substances being held in suspension in water?

6. What kind of impurities cannot be got rid of by filtration?

7. Explain the terms-soluble, insoluble, filtration, and "held in suspension." 


\section{LESSON XXVII}

SOLUBLE LIQUIDS AND GASES.

\section{PRACTICAL WORK.}

Things required.-Alcohol, olive oil, mercury, ether. Bottle of soda-water or other aerated water. Taper. Test-tubes.

\section{What to do.}

Pour some water into a bottle and then some alcohol, ${ }^{1}$ and shake them up together. Observe that the alcohol disappears in the water or dissolves in it.

The same experiment can be performed with oil of vitriol. Great care must be taken to pour a small quantity of the vitriol into water and not water into the acid. The acid is dissolved in the water.

Shake up together some olive oil and water, and allow the mixture to stand for a short time. Notice that the liquids separate into two layers, the lighter being on the top. Which is the lighter?

Repeat the experiment with quicksilver and water, and if possible with ether and water.

Examine a bottle of soda-water. Notice that it appears clear and bright, and seems to have nothing dissolved in it. Uncork,

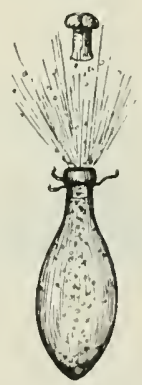

Fig. 75.- Bubbles of gas escape from a bottle of aerated water when the cork comes out. or otherwise open it. Bubbles of gas escape (Fig. 75). A lighted taper held to the mouth of the bottle has its flame put out by the gas which is given off.

1 Ordinary methylated spirit will not do, as it forms a milkiness with water. If pure alcohol cannot be obtained, whisky or brandy will do. 


\section{REASONS AND RESULTS.}

Solution of one Liquid in another.- The commonest cases of solution are when solid substances are dissolved in liquids. In addition to this, many liquids will dissolve in ocher liquids. Alcohol and oil of vitriol are examples of liquids which dissolve in water. When a liquid dissolves in water, like alcohol and oil of vitriol do, we say, in ordinary language, that the two liquids mix. This is only another way of saying that they form a solution. In the one case, we have a solution of alcohol in water; in the other, a solution of sulphuric acid in water. There is still another way of speaking about these cases. It is very common to say that we have diluted the acid with water or the alcohol with water.

Liquids insoluble in one another.--If, however, oil, water, and mercury, for example, are shaken up together, and then left

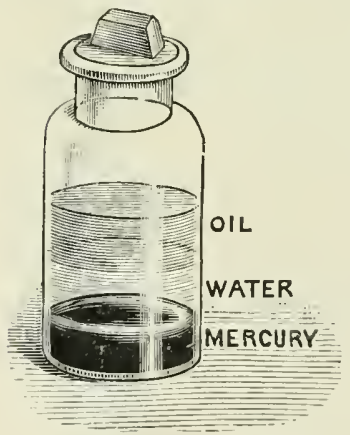

FIG. 76. - The liquids in the bottle do not mix, and if undisturbed they separate into layers-the densest at the bottom and the lightest at the top.

How to separate Liquids which do not mix.-Since liquids which do not mix will, if allowed to stand, separate from one another, and arrange themselves in layers with the densest liquid at the bottom and the least dense on the top, it is easy to separate them. All we have to do is to very gently tilt the vessel containing them and pour off the top layer. This plan is called decanting. Or, we could pour the liquids into a funnel supplied with a stop-cock at the bottom. 
as shown in Fig. 77, and allow the liquids to arrange themselves in it. Then by turning the stop-cock gently we could allow the liquids to run out, one after the other, into different vessels; the lowest first, then the next, and so on until all the liquids have been drained out.

\section{Some Gases dissolve in Liquids.}

When a bottle of lemonade, ginger-beer, or soda-water is opened, a lot of bubbles of gas rise out of it. The gas has evidently been dissolved in the liquid. This is only one of many instances of gases which will dis solve in liquids. There is a large amount of this gas, which extinguishes a flame, dissolved in soda-water. The drink is called

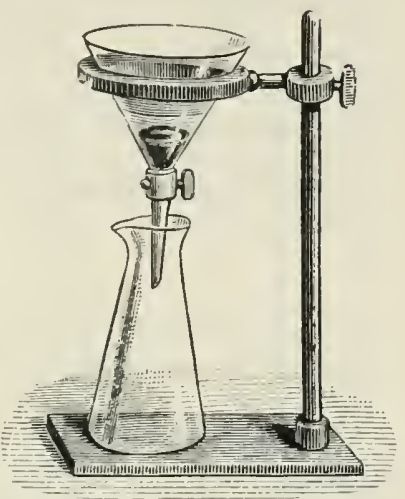

Fig. 77.-A funnel with a tap, for drawing off the liquids in it one after the other. "soda-water" because the gas dissolved in the water can be made from washing-soda. When you get to know more of the science of chemistry, you will learn of many other gases which will dissolve in water. The liquid sold by chemists as liquid ammonia is a solution of ammonia gas in water.

Importance of Air dissolved in Water.-Rain in falling through the air dissolves some of it in its passage to the earth. The air which thus becomes dissolved in the water serves a very important purpose. Both animals and plants must have air to breathe. As you know very well some animals and plants live in water, and these, like those living on land, require air to breathe. These water plants and animals depend upon the air which is dissolved in the water. When water is boiled, the dissolved air which it contains is driven out of it by the heat. If a goldfish were taken out of its bowl and placed in some water which had been boiled and allowed to cool out of contact with the air, it would die because there would be no air in the water for it to breathe. 
TO BE REMEMBERED.

Some liquids mix or dissolve other liquids. Exampies: alcohol (whisky or brandy) dissolves in water; so does vinegar.

some liquids do not mix, or are insoluble, in one another. Examples: oil, water, and mercury.

Some gases dissolve in liquids. Examples: the gas in soda-water, and ammonia gas in the so-called liquid ammonia.

The air dissolved in water is necessary for the life of water animals and plants.

\section{ExERCISE XXVII.}

1. What is really meant when we say two liquids will not mix ?

2. Give instances of (I) liquids which $\mathrm{mix},(2)$ liquids which do not $\operatorname{mix}$.

3. Will gases dissolve in water? Give reasons for your answer.

4. How do water animals, like fishes, manage to breathe?

5. What would you notice if you were to shake (I) some ink and water together, (2) some oil and water?

\section{LESSON XXVIII.}

\section{THERE IS NO LOSS DURING SOLUTION EVAPORATION.}

\section{PRACTICAL WORK.}

Things required.-Salt. Warm water. Balance and box oi weights. Flasks. Evaporating basin. Sand-bath or waterbath. 'Tripod stand. Laboratory burner or spirit lamp.

What to to.

Put some warm water in a flask, and some salt in a piece of paper. Counterpoise the flask of water and the paper of salt together, and then dissolve the salt in the water. The total mass remains unaltered (Fig. 78).

Find the mass of a flask of water. Now weigh several lumps of loaf sugar, and put this known mass of sugar 
NO LOSS DURING SOLUTION. EVAPORATION. III

into the water. When the sugar has all dissolved, weigh again. Notice that the flask and solution of sugar together have a mass exactly as much as the flask of water and sugar added together.
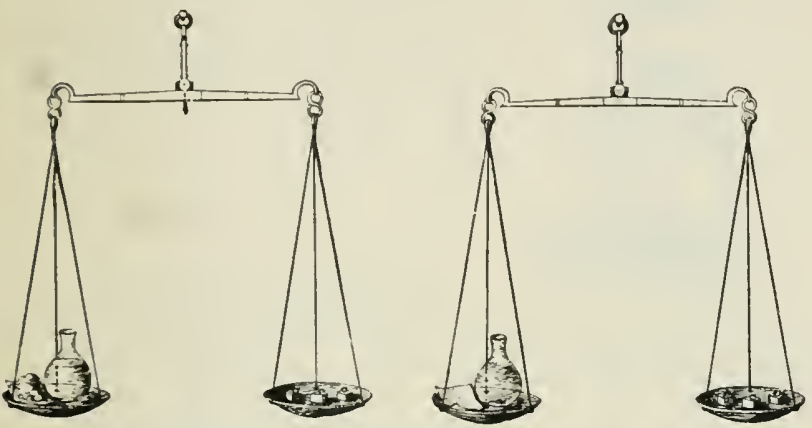

Fig. $78,-$ There is no change of mass when salt is dissolved in water.

Dissolve some salt in water, as in previous experiments, and place the solution so formed in an evaporating basin, and graduallywarm the basin or a piece of wire gauze, or over a sand-bath (Fig. 79), until the solution boils. (Instead of placing the evaporating basin in hot sand, it can be heated by the steam rising from boiling water, as in Fig. 8o.)

Allow the water to slowly boil away. When all the water

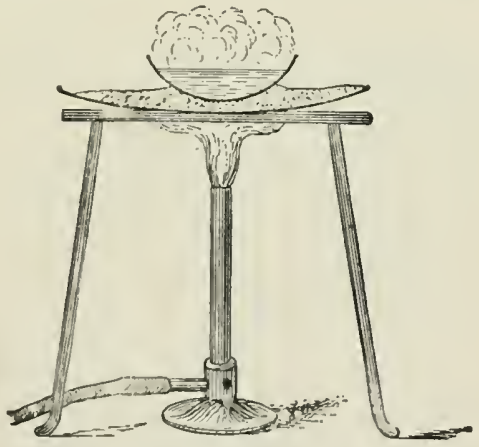

Fig. 79.- The shallow basin of water rests upon sand kept hot by a burner. The water is drying up or evaporating.

has been changed into steam, the salt will be found left behind in the basin.

Repeat the experiment in the following manner. Weigh 
out a certain mass of salt in an evaporating basin, and dissolve it in water. Heat gently as before. Note that by and by a white solid remains in the

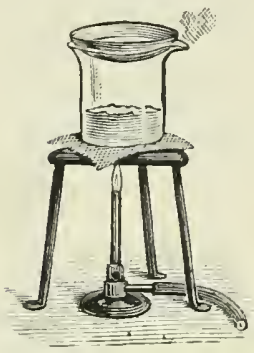

Fig 80. - The shallow basin has water in it and is kept hot by the steam rising from the water in the glass beaker. basin. Again weigh. By weighing it, we can show that its mass is equal to the mass of the basin and salt before solution, and it is easy to prove that the solid left is still salt.

\section{REASONS AND RESULTS.}

\section{Substances do not lose in Mass} when dissolved.- When a substance simply dissolves in a liquid, and so disappears from sight, it almost seems as if it is lost altogether. But this is not the case. There is no loss whatever. If a cup of tea and a few lumps of sugar are weighed separately, and then the sugar is put into the tea, their total mass is the same as the mass of the tea with the sugar dissolved in it. It is very important to remember that there is no change of mass when a substance dissolves in water. Though sugar, for example, when dissolved in tea or water, disappears from sight, it is still in the tea or water as sugar, and we shall see later that it can be obtained from the water by proper means. The same fact is true of salt and other soluble solids.

Evaporation. - If a saucer of water is left for a few days, the water disappears, or, as is generally said, dries up. The water can be made to disappear more quickly by gently heating it. When a solution containing salt or sugar is made to dry up in this way, the salt or sugar does not disappear, but remains in the saucer. The name given to this process of turning a liquid into a vapour is evaporation. The solid left behind is spoken of as a residue. Because we can recover the solid again by evaporation, and because there is no change of mass when solution takes place, we say that solution is only a physical change Salt is not changed into a new substance with new properties when it is dissolved in water. When a new substance with 
new properties is formed by bringing two substances together, we have what is called a chemical change. In our later lessons we shall have several instances of chcmical changes.

A Practical Application of Evaporation.-In some countries where salt does not occur as a mineral as it does in England, it is obtained from sea-water. Sea-water contains a large quantity of common salt dissolved in it. The sea-water is exposed to the heat of the sun's rays in shallow vessels and is consequently slowly evaporated. But only pure water passes off in the form of a vapour. The common salt and other substances in solution in the sea-water are left behind on the floor of the shallow vessel, and can be scraped off and collected for use.

In salt-mining, both solution and evaporation are sometimes made use of. Instead of bringing the salt to the surface in lumps, the plan adopted is to flood the mine with water, and leave it in the mine for a sufficient length of time for the water to dissolve as much of the salt as it can. The solution thus formed is then pumped to the surface, and evaporated, when the salt is obtained in the same way as in our experiment.

\section{TO BE Remembered.}

Matter is not lost when a substance is dissolved. A solid and liquid when separate have the same mass as when the solid is dissolved in the liquid.

Mass of Solid + Mass of Solvent $=$ Mass of Solution.

Evaporation is the prccess of slowly changing a liquid into a vapour by heat.

Dissolved substances can be recovered by evaporating the lionid containing them.

\section{Exercise XXVIII.}

I. Ilow would you prove that there is no loss of mass during solution?

2. How would you obtain the salt from a solution of the salt in water?

3. What do you know about evaporation?

4. Describe some practical applications of the processes of solution and evaporation. 


\section{LESSON XXIX.}

\section{SATURATED SOLUTIONS.}

PRACTICAL, WORK.

Things required.-Alum and nitre. Flasks. Sand-bath. Laboratory burner or spirit lamp. Tripod stand.

What to do.

Procure a supply of alum or nitre and powder it. Put some of the powdered solid into a flask and add water. Shake them up together for some time, and if all the powder dissolves add more and shake again. Continue this addition of the powcler and the shaking until some powder remains undissolved, however much it is shaken. You will thus make a cold saturated solution, that is, a solution containing as much of the solid as it will hold.

Now warm the cold saturated solution. The powder which before remained at the bottom of the flask dissolves. Continue to add more alum or nitre, and notice that a great deal must be added before you obtain a hot saturated solution.

Place the hot saturated solution on one side to cool. As cooling proceeds, some of the alum or nitre separates out in clear, well-formed crystals, because as the solution cools it cannot dissolve as much alum as before.

\section{REASONS AND RESULTS.}

Saturated Solutions.-When any given amount of water has dissolved as much of a solid as it can be made to, without warming or assisting it in any other way, it is said to be saturated. But though cold water, for instance, may be saturated with any particular solid, such as sugar, it can, if we warm it, be made to dissolve more sugar. Though there are some exceptions, it can be regarded as the general rule, that water and other liquids will dissolve more of a solid when they are warm than when they are cold. In some cases the amount 
of solid which will dissolve goes on increasing as the water is made warmer and warmer. In general, therefore, the cooler the water the less will it dissolve of a solid. Now suppose warm water is given as much sugar, salt, alum, or any substance of this kind as it will hold, and is then cooled, what would you cxpect to happen? It has to give up some of the substance, for it cannot hold as much as when it was warn. You may have noticed that when your tea has been very sweet, some of the sugar is left on the bottom of the cup when the tea cools. This is because, though the tea was able to dissolve a certain amount of sugar when hot, it could not hold so much when cold, and therefore a little of it was deposited upon the bottom of the cup.

Water as a Solvent.-Water dissolves more solids than any other liquid which is known. This makes it very useful to chemists and others. Water is such a good solvent that it is impossible to find pure water anywhere in nature, that is, in any stream or lake which we may find in any country. As you have learnt, water will not only dissolve solids, but liquids and gases as well." As soon as rain is formed from a cloud it begins to dissolve some of the gases of the atmosphere, and no sooner has it reached the earth than it dissolves all sorts of things out of the ground. Of those substances in the soil and rocks which are very soluble it dissolves a great deal, while of the insoluble things it dissolves either very little, or scarcely anything at all, for you must bear in mind that very few things are actually quite insoluble.

The purest water which can be got in nature is that collected in a vessel, after it has been raining some time, before the rain has reached the ground. In countries where the rocks are very hard and insoluble, and are covered by nothing in the way of soil, the water which is collected is always

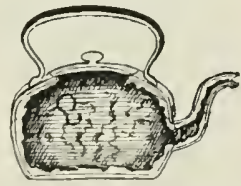

FIG. 81. - The "fur" inside a kettle consists of solids once dissolved in water, and left behind when the water boiled away. very pure compared with ordinary water. That many substances are dissolved in ordinary water you can see for yourselves if you will examine the inside of the kettle at home. There you will find a crust formed by the 
substances which were dissolved in the water, and have been left behind as the water evaporated or boiled away.

\section{TO BE REMEMBERED.}

A solution is saturated with a substance when it contains as much of that substance as it will hold at the temperature of the solution.

The effect of increase of temperature on saturation is usually to increase the amount of a substance which can be held in solution. The solubility of a substance usually decreases as the temperature is lowered.

Water dissolves most substances, but in different degrees. Salt is more soluble in water than sugar, and sugar is more soluble than chalk.

\section{EXERCISE XXIX.}

I. What is a saturated solution? Describe how to make one.

2. Which will dissolve more sugar, warm or cold water? What is the general rule about the effect of an increase of temperature on the dissolving power of water?

3. What do you know about water as a solvent?

4. Describe fully what happens if you gradually cool a hot saturated solution of alum.

\section{LESSON XXX.}

\section{SOLUBILITY OF THINGS IN ACIDS.}

\section{PRACTICAL WORK.}

Things required.-Copper turnings, granulated zinc, pieces of marble. Nitric, sulphuric, and hydrochloric acids. Testtubes. Evaporating basin, sand-bath, tripod stand, and laboratory burner or spirit lamp.

\section{What to do.}

Take a few small pieces of copper; observe their colour, and put them into a test-tube and shake up in water. They will not dissolve. Now boil the water, and notice the copper is still insoluble. 
Throw away the water, and substitute some fairly strong nitric acid. (Use the acid with great care, as it is very destructive to clothing, and burns the skin.)

Observe that the copper rapidly dissolves, and eventually disappears. Reddish-brown fumes are given off in large quantities. When breathed, these fumes are distressing and injurious. The liquid changes in colour. At first, owing to the solution of some of the reddish-brown gas in the liquid, it appears green, but when more water is added, the liquid is seen to be of a beautiful blue colour.

Evaporate some of the blue solution formed in the last experiment in an evaporating basin. When it is nearly dry, ${ }^{1}$ remove the basin from the source of heat, and set it on one side. Carefully notice the blue solid which is left behind. It is quite unlike the copper.

Take some pieces of zinc, and, as in the case of the copper, notice their colour, and prove that they are insoluble in water.

Now pour a-little dilute oil of vitriol (sulphuric acid) on them in a test-tube, and notice what happens. The zinc rapidly dissolves. Bubbles of gas are given off. The solution feels very warm. Hold your forefinger over the mouth of the tube for a minute, and then, after removing your finger, bring a lighted taper to the tube. There is a slight explosion, and the gas which comes off burns. (Caution - hold the tube with the top pointing away from your face.)

After the zinc has all dissolved, pour off some of the clear liquid, and, as before, evaporate it to dryness in an evaporating basin. A white solid is left behind.

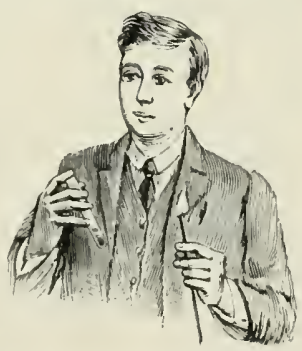

FIG. 82.-Dilute oil of vitriol and pieces of zinc are in the tube. A gas is produced and kept in by means of the finger. When a light is brought to the tube and the finger is taken away, the gas burns with a slight explosion.

Procure a lump of marble, and break it into small fragI It is not wise to evaporate to complete dryness, as the substance which is left behind is easily decomposed by heat. 
ments. Observe that it is very hard. Prove that it will dissolve neither in cold nor hot water.

Pour a few drops of strong muriatic acid (hydrochloric acid) into the water, and observe the effervescing, or fizzing, which immediately begins. Large quantities of gas are given off, and the marble gradually dissolves. Place a lighted match at the mouth of the test-tube in which the experiment is performed. The flame is put out or extinguished.

When all the marble has dissolved, evaporate some of the clear liquid left, and examine the white solid which remains. It is not marble because it is so soft. Place the basin on one side for a time, and observe that this white solid takes water out of the air and becomes wet. Notice that marble does not do this.

\section{REASONS AND RESULTS.}

Solution of Another Kind.-In all the instances of solution which we have studied before this lesson, there has never been a permanent change in the properties of the soluble substance, nor has there been any change in mass when the thing has dissolved. But these conditions are not always so, as we have now to learn. When copper is acted upon by moderately strong nitric acid in a test-tube or other glass vessel, it rapidly dissolves, and by and by disappears. At the same time large quantities of reddish-brown fumes are given off. These fumes are very unpleasant to breathe, and, what is more, they are very injurious, and should not be allowed to escape into a room in any quantity. As the copper dissolves, the acid changes colour, and soon appears quite green. But this is not the natural colour of the liquid formed as the copper dissolves. It is really blue, and appears green because some of the fumes get dissolved. If you add some water to the green liquid, the blue colour becomes very easily seen. If some of this blue solution is slowly evaporated in a basin, you obtain a blue residue which is not a bit like the copper you started with.

This Kind of Solution is a Chemical Change.-This example of solution is evidently of quite a different kind from that of 
the solution of salt or sugar in water. When sugar is dissolved in water, there is no gas given off, and there is no change in colour, and, most important of all, we can recover the sugar by evaporating the water. The change which occurs when the nitric acid is poured on the copper is a chemical change, and it is so called because it results in the formation of new substances with quite new properties. Copper and nitric acid are not at all like the nasty smelling red fumes and the blue solid left in the basin.

\section{Another Instance of the Solution of a Metal where Chemical} Change occurs.-Though pieces of zinc will not dissolve in water, yet if you place them in dilute sulphuric acid they dissolve very quickly, and bubbles of a gas which will burn are given off. After the zinc has all dissolved, a colourless solution is obtained; and if some of it is evaporated in a basin, a white residue is left behind which is in no way like the zinc we started with. This, too, is a chemical change, and, as before, it is so called, because the solution results in the formation of a new substance with new properties.

Here, using another metal-for copper and zinc are both metals - and another acid, you again have a chemical change taking place when solution occurs. You know it is a chemical change, because the gas which comes off, and burns when a lighted taper is put to it, and the white solid left in the basin are not at all like the zinc and the acid with which you started.

Other Substances besides Metals will dissolve in Acids.Metals are not the only things which will dissolve in acids. Though marble, like copper and zinc, is insoluble in water, it will dissolve in some acids, for instance muriatic or hydrochloric acid. This is another example of solution. The acid is the solvent and the marble the soluble substance. And this solution also has been accompanied by a chemical change, because the white soft solid which becomes wet in the air, and the gas which is given off and puts out a flame, are quite untike the hard marble and the liquid acid. 
TO BE REMEMBERED.

Certain Metals dissolve in Acids. - In this case the process is accompanied by the formation of new substances with new properties. It is therefore an example of a chemical change.

In this way copper dissolves in nitric acid, and zinc in dilute sulphuric acid.

other substances besides metals will dissolve in acids. The solution of marble in hydrochloric acid is an example. This is also an instance of a chemical change.

\section{EXERCISE XXX.}

I. Describe the appearance of copper and zinc.

2. How would you prove that copper is insoluble in water?

3. Describe fully what takes place when moderately dilute nitric acid is poured upon copper.

4. What do you know about the gas which is given off when dilute sulphuric acid is poured upon zinc?

5. How would you show that a new substance is formed when hydrochloric acid dissolves marble?

\section{LESSON XXXI.}

\section{CHANGES OF MASS WHEN CHEMICAL ACTION ACCOMPANIES SOL.UTION.}

\section{PRACTICAL WORK.}

Things required.-As in the last lesson, with balance and box of weights.

What to do.

Repeat the experiments with copper and nitric acid described in the last lesson; but before adding the acid letermine the mass of the copper used. Evaporate to dryness the whole of the coloured liquid obtained by dissolving the copper in an evaporating basin, the mass of 
which has been determined by previous weighing. When the basin is cool, weigh again, and, allowing for the mass of the basin, observe that the mass of the blue residue is greater than that of the copper taken.

Similarly repeat the experiment with the zinc and dilute sulphuric acid. In the same way show that the mass of the white residue obtained is greater than that of the zinc with which the experiment was started.

Repeat the experiment with marble and hydrochloric acid. Show that the mass of the white residue left in the basin is greater than that of the marble acted upon by the acid.

[A few hours before the next lesson a warm saturated solution of alum should be made and put by to cool. The reason for this will be seen on p. 124.]

\section{REASONS AND RESULTS.}

Changes in Mass when a Chemical Change accompanies Solution.-You have already learnt that one of the reasons for saying that a physical change occurs when a solid is dissolved in water, is because there is no change of mass. But whenever a chemical change takes place at the same time as the solid dissolves in a liquid, as in all the experiments we have had in this lesson, there is a most decided change of mass. This is a very important difference between physical and chemical changes, and it is very necessary that you should thoroughly understand it.

The Case of Copper and Nitric Acid.-If a piecc of copper, the mass of which has been found by weighing to be one gram, is dissolved in moderately dilute nitric acid, and then the whole of the blue solution obtained is evaporated very carefully, so that none of it is lost, the mass of the blue residue left behind will be found as nearly as possible threc grams. It is quite clear that all this cannot be copper. Indeed its appearance is quite enough to tell you that it is not copper. But it contains copper, and when you have learnt more about chemistry you will know the way in which the colper can be obtained from it. What has really happened is that the copper has combined 
or united with a part of the acid to form a new substance. The blue residue is made up of the copper you started with and a part of the acid as well. This explains why the mass of the residue is greater than that of the copper alone.

The Case of Zinc and Sulphuric Acid.-The experiment with zinc and sulphuric acid teaches just the same important lesson. If a piece of zinc, the mass of which is one gram, be completely dissolved in dilute sulphuric acid, and the whole of the solution thus obtained be evaporated to dryness, and the mass of the residue determined, it is found that just about two and a half grams of the white solid have been obtained. In this case, too, the metal combines or unites with a part of the acid to form the new substance left behind in the basin. By proper means it would be easy to again obtain the zinc from the white residue.

The Case of Marble and Hydrochloric Acid.-What you have now learnt about these changes in mass when metals are dissolved in acids is also true when things which are not metals are dissolved in acids. Marble is not a metal, but it easily dissolves in acids, for instance, hydrochloric acid. If, as before, one gram of marble is dissolved in as much hydrochloric acid as is necessary, and the whole of the solution is evaporated in a basin, it is found by weighing that the mass of the white residue left behind in the basin is more than one gram, but not so much more as in the case of the copper or the zinc. The mass of the white residue left behind when the solution obtained by dissolving the marble in hydrochloric acid is evaporated is about one and one-tenth grams ( $\mathrm{I}_{10}^{\mathrm{T}} \mathrm{grams}$ ).

The Total Mass is unaltered.-Returning to the consideration of the solution of copper in nitric acid, and taking other things into account, there are more facts to be learnt from it. If, in addition to ascertaining the mass of the copper by weighing, that of the nitric acid is also found, and these two masses are added together, a certain mass is obtained. Now, chemists discovered a long time ago that the total mass obtained in this way is the same as is got by adding together the masses of the blue residue left in the basin, all the gas which is given off, and all the steam which escapes when the blue solution is evaporated. 
These facts can be put down in the form of addition sums as below :

Examples of Cinemicai, Cilange.

Before.

After.

Mass of Copper.

Mass of Nitric Acid.

$\left\{\begin{array}{l}\text { Mass of Blue Residue. } \\ \text { Mass of the gas given off. } \\ \text { Mass of Steam. }\end{array}\right.$

Total MAss is equal to Total Mass.

$\left.\begin{array}{l}\text { Mass of Zinc. } \\ \text { Mass of Sulphuric Acid. }\end{array}\right\}\left\{\begin{array}{l}\text { Mass of White Residue. } \\ \text { Mass of Gas which burns. } \\ \text { Mass of Steam. }\end{array}\right.$

Total Mass is equal to Total Mass.

$\left.\begin{array}{l}\text { Mass of Marble. } \\ \text { Mass of Hydrochloric Acid. }\end{array}\right\}\left\{\begin{array}{l}\text { Mass of White Residue. } \\ \text { Mass of Gas which puts out flame. } \\ \text { Mass of Steam. }\end{array}\right.$

Total Mass is equal to Total Mass.

TO BE ReMEMBERED.

When chemical action accompanies solution, changes in mass occur. Thus, the blue residue in your experiment weighs more than the copper, and the white residue more than the zinc, when these metals are dissolved in acids.

The total mass of the new substances obtained when a chemical change takes place is the same as that of those originally taken. Thus, if the masses of the copper and nitric acid be added together, the same result is obtained as by adding the masses of the blue residue, the gas given off, and the steam.

\section{EXERCISE XXXI.}

I. Will the blue residue obtained by evaporating a solution of copper in nitric acid have the same mass as that of the copper? Give reasons for your answer.

2. What amount of white residue can be got by dissolving one gram of zinc in dilute sulphuric acil and evaporating the solution obtained? Why is its mass greater than that of the zinc?

3. What changes in mass do you know of which occur when marblc is dissolved in hydrochloric acid?

4. How would you show that there is no loss in the total mass when a chemical change occurs? 


\title{
LESSON XXXII.
}

\section{CRYSTALS AND CRYSTALLISATION.}

\author{
PRACTICAL WORK.
}

Things required.-Crystals of washing-soda, sugar candy, borax, rock-crystal, blue vitriol, rock-salt, and alum. Flasks. Sand-bath. Laboratory burner. Tripod stand. Blotting paper. Test-tubes.

\section{What to do.}

Examine as many crystals as you can and draw them. Write down the number of faces each has.

Make a warm saturated solution of alum as described in Lesson XXIX. While it is still hot shut the mouth of the flask with a cork, or cover it with a piece of suitably folded paper, and set it on one side to cool. After a few hours, crystals of alum will be found to have separated out.

When the solution of alum, described in the last experiment, has become quite cold, and the crystals there referred to have separated out, carefully pour off the liquid from the crystals, and allow these to gently slide on tu a piece of clean white blotting paper. Shake them on the blotting paper, and, if possible, dry them without handling.

Now take a small crystal and heat it gently in a clean, dry test-tube. Notice that it melts and gives off steam which condenses on the sides of the tube near the top in the form of water. When cold, the alum is seen to have lost its shape.

Heat a crystal of blue vitriol in a test-tube, and show that the shape and colour are lost as the water is driven out of the crystal. It regains its blue colour if water is dropped upon the powdery lump.

Inspect some clear crystals of soda (sodium carbonate), and also some which have been exposed to the air and become white and powdery. 


\section{REASONS AND RESULTS.}

Crystals.-When substances are found in lumps having a regular shape, which is always the same for the same kind of thing, it is said to be found in crystals, or to be crystalline. Generally the shapes which crystals have are wellknown forms in geometry. Thus some crystals are known which are perfect cubes (Fig. 88), such as crystals of rock-salt, fluorspar, iron pyrites. Sometimes the crystal has eight sides, like the solid known as the octahedron (Fig. 85). The diamond is sometimes found having this shape. Rock-crystal has generally six sides, and a six-sided pyramid at one or both ends (Fig. 84). When you get on farther with your study of science, you will learn that crystals can all be divided into six classes, every member of each class or family having something about its shape the same.

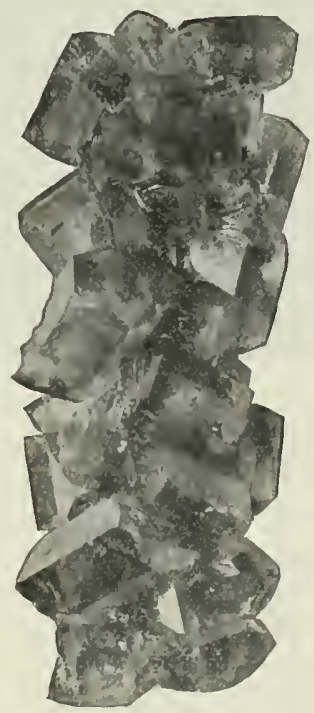

Fig. 83.- Sugar-candy, a common crystalline substance. (From a photograph by MIr. H. E. Hadley.)

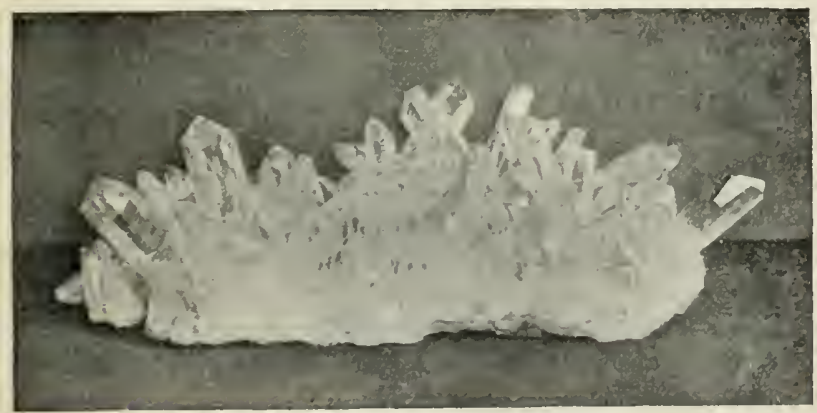

Fig. 84-- Group of rock-crystals. From a Report of the U.S. National Museum. 
How Crystals can be made.- Warm water when saturated

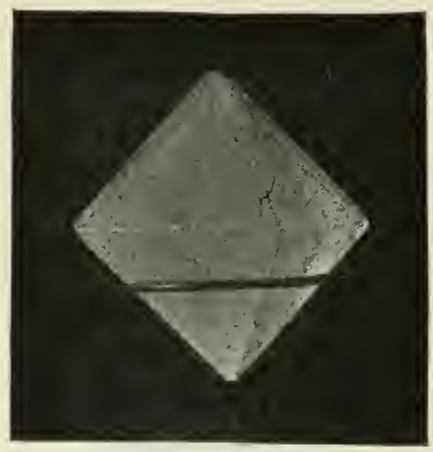

FIG. 85.-An eight-sided crystal of alum. (From a photograph by MIr. H. E. Hadley.)

with any soluble substance, as you learnt in a previous lesson, often contains more of the solid dissolved than an equal quantity of a cold saturated solution. The consequence of this is, that if you allow a warm saturated solution to get cold, the water can no longer keep all the substance in solution, and it separates out in the solid state, which, under these circumstances, always takes a crystalline character. The crystals of alum, formed in this way, generally have eight sides, or the shape of the crystal is the same as the solid called the octahedron, shown in Fig. 85. But in some circumstances the crystals only have six sides, or are cubes.

Some Crystals contain Water.-By heating a crystal of alum or blue vitriol in a clean clry test-tube, it is easy to show that they both contain water. This water is given off in the form of steam, which condenses into drops of water on the cold upper part of the tube. There are many other crystals besides those of alum and blue vitriol which also contain water. This water, which is contained in some crystals, is known as water of crystallisation. It is necessary for these crystals to have this water in them to form the regular shape of which you have learnt. If the water of crystallisation is got rid of they become powdery. Some coloured crystals not only lose their shape but also their colour when the water of crystallisation is driven out. Other crystals again, if simply exposed to the air, lose this water and become powdery. Such crystals are said to be efflorescent, and crystals of soda are a good example (Figs. 86 and 87 ). Other substances do just the opposite thing and take up more water from the air, becoming very moist. These are called deliquescent. The white residue obtained by evaporating the solution formed when marble is dissolved in hydrochloric acid is a deliquescent substance. 


\section{To be Remembered.}

Crystals are naturally formed lumps of certain substances having a regular shape, which is always the same for the same kind of thing.

Rock-salt and some other substances form crystals which are perfect cubes. The diamond crystals have the shape of the octahedron.

Crystals can be made by allowing a warm saturated solution to cool. Water of crystallisation is the water contained in some crystals. It has something to do with their shape and sometimes with their colour.

Efflorescent crystals easily give up their water of crystallisation to the air.

Deliquescent substances readily take up moisture and become wet.

\section{EXERCISE XXXII.}

I. Name six crystalline solids.

2. Give the name of a crystal which has six sides, and one which has eight sides. Make a drawing of each kind.

3. If you were given some powdered alum, explain how you would proceed to make a crystal of alum.

4. How would you show that crystals of alum contain water? What is the water called?

5. What do you mean by an efflorescent crystal? Name one.

6. What happens to a crystal of blue vitriol if it is heated in a test-tube?

7. Write down all you know about a crystal of rock-salt. Draw such a crystal. 


\section{LESSON XXXIII.}

\section{CRYSTALS AND CRYSTALLISATION-CONTINUED.}

\section{PRACTICAL WORK.}

Things required.-Crystals of washing-soda, sugar candy, borax, rock-crystal, blue vitriol, rock-salt, and alum. Flasks.

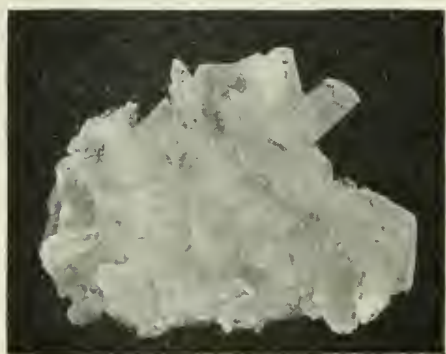

Fic. 86, - A group of fresh crystals of washing-soda. Notice how clear the crystals are. (From a photograph by Mr. H. E. Hadley.)
Sand-bath. Laboratory burner. Tripod stand. Blotting paper. Magnify'ing glass. Evaporating basin. Sulphur. Iron spoon. Test-tubes.

\section{What to do.}

Evaporate a solution of comnion salt by gently heating it, and, when the basin is dry, examine a little of the residue. Care-

ful inspection will discover small cubes, the shape of some of which can be recognised by the unaided eye. The cubical shape of the others can be easily made out under a magnifying glass.

Heat some of the dry powder in a testtube. Notice the crackling and the absence of water on the side of the tube.

Make a hot saturated solution of soda, just as you did in the case of the alum in

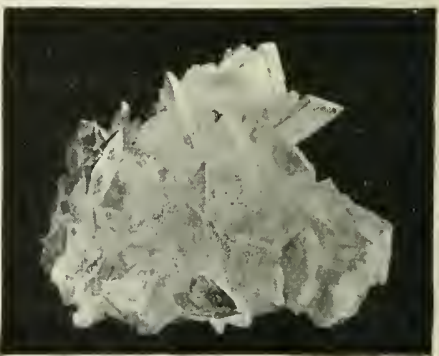

Fif. 87.- The same croup of crystals as in Fig. 86, which have effloresced after exposure to the air for a short time. Notice the changed appearance. (From a photograph by Mr. H. E. Hadley.) 
Lesson XXIX. Put the solution, when you have made quite sure that it will dissolve no more, on one side to cool. Large clear crystals will be formed.

Make a similar saturated solution of soda, and having poured some into an evaporating basin, float the latter on cold water in a bucket so that it shall cool more rapidly. Observe that the crystals formed are much smaller than in the last experiment.

Take one of the large, clear crystals previously obtained, and dry it on clean, white blotting paper, and heat it in a tube, if necessary breaking the crystal to get it in. Observe the steam given off, the water which collects, and also the white powder left behind.

Melt some powdered sulphur in an iron spoon or cup, and then allow it to cool slowly. When a solid crust has been formed over the top, make two or three holes in it, and pour off the remaining liquid sulphur. When the sulphur is cool, examine the inside of the spoon or cup, and notice the fine needle-like crystals of sulphur (Fig. 89).

Having melted some sulphur as in the last experiment, pour the liquid sulphur into some cold water. Examine the product formed, and observe it has still a crystalline appearance; the crystals are so small that individual crystals cannot be distinguished.

\section{REASONS AND RESULTS.}

Crystals of Common Salt.-Salt crystallises in six-sided solids, or cubes (Fig. 88). When the crystallisation is brought about by evaporating a solution of salt, the crystals are very small. Some natural crystals, known as rocksalt, are however of quite a large size. There is no water of crystallisation in crystals of common salt, and when they are heated no steam is given off. The crackling which

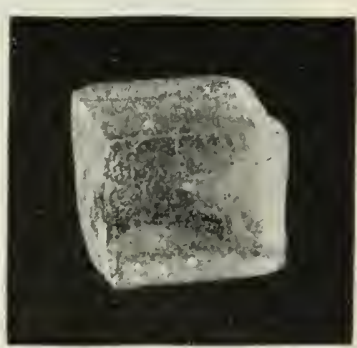

Fig. 88.-A six-sided crystal of common salt. (From a photograph by Mr. H. E. Hadley.) 
is noticed when crystals of salt are heated in a tube is spoken of as decrepitation, and is due to the breaking-up of the crystal into fragments.

Crystallisation of Soda.-Soda, as it is called in ordinary language, or sodium carbonate, as it is known to the chemist, is a common substance, both in the crystalline condition or in the form of white powder, as the carbonate of soda, which is

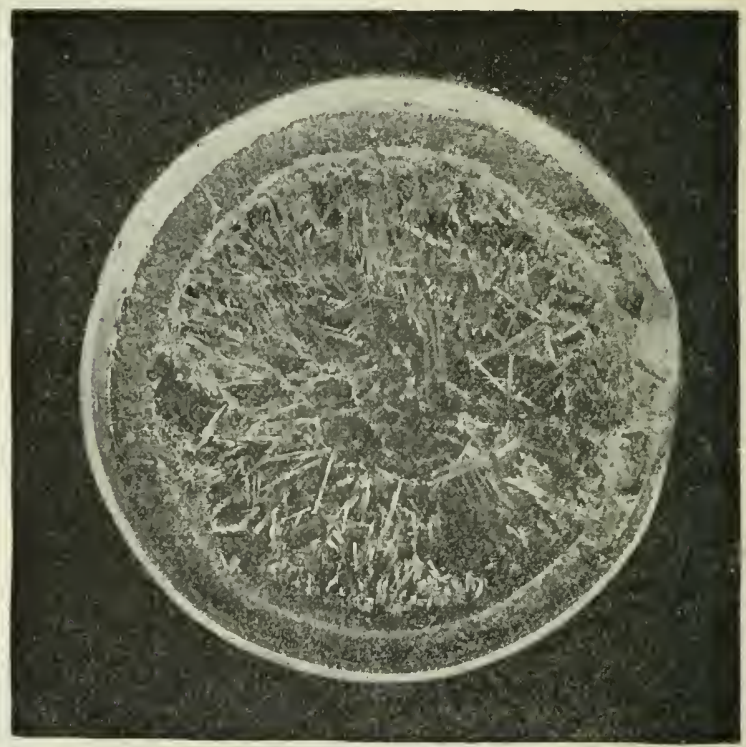

FIG. 89.-Needle-shaped crystals of sulphur. (From a photograph by Mr. H. E. Hadley.)

used for various purposes in our houses. The difference between the white powder which is perhaps best known, and the crystalline form, is the water of crystallisation which the crystals contain. We can easily obtain crystals if we have a supply of the powder, by making a warm saturated solution of 
the powder and allowing it gradually to cool, for then large crystals will separate out.

If, however, the warm saturated solution is cooled quickly, by placing the vessel containing it into cold water, the crystals rapidly separate, but are of much smaller size. This difference is true of most saturated solutions; indeed, whenever crystals are formed by cooling, we may expect them to be of a large size only when the cooling takes place slowly; if heat is given up rapidly the crystals formed are always small.

Some Crystals can be made in Another Way.-Other crystals besides those of common salt have no water in them. Many of these can be made in another way. One kind of sulphur crystals is a good example. When some powdered sulphur (milk of sulphur) is melted in a large iron spoon, or ladle, over a gas flame, and the melted sulphur is allowed to cool slowly, a solid crust is gradually formed on the top. If, as soon as this happens, two or three holes are made in the crust and the remaining, still liquid, sulphur is poured off, it will be found on examining the inside of the ladle that fine needle-like crystals of sulphur have been left behind. These, like all crystals, have smooth flat sides and sharp straight edges.

In this case, too, there is a difference when the melted sulphur cools very rapidly. The quick cooling can be conveniently brought about by pouring the melted sulphur into cold water. If this is done, the crystals formed are so small that individual examples cannot be distinguished, though the solid sulphur is seen to have a crystalline appearance.

\section{TO BE ReMEMBERED.}

Crystals of common salt have the form of cubes.

Decrepitation is the crackling sound produced by the breaking up into fragments of waterless crystals.

Soda crystals can be obtained from ordinary washing-soda by making a saturated solution of the powder and allowing it to cool.

Two examples of waterless crystals are common salt and sulphur.

Sulphur crystals can be obtained by melting sulphur and pouring out the liquid sulphur from the interior after a crust has been formed. 


\section{Exercise XXXIII.}

1. What differences would you observe if you heated salt crystals and crystals of soda in different test-tubes?

2. Explain how you would make some crystals of sulphur.

3. Describe how to make soda crystals from powdered carbonate of soda.

4. How does a crystal of salt differ in shape from a crystal of soda?

5. Explain how to obtain a crystal which has no water in it.

6. Why is steam given off when crystals of soda are heated, but nor when crystals of sulphur are heated? 


\section{LESSON XXXIV.}

\section{GRAPHIC REPRESENTATION.}

\section{PRACTICAL WORK.}

Things required.-Squared paper, or chequer drawing book such as is used for Kindergarten drawing. Ruler and pencil.

\section{What to do. ${ }^{1}$}

Draw in pencil, upon chequer or squared paper, or upon Fig. 9o, lines to represent the densities of the substances named in this figure. The line to represent the density of water, that is, I, is already drawn. Starting from the up-

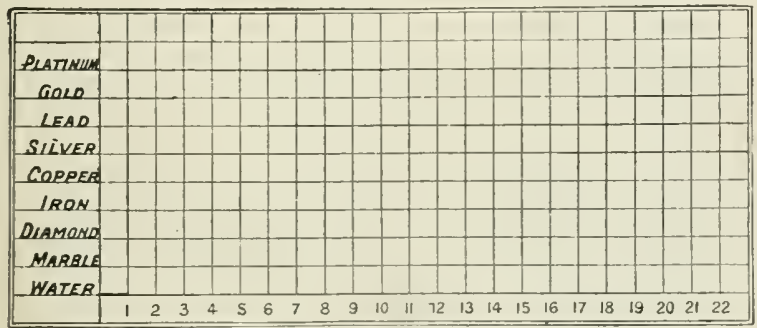

Frg. go-Copy this figure and draw lines upon your sketch to repre. sent the numbers given in the table of densities.

right line at the end of each name, draw a horizontal line for each substance, making the lines of the lengths given. in the following table:

\section{Table of Densities.}

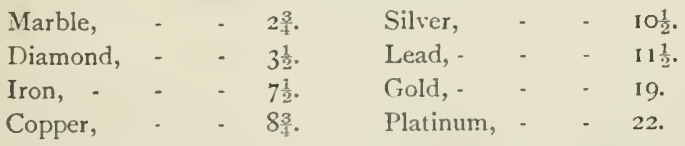

Find the number of boys present in the class on the last twenty times the register of attendance has been marked.

${ }_{1}^{1}$ Before doing these exercises it is advisable to read through the lesson. 
Write down the numbers. You should now plot these upon the squared paper in Fig. 9r. The numbers at the feet of the upright lines refer to the days of the register, and the numbers at the ends of the horizontal lines refer

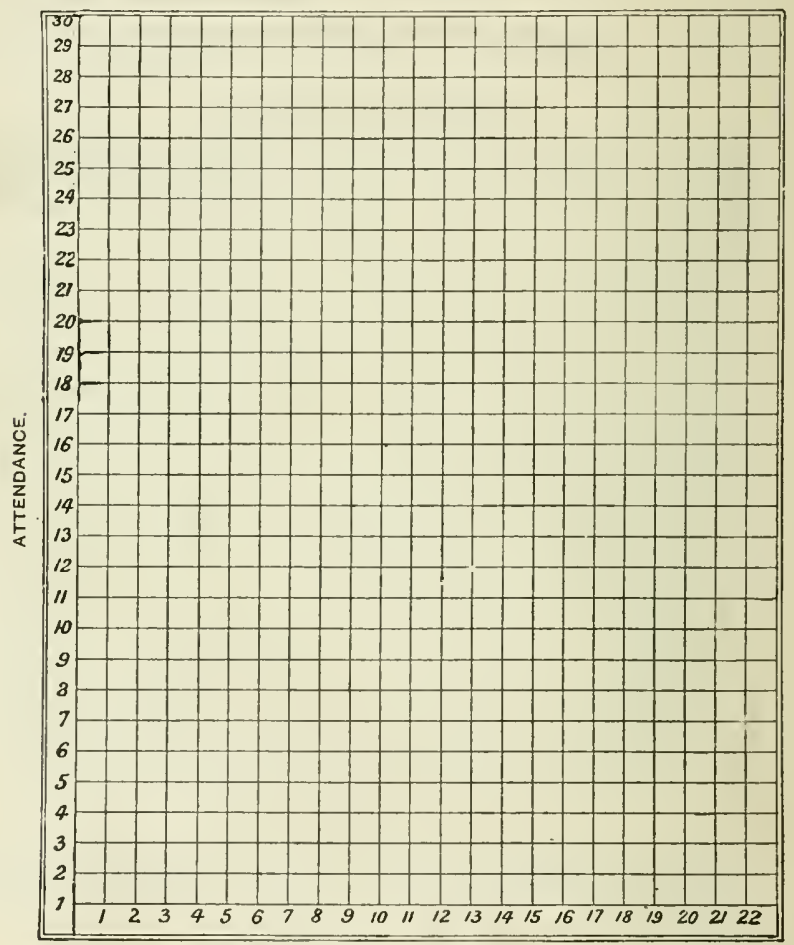

FIG. 91. - A sheet upon which the attendances of pupils at different times can be plotted.

to the number of boys present. If 15 were present at the first time selected, put a dot at the number 15 upon the first upright line; if 21 were present at the second time, put a dot on the same level as $2 \mathrm{I}$, upon the second upright line; and so on for all the twenty times the register was marked. 
Upon Fig. 92 and Fig. 93, or on a sheet of squared paper marked in the same way, represent the following readings of a certain barometer and thermometer in the month of March :

DATE.

March I, 2 ,

3 ,

4 ,

5 ,

6 ,

7 ,

8

9 ,

10 ,

II,

I2,
BAROMETER.

Inches

29.5 ,

29.7 ,

$28 \cdot 7$,

$29^{\prime} 3$,

$29^{\circ}$,

$29^{\circ} 6$,

$29^{\circ} 9$,

$30^{\circ}$,

$30{ }^{\circ}$,

$29^{\circ} 9$,

$30^{\circ} \mathrm{O}$,

$29^{\circ} 5$,
THERMOMETER.

Fahrenheit Degrees.

437.

39.5 .

$38 \cdot 6$.

$42 \cdot 8$.

$42 \%$

$39^{\circ} 1$.

36.7.

40.8 .

$4 I^{\circ} 4$.

$45^{\circ}$.

$46 \cdot 2$.

$43^{\circ} 4$.

To do this for the readings of the barometer, look at the left-hand side of the squared paper for the corresponding

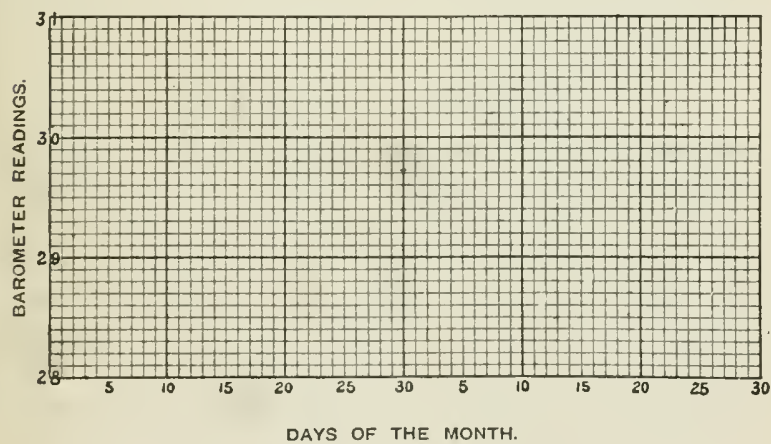

FIG. 92.-A sheet upon which the rise and fall of the mercury in a barometer can be shown.

height of the barometer, and, when you have found it, make a dot at that particular height upon the line corresponcling to the day of the month. Repeat the operation for every day, and connect consecutive dots with a straight line. 
The irregular line or curve thus produced shows at a glance the variations of atmospheric pressure.

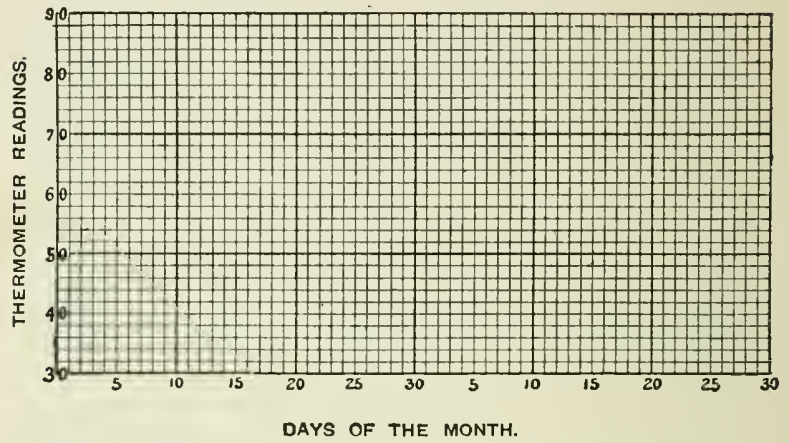

FIG. 93.-A sheet upon which the rise and fall of temperature during a month can be shown.

In the case of the thermometer the degrees are shown at the left-hand ends of the horizontal lines of the squared paper, and the days of the month are shown at the bottom of the vertical lines.

\section{REASONS AND RESULTS.}

Representation of Quantities by Numbers. - Up to the present all quantities have been represented by numbers. Thus, in one lesson, in recording the volumes of different solids, these quantities were expressed by saying how many cubic centimetres or cubic inches each solid contained. In another lesson the number of times heavier a certain volume of a substance was than an equal volume of water, that is, the relative density of the substance, was similarly expressed by a number, and in this way a table such as the following was obtained:

$$
\text { Water at } 4^{\circ} \mathrm{C} .=\mathrm{I} \text {. }
$$

\begin{tabular}{|c|c|c|c|c|}
\hline Wood (Oak), & $0 . \$_{5}$ or & $\frac{17}{2}$. & Copper, - & - 8.75 or $S \frac{3}{4}$ \\
\hline Glass, - & 275 or & $2 \frac{3}{4}$. & Silver, & - 10.5 or $10 \frac{1}{2}$ \\
\hline Diamond, & - 3.5 or & $3 \frac{1}{2}$. & Lead, & - II 5 or $11 \frac{1}{2}$ \\
\hline Zinc, & $7^{\circ} 0$ or & 7 . & Gold, & $-19^{\circ} 0$ or 1 \\
\hline Iron, & 7.5 or & $7 \frac{1}{2}$ & & \\
\hline
\end{tabular}


Other instances where quantities have been expressed by numbers you will remember for yourselves. Now the question arises, Is there no other way in which quantities like these could be compared more easily? There is. We can represent them by lines of different lengths.

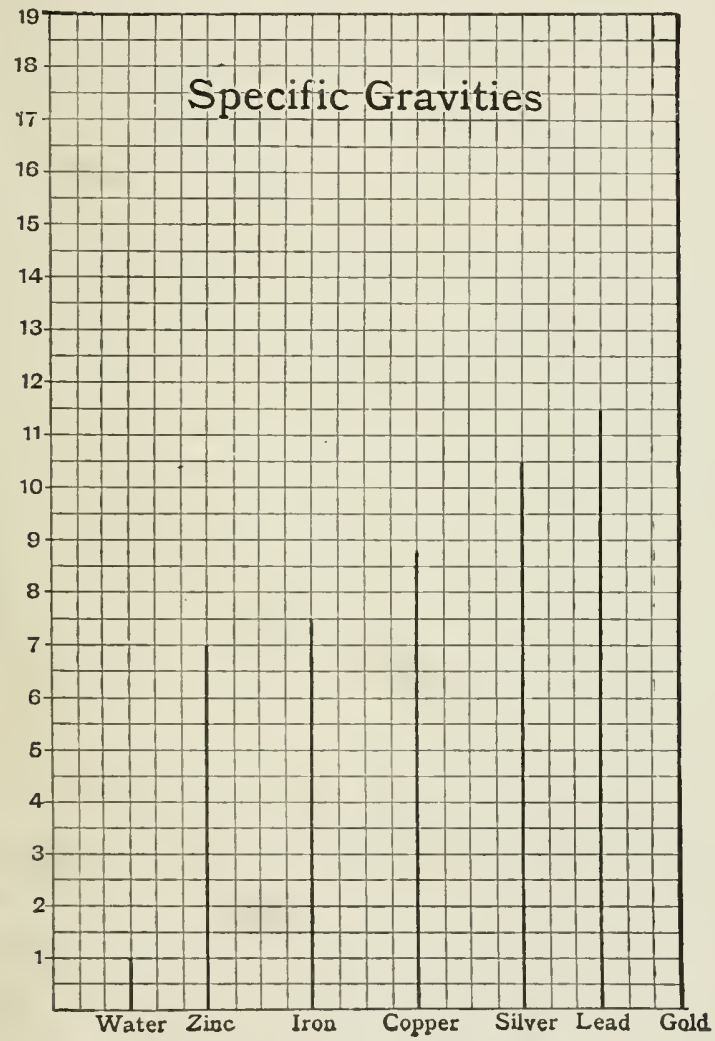

Fic. 94.-(From Gordon's Practical Science.) The lengths of the thick upright lines show the relative densities or specific gravities of the substances named at the bottom.

Representation of Quantities by Lines of Different Lengths.Suppose you want to represent the numbers in the table on p. I36, 
which tells us how many times heavier several substances are than an equal volume of water, by using lines of different lengths, you would proceed like this. Fix upon some convenient length to represent the standard density, namely that of water. Suppose you take the lengths of the sides of two adjoining squares on a piece of squared paper to represent the density of water, and then thicken the sides of these squares as in Fig. 94. All you have to do now is to make a mark, at a distance above the bottom line of the piece of squared paper shown in the diagrain, equal to the number of sides of squares which are necessary to represent the numbers in the table when the sides of two squares equal the number 1. To make this very easy the numbers arranged on this plan are placed on the left-hand side of the piece of squared paper. Thick lines are drawn from the points so obtained to the bottom of the paper. The relative densities of zinc, iron, copper, silver, lead, and gold are shown in the diagram. You should read off the numbers which the lengths of these lines represent and compare them with those in the table.

Graphic Representation.-A plan such as that described in the last paragraph is a simple case of what is known as graphic representation. This way of representing quantities which we wish to compare is often very much simpler than only using numbers. We are able to see the relation which the numbers bear to one another at a glance. Graphic representation is always employed to record the readings of the barometer and thermometer.

Daily Weather Records.-Most sharp boys and girls have noticed, either when at the sea-side or in some public park or other, that there is often a collection of instruments of different kinds for observing facts about the weather. Among these instruments there is always a barometer and a thermometer. It is very important to know what the weight of the atmosphere, or, as we have learnt to call it, the pressure of the atmosphere, has been every day and throughout each day ; and also what the temperature has been, that is, how cold or how warm the air has been. It is becoming more and more common in all sorts of places to make arrangements for observing these facts every day, and also for having a careful account kept of them. The records can be kept in various ways. 


\section{How Records of Pressure and Temperature can be kept.-}

The first plan for keeping a record of these pressures and temperatures which would occur to anybody would probably be to make some sort of diary, and to write down each day, say at nine o'clock in the morning and six o'clock in the evening: Pressure... so many inches on the barometer; Temperature ... so many degrees on the thermometer. Thus :

October 26th, i $\$ 9 S$.

PRESSU P.E.

TEMPERATURE.

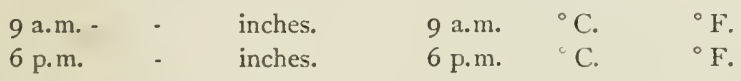

But at the end of a week or month, when you wished to compare the readings of the different days, it would take too much time and thought to make such a comparison. Though at the time of observation the pressure and temperature may-be written down in the diary form, it is best to arrange the readings in a different manner when they have to be compared. The plan adopted will now be explained.

Graphic Plan of showing Temperatures.-You know that the mercury in a thermometer expands with heat and contracts with cold. The number against which the top of the mercury in a thermometer stands depends, therefore, upon the condition of the weather as regards warmth or cold. The seven illustrations of a thermometer in Fig. 95 show the temperature indicated by a certain thermometer at 8 a.m. on the

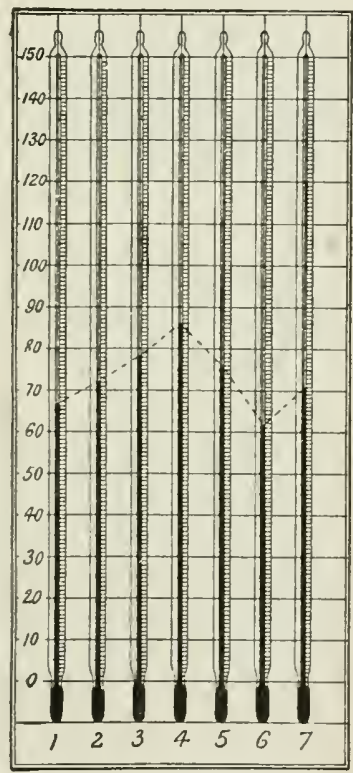

FIg. 95.-To show the position of the mercury in a certain thermometer on seven different days. first seven days of a certain month. A dotted line has been drawn from the point at which the top of the mercury 
stood on each day to that which it occupied the next day, so that you can see at once whether there was a fall or a

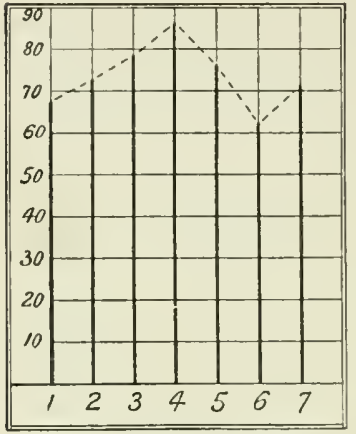

Fig. 96.-The upright lines represent the mercury in a thermometer on seven different days. Notice the broken line connecting the tops of the mercury columns. rise of temperature from one day to another. The line is, in fact, a graphic representation of the changes of temperature from day to day.

Now, it is easy to understand that if you wish to represent temperatures by a line it is not necessary to draw a thermometer for each day. You 'can take a sheet of paper similar to that shown in Fig. 96, and mark at the side numbers like those upon the thermometer, while along the bottom the days of the week or month can be put. The thick vertical lines in this diagram may thus be imagined to represent the mercury in the thermometer on the same days as before, and the line joining the tops is, therefore, just like that shown in Fig. 95 .

But it is not necessary even to draw the thick upright lines. A simpler plan is to put a dot at the point where the top of the mercury stands day by day, and then the dots can afterwards be connected, as shown in Fig. 97. IVe thus obtain a wavy line showing the rise and fall of temperature, and a line of this kind is called a temperature curve.

Graphic Plan of showing Rise

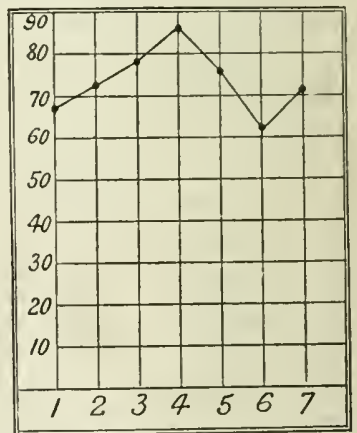

FIG. 07.-The zig-zag line represents the rise and fall of temperature during seven days. It is called a temperature curve. or Fall of the Barometer.-The plan by which the readings of a thermometer can be shown 
graphically is also used to exhibit the readings of a barometer, and it is adopted in many newspapers. The thick upright lines in Fig. 98 represent the mercury near the top of a barometer, as shown by the Daily News. The numbers 29 and 30 at the side of these lines mean inches, and the divisions between the numbers are tenths of inches. The height of the mercury upon the dates marked upon the chart can thus be seen at once. The dotted lines indicate the highest and lowest readings of the barometer observed upon each of the days referred to.

Now look at Fig. 99,

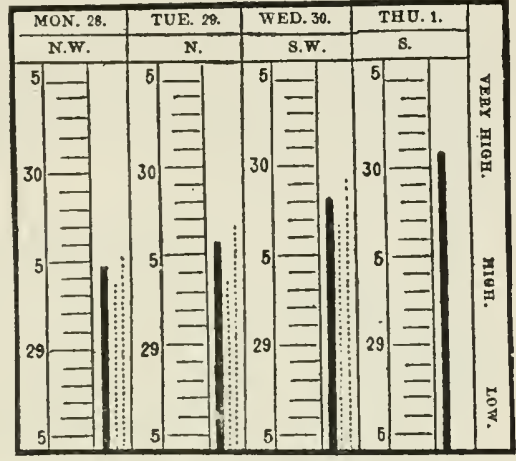

FIG. 08. - The Daily Nerus weather chart. The thick upright lines represent the top part of the mercury in a barometer.

which shows the Daily Chronicle charts for the same days as the Daily News. There are no thick upright lines in the Daily Chronicle's charts, but the position of the top of the mercury is

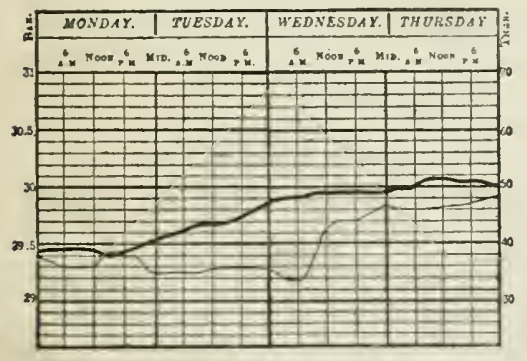

FIG. 99.-The Daily Chronicle weather chart for the same days as in Fig. 08 . The thick wavy line represents how the top of the mercury in a barometer varied in height during four successive days. shown by a thick line running across the chart. This line shows very clearly how the mercury rose and fell on the four days included in the charts. The barometer is observed at the Daily Chronicle office four times a day instead of once a day, so the diagram differs a little from that of the Daily News. The thin line shows how the temperature varied on the same days, the 
numbers which refer to temperatures being printed at the right side of the chart.

\section{TO be Remembered.}

It is sometimes more useful to represent quantities by the length of lines than by numbers.

Comparison is made easier by this means.

This and similar methods are known as graphic representation.

Graphic representation is very convenient for recording readings of the barometer and thermometer.

\section{EXERCISE XXXIV.}

1. Can quantities be represented in any other way than by numbers?

2. Give a description of how to represent relative densities or volumes graphically.

3. What do you understand by a temperature curve?

4. How is squared paper used to record temperatures and pressures?

5. Make a sketch of a temperature curve, marking the divisions necessary to understand it.

\section{LESSON XXXV.}

GRAPHIC REPRESENTATION-CONTINUED.

\section{PRACTICAL WORK.}

Things required.-Squared paper, or chequer drawing book such as is used for Kindergarten drawing. Ruler and pencil.

What to do.

Using squared paper, practise representing graphically by making diagrams for the following cases :

1. The number of 3 rd class passengers by a certain popular train throughout a week:

\begin{tabular}{ll|ll} 
& Passengers. & & Passengers. \\
Monday, - & -250 & Thursday, & -220 \\
Tuesday, - & -215 & Friday, & -185 \\
Wednesday, & -190 & Saturday, - & -235
\end{tabular}


2. The number of visitors to an exhibition throughout a fortnight. Suppose the returns to be as follows :

No. of Visitors.

\begin{tabular}{|c|c|c|c|c|}
\hline May & 2 & - & - & I0, 500 \\
\hline ", & 3 & - & - & IO, IOO \\
\hline , & 4, & - & - & 9,850 \\
\hline & 5 , & - & - & 10,200 \\
\hline & 6 & - & - & 9,900 \\
\hline & 7 & - & - & 12,500 \\
\hline
\end{tabular}

No. of Visitors.

\begin{tabular}{|c|c|c|c|c|}
\hline May & 9 & - & .. & 9,650 \\
\hline " & IO, & - & - & 9,700 \\
\hline , & I I, & - & - & 8,340 \\
\hline & 12, & 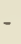 & & 9,870 \\
\hline פ & I3, & - & & 6,520 \\
\hline . & 14, & - & - & 9, \\
\hline
\end{tabular}

In this exercise mark the days of the month at the bottom of the vertical lines. Let the bottom horizontal line represent 6000 , the tenth horizontal line 7000 , and so on up to $1 \mathrm{r}, 000$.

3. The amounts of the collection in pence at a church on every Sunday throughout a quarter :

$$
6 \text { s. D. }
$$

6 s. D.

$\begin{array}{rrrrr}\text { Ist } & \text { Sunday, } & 6 & 7 & 5 \\ \text { 2nd } \quad, & 7 & \text { I0 } & 3 \\ \text { 3rd } \quad, & 5 & 5 & 9 \\ \text { 4th } & & 6 & \text { I } 3 & 7 \\ \text { 5th } & , & 7 & 5 & 4 \\ \text { 6th } & & 8 & 9 & 2\end{array}$

All the amounts should be reduced to pence before commencing this exercise.

\section{REASONS AND RESULTS.}

Cases in which Graphic Representation is useful.-Graphic representation can be usefully employed in very many other cases besides those named in the last lesson. In fact, it is the most satisfactory way of representing any two quantities which vary together. A graphic diagram can thus be constructed from the record of a cricketer's scores during a season's batting. Let us suppose that some particular batsman plays his first match on Saturday, May 13 th, and that he is fortunate enough 
to get an innings every Saturday until the end of August, and that he makes the following scores:

\begin{tabular}{|c|c|c|c|c|c|c|c|c|}
\hline \multirow{2}{*}{ May } & \multicolumn{3}{|r|}{ Score. } & \multicolumn{5}{|c|}{ Score. } \\
\hline & I3, & - & - IO & July & I, & - & - & 16 \\
\hline " & 20 & - & $-\quad 15$ & ", & 8 , & - & - & 5 \\
\hline$"$ & 27, & - & -5 & " & I 5 & - & - & $1 \mathrm{I}$ \\
\hline June & 3 , & - & -23 & " & 22 & - & - & 30 \\
\hline " & IO, & - & -0 & " & 29 & - & - & 0 \\
\hline " & I7, & - & 2 & August & 5 & - & - & I7 \\
\hline$"$ & 24, & - & - & $"$ & 12 & - & - & 5 \\
\hline & & & & & $\begin{array}{l}19, \\
26\end{array}$ & - & - & I9 \\
\hline
\end{tabular}

He could make a graphic representation of his scores as in the illustration, in which the marks at the left-hand ends of

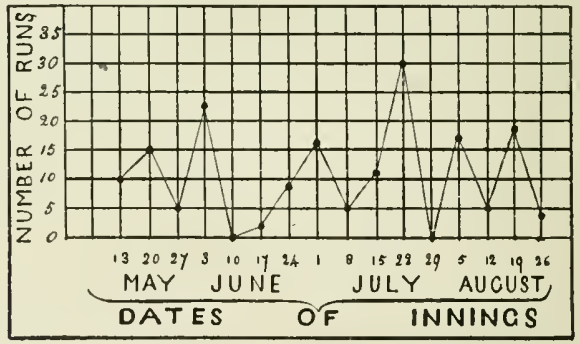

FIG. 100.-A graphic diagram of a cricketer's score on different dates.

the horizontal lines represent scores, and those at the bottom of the vertical lines stand for the dates of innings.

Other Graphic Diagrams.-It is often very convenient and instructive to construct diagrams similar to those already explained, to show at a glance how prices have varied from time to time. The diagram here shown, for instance (Fig. IoI), represents clearly how the price of india-rubber has altered from year to year since 1877 . The years are numbered at the top of the diagram. In the vertical column for every year is a dot to show the price of india-rubber per pound in that year. The prices are printed at the left hand ends of the horizontal lines. Beginning with 1877 it will be seen that the price per pound 
was then between $2 / 1$ and $2 / 3$. In 1878 the price was $1 / 1$ I per pound, in 1879 between $2 / 7$ and $2 / 9$, and so on for other years. The diagram shows at once that india-rubber was cheapest in

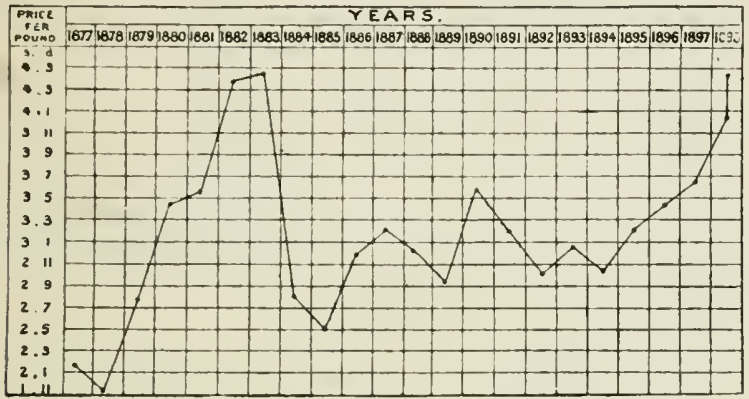

Fig. ror.-To show how the price of india-rubber per lb. rose and fell between 1877 and 1898 . (From the Kerv Bulletin.)

1878 , for the price per pound was then at the lowest point. The highest price was obtained in 1883 and 1898 . Diagrams of this kind can be used to represent graphically the rise and fall in price of anything. A rise of the line shows a rise in price, and a fall shows a fall in price.

Solubility Curves.-An interesting and important application of graphic representation is to show easily how the solubility of a solid in a liquid varies with the temperature. Thus, Fig. 102 shows the number of grams of the three solids, nitre, common salt, and chlorate of potash, which will dissolve in 100 grams of water at different temperatures. The degrees on a Centigrade thermometer are marked along the bottom horizontal line, and the length of the side of one square represents five degrees. The number of grams of solid which the 100 grams of water contain is read off from the scale on the left-hand of the diagram. The length of the side of one square represents five grams of dissolved solicl. Thus, a reference to Fig. 102 shows that 100 grams of water dissolve at $0^{\circ}$ C. $12 \frac{1}{2}$ grams of nitre. 
I46 ELEMENTARY PHYSICS AND CHEMISTRY.

At $5^{\circ} \mathrm{C} .100$ grams of water dissolve I 5 grams of nitre. $10^{\circ} \mathrm{C}$.

$15^{\circ} \mathrm{C}$.

$20^{\circ} \mathrm{C}$.

$25^{\circ} \mathrm{C}$.

$30^{\circ} \mathrm{C}$

$35^{\circ} \mathrm{C}$.

$40^{\circ} \mathrm{C}$.

$45^{\circ} \mathrm{C}$.

$50^{\circ} \mathrm{C}$.

$55^{\circ} \mathrm{C}$.

$n$
$n$
$n$
9
,
,
,

$n$
$n$
$n$
$n$
$n$
$n$
$n$

20

25

32

$37 \frac{1}{2}$

45

55

64

75

$87 \frac{1}{2}$

,

,

100

We could read off the amounts of common salt and chlorate of potash dissolved in 100 grams of water at different temperatures in just the same manner.

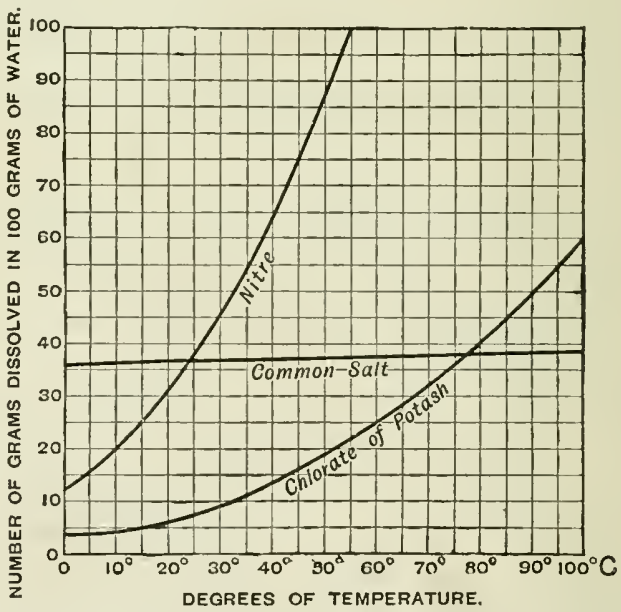

FIG. I02.- The number of grams of nitre, common salt, and chlorate of potash which can be dissolved in roo grams of water at any temperature from $0^{\circ}$ to $100^{\circ} \mathrm{C}$. is shown in this diagram.

But when we have several solubility curves together in this way, we can very easily compare the solubility of the different solids together. We see, for instance, that the amount of nitre which will dissolve in Ioo grams of water increases very rapidly 
as the temperature rises, as the steepness of this particular curve shows. The amount of common salt which 100 grams of water will dissolve increases very little as the temperature rises. The curve is almost a horizontal line, for while at $0^{\circ} \mathrm{C}$. about 36 grams are dissolved by 100 grams of water, at $100^{\circ} \mathrm{C}$. the amount in solution is only 38 grams.

TO BE REMEMBERED.

Graphic representation is very convenient wherever we have two sets of quantities varying together.

Solubility curves show the amounts of solids which will dissolve in liquids at different temperatures.

\section{EXERCISE XXXV.}

I. How could a cricketer represent his scores for a whole season graphically?

2. Explain how graphic representation is useful in recording regular variations in the price of any article.

3. What is a solubility curve? Draw the solubility curve for nitre and common salt.

4. A boy counted his marbles every night for ten days, and found he possessed the following numbers :

\begin{tabular}{cc|cc} 
Days. & Marbles. & Days. & Marbles. \\
I & 50 & 6 & 36 \\
2 & 65 & 7 & 24 \\
3 & 78 & 8 & 43 \\
4 & 49 & 9 & 59 \\
5 & 43 & 10 & $7 \mathbf{I}$
\end{tabular}

Try to represent these numbers on a piece of squared paper.

5. Represent by a diagram the following number of horse chestnuts which a boy possessed during the first fortnight of October :

\begin{tabular}{|c|c|c|c|}
\hline $\begin{array}{l}\text { Date. } \\
\text { Oct. I }\end{array}$ & $\begin{array}{c}\text { Chestnuts. } \\
7\end{array}$ & $\begin{array}{l}\text { Date. } \\
\text { Oct. } 8\end{array}$ & $\begin{array}{c}\text { Chestnut } \\
142\end{array}$ \\
\hline , & 25 & , 9 & 127 \\
\hline 3 & 40 &, 10 & 109 \\
\hline 4 & 76 & , I I & 97 \\
\hline 5 & 130 & , 12 & 54 \\
\hline 6 & I5I & "13 & 10 \\
\hline 7 & 197 &, 14 & 4 \\
\hline
\end{tabular}




\section{INDEX.}

Air, around us, $7 \mathbf{1}-75$; has mass, 74 ; excrts pressure, 77 ; presses in all directions, 77 ; dissolved in water, Iog.

Amorphous, 17, 18.

Archimedes, principle of, 64-68.

Area, measurement of, 24.

Balance, 44; principle of, $42-45$; used for conparing inasses, 45 .

Balloon, 67.

Barometer, $79-83$; definition of, $8 \mathrm{I}$; air pressure shown by, $8 \mathrm{I}$; when height of mercury in alters, 84 ; another form of, 84 .

Bellows, 78.

Boiling point of water, IOI.

Brittle, I4.

Buoyancy, 66.

Camphor, I04.

Cane, 17.

Carbon bisulphide, I04.

Centigrade thermometers, Ioo.

Centimetre, 22.

Chemical change, II3, I19.

Combustible, I7, 19.

Crystalline, 17, I8.

Crystallisation of soda, 130 .

Crystals, I8, 125, and crystallisation, I24; how made, I26; of alum, I26; of common salt, I30 ; of sulphur, I3 $\mathbf{3}$.
Cube, 125.

Cubic measurements, 28, 30-32.

Decanting, $\mathbf{1 0 8 .}$

Decimetre, 2 I.

Decrepitation, $\mathbf{3} 30$.

Dekametre, 22.

Deliquescent, 126.

Density, 46-49; meaning of, 47 ; high and low, 48 ; standard of, 49; how measured, 51: experimental determination of, 52 ; of solids, 69 .

Density bottle, 53 .

Diamond, 9 .

Dissolve, 17, 18.

Efflorescent, I26.

Elastic, 15.

Elasticity, 15 .

Emery, 9.

Evaporation, IIO-II4; a practical application of, $\mathbf{I I}_{3}$.

Expansion, 95.

Fahrenheit thermometers, roo.

Feeling, 2.

Filter, 18.

Filtering, 105.

Fixed points, 98-IO2 ; on a thermoneter, 99.

Flexible, I 5.

Foot, 2 I. 
Gases, 12; dissolved in liquids, rog.

Glass, I4.

Graduation of thermometers, 98-102.

Gram, 39.

Graphic representation, I33-I.47.

Hardness, 7,8 ; table of, 8 .

Hearing, 3 .

Height of barometer, $8 \mathbf{r}$.

Hektometre, 22.

Impervious, 17.

Inch, 2 I.

Incombustible, 17, 19.

India-rubber, 15.

Insoluble, $17, \mathbf{1} 8$, and soluble solids, IO2-105; liquids, 108.

Kilogram, 39.

Kilometre, 22.

Lactometer, 62.

Lead, If.

Length, measurement of, 20.

Liquids, $\mathbf{I}$.

Litre, 3 I.

Loss of weight, of things in water, 66.

Malleable, I4.

Mass and weight, 33-37 ; measurement of, $37 \cdot 41$; what mass is, 34 ; mass is not weight, 35 ; metric measurement of, to.

Matter, 6.

Mercury, a convenient liquid for barometers, 85 .

Metre, 21 ; square, 26.

Metric, 22, 26 ; masses, how to remember, 40 .

Millimetre, 22.

Octahedron, 125.

Opaque, 14.
Physical change, II2.

Pint, 3I.

Pliable, I5.

Porous, 16, 17.

Pound, imperial standard pound avoirdupois, 39 .

Pressure of air, how measured, 80; at different altitudes, 86.

Residue, I I2.

Rock-crystal, 125.

Salt, 18.

Saturated solution, I I4-1 16.

Science, how studied, I.

Seeing, 2 .

See.saw, 43 .

Senses, I-5; five, 4.

Size, change of, 90 .

Snelling, 3.

Soda crystals, I28, I29.

Soda-water, 109.

Solids, II.

Solubility curves, I +5 .

Solubility of things in acids, I16-1 I9.

Soluble, 17, 19, and insoluble solids, I02-105.

Solution, I04; of liquids, I08; another kind of, $\mathbf{I} 8$.

Solvent, water as a, I 5 .

Sponge, I7.

Spring balance, 35 .

Square measure, 26.

State, change of, 91 .

Substances, 6; soluble, ro.4; insoluble, I04; in suspension, 105.

Sucker, 78 .

Sugar, 18.

Tasting, 3 .

Temperature, change of, $9 \mathbf{I}$.

Thernometer, 92, 93.97; marks on, 96. 
Things, 6; many kinds of, 7 ; differ, 7.

Transparent, I4.

U-tube, $55,80$.

Varnish, ro4.

Volume, measurement of, 29; metric measure of, 30.

Volume, of water displaced, 57 ; of an irregular solid, 58 .
Washing-soda, 128.

Water, displaced by solids which float, $6 \mathrm{I}$; as a solvent, 115 ; of crystallisation, I26.

Water-dust, 90.

Weather glass, 82.

Weather records, 138 .

Weight, 36 ; avoirdupois, 39.

Weight of air, why not felt, 78 .

Yard, 2 I. 


\section{PROF. R. A. GREGORY AND A. T. SIMMONS, B.Sc.}

EXERCISES IN PRACTICAL PHYSICS. Adapted to First and Second Year's Work of Schools of Science. In two vols. Globe 8 vo. 2s, each.

BDUCATIONAL NEWS. - "This book is neither of too advanced a type for the scholars in a higher grade school nor too elementary for students beginning their course in a Technical Institute or College. The experiments are sufficiently detailed, and sufficiently illustrated by diagrams to allow of correct working. Its bulk is not needlessly increased by theoretical explanations; it professes to be not a scientific treatise, but a practical text-book, and as such we ean recommend it. The diagrams are good; we would particularly call onr readers' attention to those on the use of the veruier."

EDUCATIONAL TIMES.-"The opening words of this volume- "Yon are provided with a foot-rule - - re typical of its thoroughly practical character."

PHYSICS FOR IRISH IN'TER MEDIATE SCHOOLS. Being a Finst Year's Course of Exercises in Practical Physics. Globe 8 vo. 2s.

A MANUAL OF ELEMENTARY SCIENCE. A Course of Work in Physics, Chemistry, and Astronomy for Scholarship Candidates (Sections I. aud II.). Globe 8vo. 3s. 6d.

EXPERIMENTAL SCIENCE-PHYSIOGRAPHY. (SECTion I.) An Elementary Course of Physics and Chemistry. Adapted to the Syllabuis of the Science and Art Department. Globe 8vo. 2s. 6d.

ELEMENTARY PHYSICS AND CHEMISTRY. In Three Stages. Adapted to the Syllabuses of (1) Alteruative Class Subject-Course H; (2) Specific Subject XIII.; (3) Practical Science in Evening Continuation Schools. Globe 8vo. 1s. 6d. each.

\section{STAGE I.}

GUARDIAN. - "The edncational value of this first course, if the experiments are really performed, thought out, and writ ten about, as herein indicated, is dis. tinctly great-far greater, in fact, than Paul Bert's book. . . . The book merits very extensive use in schools: it is a good stepping-stone to higher things,"

STAGES II. AND III.

SCAOOLMASTER.-"These books are well worth the attention of those who are interested in the teaching of the elements of science in our elementary schools. They are useful because they contain a large amount of instruetion respecting many of the chemical and physical changes which almost daily come under onr notice. They are educational because the course of instruction is so arranged as to cultivate the powers of observation and reasoniug."

LESSONS IN SCIENCE. A Preliminary Course of Physies and Chenistry. New Impression. With Model Answers to Recent Questions set in the Preliminary Examination for the Certificate of the Board of Education. Globe 8vo. 3s. $6 \mathrm{~d}$.

SCHOOLMASTER.-"'The book is capable of rendering excellent service to those who use it."

$$
\text { MACMILLAN AND CO., LTU, LONDON. }
$$




\section{WORKS BY PROF. R. A. GREGORY.}

AN EXERCISE BOOK OF ELEMENTARY PRACTICAL PHYSICS. Feap. 4to. 2s. 6d.

EDUCATIONAL TIMES.-"Mr. Gregory is no mere intelligent dispenser of other men's prescriptions. His book is essentially original. He has one of the most valuable qualities in a teacher-a ready invention."

THE PLANET EARTH. Globe 8vo. 2s.

\section{WORKS BY A. T. SIMMONS, B.Sc.}

PHYSIOGRAPHY FOR BEGINNERS. Globe 8vo. 2s. Gi.

ROYAL COLLEGE OF SCIENCE MAGAZINE.--"Mr. Simmous' book should have a large circulation, and we recommend it both to those who will use it as a text-book, or as ground-work for lectures and demonstrations."

PHYSIOGRAPHY FOR ADVANCED STUDEN'TS. Globe 8 vo. $4 \mathrm{~s} .6 \mathrm{~d}$.

EDUCATIONAL NEWS.-"No better book on the subject has hitherto come under our notice, and we recommend it with full confidence."

\section{By PROF. R. A. GREGORY and H. E. HADLEY, B.Sc.}

A CLASS BOOK OF PHYSICS. Crown 8vo. Parts I. and II., Fundamental Measurements, Hydrostatics and Mechanics, 1s. 6d. Parts I., II., and III., Fundamental Measurements, Hydrostatics and Mechanics, Heat, 2s. Parts III. and IV., Heat and Light, 1s. 6d. Parts III., IV., and V., Heat, Light, and Sound, 2s. Parts IV. and V., Light and Sound, 1s. 6d. Parts VI., VII., and VIII., Magnetism, Static Electricity, Voltaic Electricity, 1s. 6d. Complete, 4s. 6d.

\section{BY A. T. SIMMONS, B.Sc., AND L. M. JONES, B.Sc.} ELEMENTARY GENERAL SCIENCE. Globe 8vo. 3s,6d.

\section{By A. T. SIMMONS, B.Sc., and H. RICHARDSON, M.A.}

IN'TRODUCTION TO PRACTICAL GEOGRAPHY. Globe 8vo. Sections I-IV. 3s.6d. Also Section I., Maps. Section II., The Globe. Section III., Climate. Globe 8vo. Limp Cloth. 1s. each. Key, 3s. 6d. net.

\section{BY A. T. SIMMONS, B.Sc., AND E. STENHOUSE, B.Sc.} SCIENCE OF COMMON LIFE (Experimental Hygiene). An Introductory Course of Work in the Principles of Domestic Science. Globe 8vo. 2s. 6d.

A work in elementary science designed for girl students. Its ohject is to explain the broad principles of physical and chemical science, and to illustrate them by application to the ordinary facts of household life. Thus the student learns something of the composition of the air and the principles of ventilation, the composition of water and its propertics, with their practical effects; the chief constituents of ordinary food, and the chemistry of cooking; with some rudimentary account of the human frame. Experiments are fully illustrated by diagrams.

MACMILLAN AND CO., LTD., LONDON. 


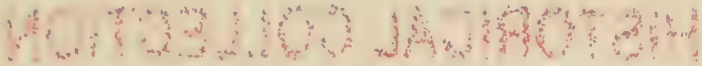

$$
\begin{aligned}
& \text { का }
\end{aligned}
$$




\section{HISTORICAL COLLECTION EDUCATION LIBRARY UBC}


